\title{
A Three-Factor Model of Personality Predicts Changes in Depression and Subjective Well-Being Following Positive Psychology Interventions
}

\author{
Caroline Barnes
}

A Dissertation submitted to the Faculty of Graduate Studies in Partial Fulfillment of the Requirements for the Degree of Doctor of Philosophy

Graduate Program in Clinical Psychology

York University, Toronto, Ontario

September, 2017

(C) Caroline Barnes, 2017 


\begin{abstract}
These studies investigated a new model of personality and its relationship to positive psychology interventions. Previous theoretical models and research into the structure of personality has seen disagreement concerning the true number of factors at the basis of personality. Furthermore, the link between personality and positive psychology interventions has been unclear. The following studies were undertaken to determine the structure of personality in a Canadian sample $(N=$ 4375 at baseline) and to investigate how these personality factors predict depression, satisfaction with life, and affect following positive psychology interventions. Participants were recruited online and randomly assigned to one of ten exercise conditions which were performed every day for one week. Follow-ups were conducted one, three, and six months later. Using half of the sample $(n=2188)$, exploratory factor analysis was conducted on a comprehensive battery of personality questionnaires, which included measures of extraversion, neuroticism, conscientiousness, agreeableness, and openness to experience (the five-factor model) in addition to neediness, self-criticism, efficacy, self-esteem, gratitude, self-compassion, and attachment styles. The resulting three-factor model was validated using confirmatory factor analysis with the second half of the sample $(n=2186)$. The best fitting model for personality involved a threefactor solution interpreted to represent Equanimity, Insecurity, and Agency. The factors were then included in a latent growth curve model to determine how personality interacted with positive psychology interventions to predict depression and subjective well-being, both at baseline and over time. The results support the validity of a three-factor model of personality. In addition, this model proved useful in the study of individual differences in responding to positive psychology interventions. Limitations of this research and future directions are discussed.
\end{abstract}




\section{Acknowledgments}

I want to start by acknowledging all of my family and friends for their encouragement throughout the years. Thank you to my partner, Zack, for your love, patience, and unwavering support. I could never have achieved this without you. To my parents: thank you for giving me a love of learning and encouraging me to accomplish my dreams. To Stephanie, thank you for being my sister, my cheerleader, and my best friend. To my grandparents, thank you for your unending belief in me and for helping me believe in myself.

I am so incredibly grateful to Dr. Myriam Mongrain for your supervision, guidance, and support. I feel very fortunate to have benefitted from your knowledge over the years and to have learned so much from you! Thank you for always pushing me to do my best.

Thank you to my committee members, Dr. Dave Flora and Dr. Henny Westra, for your advice and insights. I greatly appreciate the time you both dedicated to this dissertation!

Finally, thank you to all others who have helped me throughout this process. Thank you to the faculty and staff at York University, and to the other graduate students who have become lifelong friends. 


\section{Table of Contents}

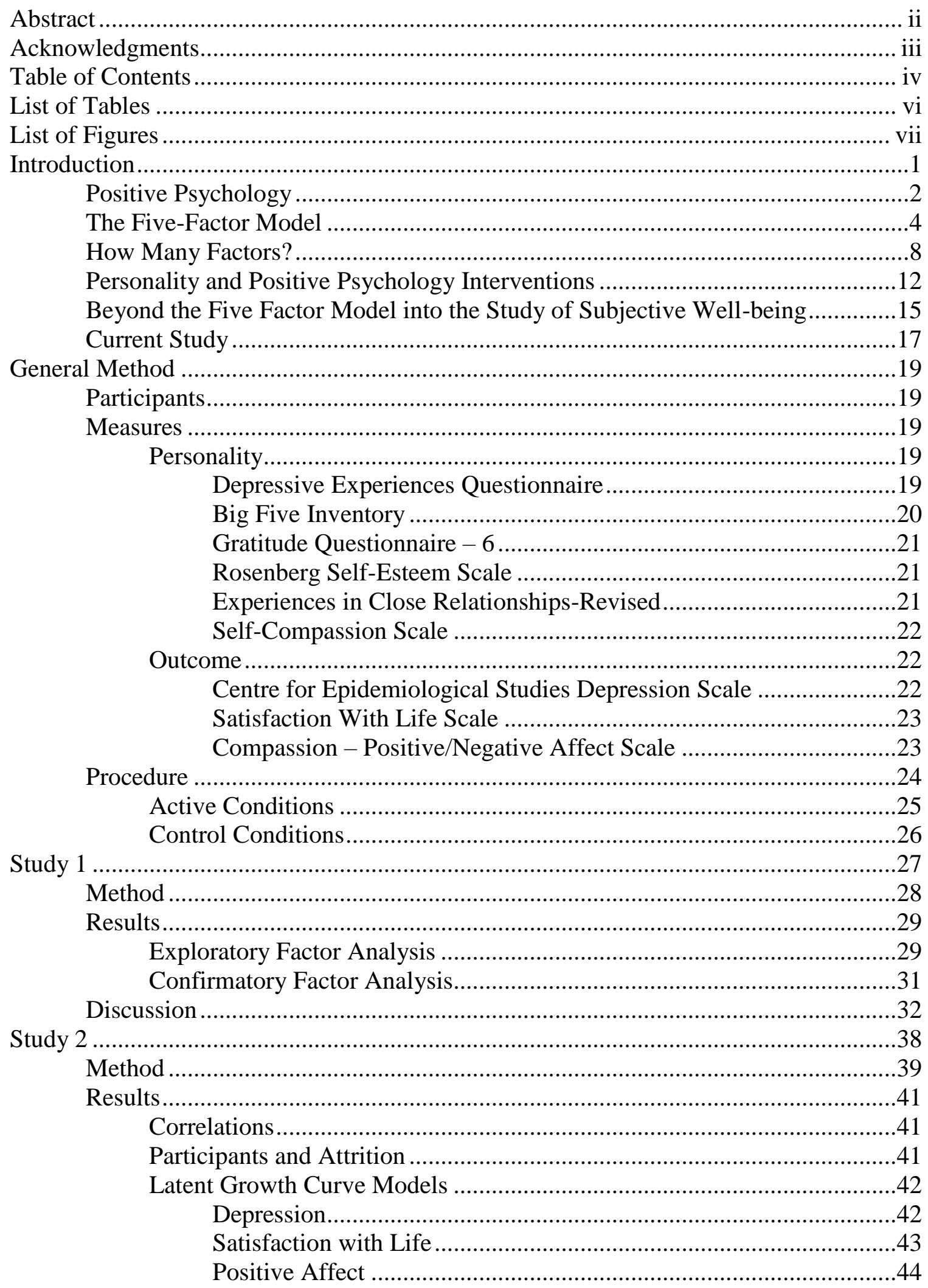


Negative Affect .................................................................45

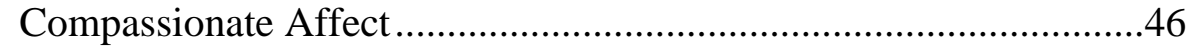

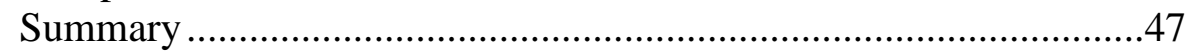

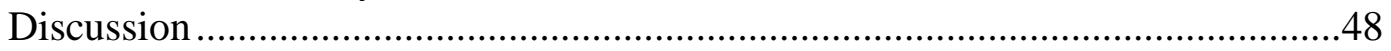

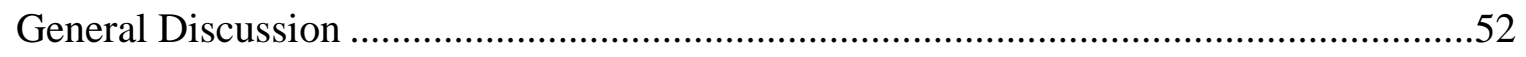

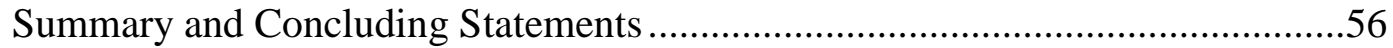

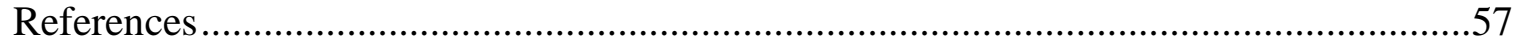

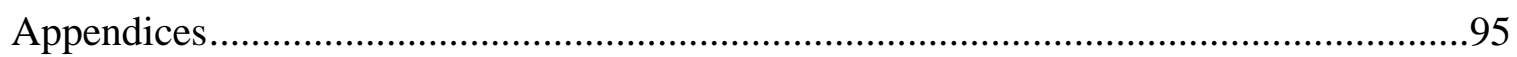

Appendix A: Project HOPE Advertisement .....................................................95

Appendix B: Consent Form ......................................................................96

Appendix C: Personality and Outcome Measures ............................................98

Appendix D: Exercise Instructions ...........................................................111 


\section{List of Tables}

Table 1: Correlation matrix and descriptive statistics for Study 1 personality variables at baseline 80

Table 2: Standardized factor loadings and communalities for the three-factor model ............... 81

Table 3: Inter-factor correlations for the three-factor model ........................................... 82

Table 4: Completely standardized factor loadings, standard errors, and p-values for Model 2 ... 83

Table 5: Correlation matrix and descriptive statistics for Study 2 variables at baseline ............. 84

Table 6: Sample size over time (active conditions vs. control conditions) ............................ 85

Table 7: Mean scores on baseline variables for completers versus non-completers .................. 86

Table 8: Regression estimates for the latent growth curve model of depression....................... 87

Table 9: Regression estimates for the latent growth curve model of satisfaction with life......... 88

Table 10: Regression estimates for the latent growth curve model of positive affect................ 89

Table 11: Regression estimates for the latent growth curve model of negative affect ............... 90

Table 12: Regression estimates for the latent growth curve model of compassionate affect....... 91 


\section{List of Figures}

Figure 1: Confirmatory Factor Analysis, Model 1 ...............................................92

Figure 2: Confirmatory Factor Analysis, Model 2 ................................................93

Figure 3: Latent growth curve model..............................................................94 


\section{A Three-Factor Model of Personality Predicts Changes in Depression and Subjective}

\section{Well-Being Following Positive Psychology Interventions}

Positive psychology is the study of positive experiences, emotions, and traits (Seligman \& Csikszentmihalyi, 2000) and includes research into interventions that increase well-being and prevent mental illness (Joseph \& Wood, 2010; Mitchell, Vella-Brodrick, \& Klein, 2010; Sin \& Lyubomirsky, 2009). The positive psychology movement began at the turn of this century and has since thrived (Seligman, Steen, Park, \& Peterson, 2005; Mitchell et al., 2010). This movement has addressed an important gap in clinical psychology by expanding the focus to include flourishing and well-being, beyond mental illness alone (Joseph \& Wood, 2010; Seligman \& Csikszentmihalyi, 2000). Positive psychology interventions have been shown to increase well-being and decrease depression (Senf \& Liau, 2013; Sin \& Lyubomirsky, 2009) but there is increasing interest in how individual differences in personality can maximize the effectiveness of these interventions (Lyubomirsky \& Layous, 2013; $\mathrm{Ng}$, 2015). The first step is identifying the personality factors that are most predictive of benefits from positive psychology interventions. Existing models of personality have been criticized as incomplete (Ashton \& Lee, 2007; Carlo, Knight, Roesch, Opal, \& Davis, 2014; McAdams \& Walden, 2010) and lacking factors that are important to the study of positive psychology (Sheldon, 2009). The current studies were undertaken to determine what personality factors predict reduced depression and increased subjective well-being (operationalized as satisfaction with life, presence of positive affect, presence of compassionate affect, and absence of negative affect) for participants practicing positive psychology interventions. Working with the existing dataset from an adult, Canadian sample, the best factor solution was determined from a comprehensive battery of personality measures and validated both conceptually and analytically. These personality factors were theorized to provide a more complete understanding of individual differences that are 
relevant to the study of positive psychology. These factors were then investigated in relation to levels of depression and subjective well-being at baseline and following online positive psychology interventions.

\section{Positive Psychology}

It has been demonstrated that many positive psychology interventions can improve wellbeing and decrease depressive symptoms (see Sin \& Lyubomirsky, 2009, for a review). Here, depression and well-being are conceptualized as separate concepts rather than anchors of the same continuum (Keyes, 2005). Well-being refers to "optimal psychological functioning and experience" (Ryan \& Deci, 2001). Well-being has been categorized as either eudaimonic wellbeing (psychological well-being) or as hedonic well-being (subjective well-being) (Deci \& Ryan, 2008). Eudaimonic and hedonic well-being are highly correlated but distinct constructs (Joshanloo, 2015). Psychological or eudaimonic well-being means living to your fullest potential, fulfilling your true self, and generally living a meaningful life, which includes pursuing worthwhile goals and meaningful activities (Joshanloo, 2015). Subjective or hedonic well-being refers to the presence of positive affect, the lack of negative affect, and feeling contentment with your life (Diener \& Lucas, 1999; Keyes, 2013). Subjective well-being is often considered synonymous with happiness (Deci \& Ryan, 2008). The current studies investigated the relations between positive psychology interventions and subjective well-being, specifically satisfaction with life, presence of positive and compassionate affect, and absence of negative affect. Depression was operationalized as frequency of depressive symptoms over the previous two weeks (Radloff, 1977).

A wide variety of positive psychology interventions have been shown to produce substantial and long-lasting increases in subjective well-being and decreases in depression 
(Seligman et al., 2005; Senf \& Liau, 2013; Sergeant \& Mongrain, 2011; Sin \& Lyubomirsky, 2009). In an early study of positive psychology interventions, Seligman and colleagues (2005) randomly assigned participants to one of six exercises. Two of the conditions (using your "signature strengths" in a new way; writing down three good things about your life) increased happiness and decreased depressive symptoms over a six-month follow-up period compared to a control condition. A practicing gratitude exercise also led to improvements that lasted up to one month following the exercise period. Other researchers have seen similar success with interventions that capitalize on one's personal strengths (Mongrain \& Anselmo-Matthews, 2012; Senf \& Liau, 2013) and bolster gratitude (Dickerhoof, 2007; Emmons \& McCullough, 2003; Senf \& Liau, 2013; Sergeant \& Mongrain, 2011). Additional interventions that have been found to be beneficial include listening to music (Sergeant \& Mongrain, 2011), expressing selfcompassion (Shapira \& Mongrain, 2010), practicing optimism (Dickerhoof, 2007; Shapira \& Mongrain, 2010), and acts of kindness (Buchanan \& Bardi, 2010; Mongrain, Barnes, Barnhart, \& Zalan, in press).

The Internet has been used to great effect in delivering positive psychology interventions (Mitchell et al., 2010). Multiple studies have shown that these interventions can increase happiness and decrease depression (see Mitchell et al., 2010, for a review; Seligman et al., 2005; Sergeant \& Mongrain, 2011; Shapira \& Mongrain, 2010). Delivering positive psychology interventions online has multiple advantages over traditional methods. Using the Internet reduces costs, offering a more convenient and sustainable option for researchers (Korp, 2006; Mitchell, Stanimirovic, Klein, \& Vella-Brodrick, 2009; Ritterband et al., 2003). Researchers are able to include populations that are often underrepresented in the literature, such as people living in rural areas or individuals who wish to remain anonymous (Korp, 2006; Mitchell et al., 2010). Additionally, online delivery permits greater tailoring of exercises by offering a broad range of 
interventions and allowing researchers to assign interventions based on the specific personality characteristics and needs of each individual (Mitchell et al., 2010; Ritterband et al., 2003).

The efficacy of online positive psychology interventions could be considerably improved through better understanding of who benefits and why. One avenue of research has examined matching participant characteristics to specific interventions (Lyubomirsky \& Layous, 2013). Preliminary studies have provided evidence for different personality traits predicting higher benefits from specific interventions (Ng, 2012; Senf \& Liau, 2013; Sergeant \& Mongrain, 2011; Shapira \& Mongrain, 2010). Investigation into the role of personality in the outcome of online positive psychology interventions has begun, but there is important research still to be done. The first step is identification and clarification of which individual difference variables are important in the field of positive psychology. The following sections summarize models of personality and introduce different theoretical frameworks for understanding individual differences.

\section{The Five-Factor Model}

Models of personality describe "broad individual differences in behavior, thought, and feeling that account for general consistencies across situations and over time" (McAdams \& Pals, 2006, p.212). The five-factor model is arguably the most widely accepted comprehensive model of personality. McCrae and Costa (1986) and Goldberg (1990) have provided the prevalent conceptualizations of these five factors. The five factors of McCrae and Costa are extraversion, neuroticism, agreeableness, conscientiousness, and openness to experience. Goldberg's five are surgency (similar to extraversion), emotional stability (similar to reversed neuroticism), agreeableness, conscientiousness, and intellect (similar to openness to experience). Extraversion (surgency) includes traits such as assertiveness, positive emotionality, sociability, and energy. Neuroticism, or reversed emotional stability, refers to one's susceptibility to distress and a 
tendency to experience negative emotions. Agreeableness is a tendency to be compassionate and forgiving towards others as well as friendly and compliant. Conscientiousness involves traits such as diligence, organization, perfectionism, high achievement, and self-discipline. The last factor, openness to experience, is described by Costa and McCrae as imaginativeness, appreciation for artistic creations, and inclination to explore and try new things. Goldberg called this factor intellect and his conceptualization included intellectual engagement and curiosity. This factor has also been named 'culture' (McCrae \& John, 1992). The most common measures of these factors are the Revised NEO Personality Inventory (NEO-PI-R; Costa \& McCrae, 1992) and the Big Five Inventory (BFI; John, Donahue, \& Kentle, 1991).

Proponents of this model maintain that these five factors constitute the basic dimensions of personality (Costa \& McCrae, 1992) and represent the most general level of explanation for individual differences (McCrae \& Costa, 1986). These factors form lasting dispositions that can be seen in children and adolescents (Morizot, 2014; Olivier \& Herve, 2015) and across the lifespan (Lamb, Chuang, Wessels, Broberg, \& Hwang, 2002). Moreover, these factors have shown utility in predicting a wide range of behaviours, including creative achievement (Hirsh \& Peterson, 2008), interpersonal networking behaviours (Wolff \& Kim, 2012), academic success (Hirsh \& Peterson, 2008; Zeidner \& Shani-Zinovich, 2011), and job performance (Gill \& Hodgkinson, 2007; You, Kim, \& Lee, 1997). This personality structure has been confirmed by multiple statistical analyses (Borkenau \& Ostendorf, 1990; Costa \& McCrae, 1992; Goldberg, 1990; John, 1990). In addition, the structure has been confirmed in more than 56 countries (Schmitt, Allik, McCrae, \& Benet-Martinez, 2007; Yamagata et al., 2006), including Romania (Ispas, Iliescu, Ilie, \& Johnson, 2014), Korea (You et al., 1997), Sweden (Lamb et al., 2002), the Netherlands (Denissen, Geenen, van Aken, Gosling, \& Potter, 2008), China (Zheng et al., 2008), and France (Olivier \& Herve, 2015). In short, the five-factor model is considered the best-known 
and most widely researched approach to personality today (Roberts, Kuncel, Shiner, Caspi, \& Goldberg, 2007; Schmitt et al., 2007; Yamagata et al., 2006).

The five factors have their roots in the lexical hypothesis, the theory that "... the most important individual differences in human transactions will come to be encoded as single terms in some or all of the world's languages" (Goldberg, 1990). Goldberg gathered over 1431 trait terms (adjectives describing personality traits) that were classified in 75 clusters. Goldberg then gathered self-report ratings from 187 college students on all of the 1431 terms and analyzed the correlations between the 75 clusters. Across a variety of factor-analytic strategies, he found that the five factors consistently emerged. McCrae and Costa (1987) expanded on the lexical background by showing that the five-factor model emerges not solely from adjectives, but also across questionnaires and observers. McCrae and Costa added 40 items (intended to measure openness to experience) to a 40-item adjective-rating scale from Goldberg, and compared that with the three-dimensional version of the NEO-PI (with an additional 60 items intended to measure agreeableness and conscientiousness). Self-report and peer ratings were taken for 275 adult participants. The researchers found convergence on all five factors using both adjective factors and questionnaire scales, and across raters. To McCrae and John (1992), this was evidence that the five factors captured the true structure of personality, as the same factors emerged from factor analyses of personality measures and from the perspectives of different observers. At the same time, this study was based, at least in part, on a lexical foundation by using Goldberg's adjective scale.

The most ardent advocates of this approach conclude that these five factors are necessary and sufficient for understanding an individual's personality (McCrae \& Costa, 1986) but other researchers have called these conclusions premature (Block, 1995). The lexical hypothesis has 
been criticized on numerous fronts, including the fact that it relies on the vocabularies of laypeople, using common trait words that change over time and across cultures or communities (John, Angleitner, \& Ostendorf, 1988). Personality facets that may be of interest to psychologists may be unknown to the average person (Block, 1995). Additionally, lay individuals may use trait words in ambiguous ways rather than as precisely defined constructs (Trofimova, 2014). The use of single-word adjectives is also suspect; there are nuances of personality that cannot be captured without nouns or full sentences (Block 1995). In addition, the lexical hypothesis has been criticized for being "atheoretical": that is, not being based on or fitting any theory of personality (Block, 2010). One of Digman's (1997) main criticisms of the five-factor model was the lack of connection to the theories of personality development. McCrae and John (1992) have acknowledged that the five-factor model "is not a complete theory of personality".

Additional criticism has been levied at the content of the five factors, which can vary substantially. Items, and even facets, relate to different factors across cultures (Carlo et al., 2014). The conceptualizations of the factors also vary across different researchers. This is especially true for openness to experience, which is often characterized as having more to do with intelligence than personality and does not always reliably emerge in studies (Block, 2010). Authors have suggested that the dimension of openness may not be completely personality based due to the association between this factor and intelligence or problem solving (Ferguson $\&$ Patterson, 1998). One measure, the Big Five Aspect Scales (BFAS: DeYoung, Quilty, \& Peterson, 2007) separated openness to experience into two facets: openness and intellect. The prominence and nature of openness varies across cultures and languages (De Raad, 1998) and some have criticized this factor as a major weakness of the five-factor model (McKenzie, 1998). 
Block has also expressed concern with the conclusion that the five factors are the fundamental basis of personality (Block, 1995). Similarly, Eysenck (1990) has contended that there are no clear criteria for forming the different levels in the hierarchy of personality traits. While the five-factor model places agreeableness and conscientiousness in the top level, other models (including Eysenck`s own) subsume them under other higher-order factors. Others have argued that none of the five factors are at the highest level of personality organization and that there are higher-order factors which incorporate all the factors of the five-factor model (DeYoung, 2006; Digman, 1997; Draycott \& Kline, 1995; Scholte \& De Bruyn, 2004). However, many of these studies are based on factor analysis of only the five factors.

Despite these critiques, the five-factor model has seen continued popularity in psychology (Roberts et al., 2007; Schmitt et al., 2007; Yamagata et al., 2006). Between 1995 and 2010 alone, there were more than 3000 new publications on the Big Five (John \& Naumann, 2010). This model has demonstrated far-reaching applications and has gained the greatest empirical attention in the field of personality.

\section{How Many Factors?}

Many of the alternative models of personality feature fewer factors, which are theorized to constitute higher levels of personality than the Big Five. For example, Eysenck $(1967 ; 1990)$ proposed a well-known model of personality made up of three factors labelled psychoticism, extraversion, and neuroticism. The three-factor model is measured using the Eysenck Personality Questionnaire-Revised (EPQ-R; Eysenck \& Eysenck, 1991). Extraversion and neuroticism are conceptually very similar to the same traits in the five-factor model while psychoticism captures subtraits of being cold, aggressive, impulsive, and antisocial (Eysenck, Eysenck, \& Barrett, 1985). Other researchers have confirmed Eysenck's 'Big Three', and defined the third factor 
(psychoticism) as "sensation seeking, impulsivity, nonconformity, and a lack of restraint... [or] socialization" (Zuckerman, Kuhlman, \& Camac, 1988). When compared to the Big Five, agreeableness and conscientiousness are included under psychoticism while openness to experience has been shown to relate to either extraversion or psychoticism in different samples (Aluja, Garcia, \& Garcia, 2002; Draycott \& Kline, 1995; Scholte \& De Bruyn, 2004). Eysenck’s three factors (extraversion, neuroticism, and psychoticism) can be seen across ages, sexes, races, and cultures (Eysenck et al., 1985; Kokkinos, Panayiotou, Charalambous, Antoniadou, \& Davazoglou, 2010; Sandin, Valiente, Olmedo, Chorot, \& Santed, 2002). One advantage of Eysenck's model is that it was theorized to have a biological basis (Eysenck, 1967), unlike the five-factor model. Eysenck postulated that extraversion was mediated by activation in the reticular formation while neuroticism was associated with the limbic system. Twin and adoption studies support that Eysenck's model has strong evidence of heritability (Eaves, Eysenck, \& Martin, 1989; Scarr, Webber, Weinberg, \& Wittig, 1981).

Draycott and Kline (1995) compared the EPQ-R to the NEO-PI. They found that the three- and five-factor models shared the majority of their variance, most of which was along the factors of extraversion and neuroticism. They also found that there was variance in the NEO-PI left unexplained by the three-factor model that was covered by the five-factor model. However, the additional variance that was unaccounted for by Eysenck's factors did not form adequately sized factors in addition to psychoticism, extraversion, and neuroticism. Draycott and Kline concluded that there is not enough additional variance to justify the creation of two more factors, and that the "Big Three" are a better alternative to the five-factor model. Similar studies have concluded in favor of Eysenck's model (Aziz \& Jackson, 2001; Scholte \& De Bruyn, 2004). 
Cloninger (1987) proposed an alternative to Eysenck's model. His three-factor model included Novelty Seeking, Harm Avoidance, and Reward Dependence. Novelty Seeking is active pursuit and approach in response to novel stimuli and rewards. An individual high in Novelty Seeking is impulsive, excitable, quick-tempered, and prone to exploration. Harm Avoidance is the inhibition of behaviour in response to aversive stimuli in order to avoid punishment. An individual high in Harm Avoidance is shy, cautious, tense, and fearful. Reward Dependence governs the maintenance of behaviour that has been previously rewarded. An individual high in Reward Dependence is eager to help others, persistent, industrious, and interpersonally warm. Cloninger theorized that these three factors are based in neurobiology. Specifically, Novelty Seeking is associated with the dopamine system, Harm Avoidance with levels of serotonin, and Reward Dependence with the noradrenergic system (Cloninger, Svrakic, \& Przybeck, 1993; Kim et al., 2006). There is evidence that these factors are heritable and genetically independent (Cloninger, Przybeck, \& Svrakic, 1991; Heath, Cloninger, \& Martin, 1994).

Others have proposed that there are only two overarching personality factors. Similar to Cloninger's Novelty Seeking and Harm Avoidance, Gray (1982) proposed two systems that underlie personality. These are two neuropsychological systems that respond to rewarding or punishing stimuli. The Behavioural Inhibition System controls the avoidance of negative stimuli, is sensitive to punishment, and is theorized to be related to the septohippocampal system (Carver \& White, 1994). The Behavioural Approach System controls the approach towards positive stimuli, is sensitive to reward, and has been linked to dopamine. Gray's systems have been found to relate empirically to Cloninger's factors of Harm Avoidance (related to the Behavioural Inhibition System) and Novelty Seeking (related to the Behavioural Approach System), indicating conceptual overlap (Mardaga \& Hansenne, 2007). 
Another two-factor model was proposed by Digman (1997). Digman studied the correlations among personality variables from 14 studies with five-factor solutions and found evidence for two higher-order factors at a more general level than the five factors. He titled the new factors Alpha and Beta. Alpha subsumes agreeableness, conscientiousness, and emotional stability (reversed neuroticism). Digman stated that Alpha might be a reflection of socially desirable communal traits and related it to the theoretical construct of Communion (Bakan, 1966; Wiggins, 1991). This factor describes personality development and how children learn to act in an agreeable, conscientious, and emotionally stable way. Beta subsumes extraversion and openness to experience. This factor describes personal growth versus personal constriction and involves the actualization of self through creativity, curiosity, self-esteem, and sociability, similar to the concept of Agency (Bakan, 1966; Wiggins, 1991).

Factors similar to these "Big Two" of Alpha and Beta have been identified many times, though often under other names. DeYoung and colleagues found two similar factors in their analyses, which they named Stability and Plasticity (DeYoung, 2006; DeYoung, Peterson, \& Higgins, 2002). They confirm that the correlations of the five-factor model yield two factors, with neuroticism, agreeableness, and conscientiousness loading onto one (Stability) and extraversion and openness to experience loading onto the other (Plasticity). Stability reflects negative neuroticism (indicating emotional stability), agreeableness (indicating social stability), and conscientiousness (indicating motivational stability). Stability is similar to Alpha. Plasticity denotes a tendency towards exploration and personal betterment, which is similar to Beta. Similarly, Blackburn and colleagues (2004) replicated Digman's (1997) two factors from the NEO Five Factor Inventory in a forensic population. 
Many of the two- and three- factor solutions that have been proposed have considerable merit (showing evidence of heritability, and existence across cultural and language groups), and share significant conceptual agreement. The major critique of Digman's (1997) and DeYoung's (2006) models is that the two-factor solutions were based on the five-factor model, which has been criticized for presenting an incomplete model of personality (Ashton \& Lee, 2007; Carlo et al., 2014; McAdams \& Walden, 2010). Some have suggested potential missing factors, including self-efficacy (Deci \& Ryan, 2000), self-esteem (Sheldon, 2009), and attachment style (Shiota, Keltner, \& John, 2006). Others have argued that personality is more than solely traits and that the five-factor model ignores elements of personality such as social roles or relationships (Carlo, et al., 2014), narrative identity, goals, and personal strivings (McAdams \& Walden, 2010). If the five factors are incomplete, then any resulting higher-order factors based on the Big Five may be as well. The incomplete nature of these personality models is a barrier to properly investigating and understanding how individual differences relate to depression and subjective well-being, and how positive psychology interventions may have different outcomes for participants based on these personality factors.

\section{Personality and Positive Psychology Interventions}

Several individual difference factors have been found to moderate the effectiveness of positive psychology interventions (Dickerhoof, 2007; Ng, 2015). For example, in a longitudinal study of two positive psychology exercises (practicing optimism and practicing gratitude), higher motivation and higher self-efficacy predicted the greatest improvements in well-being over time (Lyubomirsky, Dickerhoof, Boehm, \& Sheldon, 2011). Some studies have found increased efficacy when there is a 'fit' between the positive psychology intervention and the person (Lyubomirsky \& Layous, 2013; Lyubomirsky, Sheldon, \& Schkade, 2005; Sergeant \& 
Mongrain, 2011). It is unlikely that every positive psychology intervention is equally optimal for every participant $(\mathrm{Ng}, 2015)$. Tailoring exercises to the needs of the individual may allow participants the maximal benefits possible.

Furthermore, initial levels of depression often influence how much participants benefit from positive psychology interventions. For example, participants who are distressed at baseline have been found to profit the most from online exercises (Parks, Della Porta, Pierce, Zilca, \& Lyubomirsky, 2012; Sergeant \& Mongrain, 2015; Sin \& Lyubomirsky, 2009). These gains were sustained for distressed participants over the six-month follow-up period, suggesting that these findings were more than solely "regression toward the mean" (Sergeant \& Mongrain, 2015). Higher distress levels at baseline predict better outcomes overall.

Research has supported the role of personality as a general moderating influence on the effectiveness of positive psychology interventions ( $\mathrm{Ng}, 2015)$. For example, neuroticism of the Big Five has been frequently pinpointed as a critical factor in the benefits gained from positive psychology exercises. $\mathrm{Ng}$ (2012) found that a savoring exercise (writing down three positive things about a situation and savoring positive feelings) and a gratitude exercise (writing down four things you are grateful for in your life) were more helpful in increasing positive affect for participants high in neuroticism. However, compared to low-neuroticism participants, highneuroticism participants did not reach or sustain the same high levels of positive affect over time. Extraversion has also been found to moderate the effectiveness of positive psychology exercises. For example, a gratitude exercise and a strengths-based exercise were significantly more effective in reducing depression and increasing happiness for extraverted participants compared to introverted participants (Senf \& Liau, 2013). Extraversion continued to predict fewer depressive symptoms at the one-month follow-up while openness predicted increased happiness 
at post-test (Senf \& Liau, 2013). Agreeableness has also been found to predict varying levels of change following online positive psychology interventions (Mongrain et al., in press). More disagreeable participants showed the greatest benefits, with significant long-term decreases in depression following a kindness exercise.

Few researchers have looked beyond the five-factor model. Some attempts have been made to tailor positive psychology interventions to remedy the specific vulnerabilities to depression that are conferred by dependency and self-criticism (Blatt, D’Afflitti, \& Quinlan, 1976). Several interventions have proved successful for self-critical individuals. Practicing optimism led to increases in happiness at post-test and at a one-month follow-up for self-critical participants (Shapira \& Mongrain, 2010). High self-criticism also predicted the greatest improvements in happiness for participants in a gratitude condition (Sergeant \& Mongrain, 2011). However, no study thus far has found a positive psychology intervention that is specifically effective for needy individuals. In fact, some positive interventions had detrimental effects for those high on neediness (Sergeant \& Mongrain, 2011). It is therefore imperative to specify not only those who might profit but also those for whom interventions may be harmful.

Attachment style has also been shown to moderate the benefits of a compassion exercise (Mongrain, Chin, \& Shapira, 2011). In one study, performing random acts of kindness was particularly effective for anxiously attached participants, who showed the greatest decreases in depression at post-test compared to those with secure or avoidant attachment styles. Finally, another study demonstrated that higher pessimism was related to greater decreases in depression at post-test for participants practicing optimism (Sergeant \& Mongrain, 2014).

Only a few studies have investigated personality factors as moderators in the efficacy of positive psychology interventions $(\mathrm{Ng}, 2015)$. Overall, the research into "person-activity fit" for 
online positive psychology exercises is in its initial stages, and much more comprehensive empirical data is required for informed conclusions as to who would profit most from these interventions. Furthermore, current research is limited by the incomplete nature of personality models. A better awareness of individual difference factors important to the study of positive psychology is required.

\section{Beyond the Five-Factor Model into the Study of Subjective Well-Being}

Many studies have found associations between current models of personality and measures of well-being, supporting that these factors may play a role in the study of depression and subjective well-being (DeNeve \& Cooper, 1998; Gross, Sutton, \& Ketelaar, 1998; McCrae \& Costa, 1991; Shiota et al., 2006). The five factors have been shown to predict both subjective and psychological well-being (DeNeve \& Cooper, 1998; Furnham \& Christoforou, 2007; Gross et al., 1998; Halama, 2005; Işık, \& Üzbe, 2015; McCrae \& Costa, 1991). Similarly, Eysenck’s measures of neuroticism and extraversion correlate with positive affect, negative affect, depression, and happiness (Cheng \& Furnham, 2003).

At the same time, researchers have proposed important personality factors beyond the five factors, suggesting 'missing traits' that may be critical to the study of positive psychology. For example, Sheldon (2009) proposed a hierarchical framework of individual differences in personality that he calls the "Six Levels of Personality in Context". The six levels are culture (e.g., individualistic versus collectivistic), social interaction (e.g., attachment style, dependency, social support), self (e.g., self-compassion, self-efficacy), goal (e.g., goal-seeking, goalattainment), traits (e.g., neuroticism, gratitude), and psychological needs (e.g., self-esteem).

In support of this personality framework, Sheldon and Hoon (2007) found that subjective well-being (as measured by life-satisfaction, high positive affect, and low negative affect) was 
best predicted by need-satisfaction, low neuroticism, goal-attainment, social support, and culture. Other research has supported that personality factors beyond the five-factor model are important predictors of subjective well-being, including self-efficacy (Deci \& Ryan, 2000) and having a secure attachment style (Mikulincer \& Shaver, 2007). Shiota, Keltner, and John (2006) also considered attachment styles a core part of personality, distinct from but as vital as the five factors. Both anxious and avoidant attachment styles are associated with fewer positive emotions and more negative emotions in intimate relationships (Simpson, 1990).

Blatt proposed a framework of personality based on vulnerability to depression (Blatt et al., 1976; Blatt \& Zuroff, 1992). His two factors of dependency and self-criticism are theorized to relate to early development. Blatt conceptualized dependency as emerging from disruption in the developmental task of relating to others, while self-criticism is due to difficulties in the development of one's identity. Self-criticism is the tendency to fear personal failure, setting high standards and being harshly critical of oneself (Blatt \& Zuroff, 1992). Dependency describes significant insecurity in interpersonal relationships and fears of rejection. Dependency can be further divided into mature and immature dependency, also called connectedness and neediness, respectively (Blatt, Zohar, Quinlan, Zuroff, \& Mongrain, 1995; Rude \& Burnham, 1995; Schulte, Mongrain, \& Flora, 2008). Self-criticism and neediness are both significantly related to depression (Blatt \& Zuroff, 1992; Schulte et al., 2008).

Other traits, such as gratitude, self-compassion, and self-esteem are important predictors of mental health and well-being (Aluja, Rolland, Garcia, \& Rossier, 2007; Emmons \& McCullough, 2003; Neff, Rude, \& Kirkpatrick, 2007). These traits have been excluded from many popular models of personality. The construct of gratitude has been thoroughly studied in the positive psychology literature (Emmons \& McCullough, 2003; Lyubomirsky et al., 2011; 
Sergeant \& Mongrain, 2011). Gratitude is recognition of the positive things in life along with being aware of how others may have contributed to these good things (Emmons, 2004). Selfcompassion is another variable that relates to psychological health, above and beyond the five factors (Neff et al., 2007). Self-compassion is a warm and accepting attitude toward one's self, including any perceived flaws or failures (Neff, 2003; Neff et al., 2007) and it is believed to be a necessary component of mental health and adaptive functioning (Gilbert, 2009; Neff, 2003; Neff et al., 2007). Self-esteem is a general positive or negative stance towards the self, encompassing both judgements and emotional states (Hewitt, 2009), distinct from self-compassion (Krieger, Hermann, Zimmermann, \& grosse Holtforth, 2015). Self-esteem has also held a central place in the literature on personality and positive functioning (Cheng \& Furnham, 2003).

All of the above facets of personality provide a nuanced and comprehensive description of well-being, and are important to include in a full model of personality functioning. These personality factors go beyond traits into developmental and interpersonal models of personality functioning. The current work included measures of attachment styles, dependency, selfcriticism, efficacy, gratitude, self-compassion, and self-esteem, along with the Big Five, to provide a more comprehensive representation of personality across a number of domains.

\section{Current Study}

Preliminary research indicates that personality is important to the study of positive psychology. Findings to date suggest that certain traits influence subjective well-being, depression, and the outcome of intentional exercises. The role of personality as a moderator for the effectiveness of positive psychology interventions requires more substantial investigation to be fully understood. The first step is to identify a complete model of personality functioning. This research examined existing datasets from a large adult sample containing responses to a 
wide range of personality measures. These measures offer a comprehensive representation of personality functioning in a number of domains and should shed some light on the factor structure of personality. Further, these factors should relate to measures of depression and subjective well-being and predict responses to positive psychology interventions.

The data for this research is from Project HOPE (Harnessing One's Personal Excellence; Mongrain, 2007), a positive psychology trial with a large Canadian sample. Ten positive psychology intervention conditions were investigated, which included two control groups. Several personality measures were obtained at baseline. In the first study, these measures were factor-analyzed for parsimony and the solution was predicted to represent a comprehensive model of personality. In the second study, this model's relevance and utility in the study of positive psychology interventions was examined.

The following questions were investigated:

1) What model of personality will best fit an adult, Canadian sample? An exploratory factor analysis was conducted with half the participants in the sample from Project HOPE. These results were validated with a confirmatory factor analysis with the second half of the sample.

2) Are these personality factors related to measures of depression and subjective well-being (satisfaction with life, presence of positive and compassionate affect, and absence of negative affect) at baseline prior to the intervention period?

3) Which personality factors predict the best benefits from positive psychology interventions as a whole? 


\section{General Method}

\section{Participants}

There were 4374 initial participants between the ages of 18 to 72, with a mean age of 33.5 years $(\mathrm{SD}=11.4)$. The sample was largely female $(79.6 \%)$ and Caucasian $(77.3 \%$ White, 6.7\% Asian, 2.5\% East Indian, 1.5\% Aboriginal or Inuit, 1.3\% Black, 1.3\% Middle Eastern, 1.0\% Hispanic, $5.4 \%$ mixed heritage, $2.1 \%$ Other). A majority of participants had at least one post-secondary degree (51.5\%) and almost all had completed high school at minimum (93.9\%). Almost half reported a yearly income of $\$ 20,000$ or less $(48.1 \%)$. Over a third of the sample reported being single $(37.1 \%)$, approximately half was cohabitating or married $(44.3 \%)$, and 43.4\% reported having at least one child.

The participants had a mean baseline score of $20.7(\mathrm{SD}=14.5)$ on the Centre for Epidemiological Studies - Depression Scale (CES-D; Radloff, 1977), indicating significant depressive symptoms in the mild to moderate range (Houston, et al., 2001; Zich, Attkisson, \& Greenfield, 1990). Approximately 63\% reported past or current depression and $57.6 \%$ of reported past or current anxiety. Half of participants reported a past or present course of psychotherapy (49.4\%) and half said they were also prescribed medication for depression, anxiety, or another mental illness (49.2\%).

\section{Measures}

\section{Personality.}

Depressive Experiences Questionnaire (DEQ; Blatt et al., 1976). The DEQ is a 66-item self-report measure of dependent and self-critical personality traits (e.g., "I am very sensitive to others for signs of rejection" and "If I fail to live up to expectations, I feel unworthy" 
respectively). The DEQ also includes a measure of self-efficacy (e.g. "I feel comfortable when I am given important responsibilities”). Participants rate each item using a seven-point Likert-type scale that ranges from strong disagreement (1) to strong agreement (7). The DEQ was designed to assess personality styles that create vulnerability to depression, but does not assess direct symptoms of depression. The three factors that make up the DEQ are Dependency, SelfCriticism, and Efficacy. Dependency has been further divided into mature (connectedness) and immature (neediness) dependency (Rude \& Burnham, 1995). In these analyses, neediness was used, rather than the full Dependency scale, to better represent the maladaptive personality variable that creates a vulnerability to depression (Blatt et al., 1995; Rude \& Burnham, 1995; Schulte et al., 2008).

The DEQ has also demonstrated strong discriminant validity and convergent validity with the Anaclitic and Introjective Dysfunctional Attitude Scales (DAS) which measure analogous constructs to Dependency and Self-Criticism (Blaney \& Kutcher, 1991). Additionally, the DEQ has shown high test-retest reliability, with correlations of .79 for both Dependency and SelfCriticism over a year (Zuroff, Igreja, \& Mongrain, 1990). The DEQ has been validated for use with various age groups, cultures, and languages (Blatt, Schaffer, Bers, \& Quinlan, 1992; Fang \& Yao, 2008; Santor, Zuroff, \& Fielding, 1997)

Big Five Inventory (BFI; John et al., 1991). The BFI is a 44-item, self-report inventory that measures an individual on the Big Five factors of personality: extraversion versus introversion, agreeableness versus antagonism, conscientiousness versus lack of direction, neuroticism versus emotional stability, and openness versus closedness to experience (John \& Srivastava, 1999). Participants indicate how much each item reflects their perception of themselves on a scale from 1 (strongly disagree) to 5 (strongly agree). Examples of items 
include "I am someone who is full of energy" (extraversion), "I am someone who is helpful and unselfish with others" (agreeableness), "I am someone who does a thorough job" (conscientiousness), "I am someone who worries a lot" (neuroticism), and "I am someone who is curious about many different things" (openness to experience). The BFI has good internal consistency, and good convergent and discriminant validity compared to other measures of the five-factor model (John \& Srivastava, 1999).

Gratitude Questionnaire-6 (GQ-6; McCullough, Emmons, \& Tsang, 2002). The GQ-6 is a six-item self-report measure of gratitude, with items such as "I have so much in life to be thankful for". Statements are hypothesized to tap into four facets of gratitude: intensity, frequency, span, and density. Each statement is rated with a scale from 1 (strongly disagree) to 7 (strongly agree). Higher scores indicate higher gratitude. The GQ-6 has good convergent and discriminant validity (McCullough et al., 2002). Internal consistency is high and the measure has demonstrated good test-retest reliability at a one-year interval (McCullough et al., 2002).

Rosenberg Self-Esteem Scale (RSES; Rosenberg, 1965). The RSE is a self-report measure of global self-esteem. The measure includes ten items rated on a scale of 1 (strongly disagree) to 4 (strongly agree). Participants indicate agreement about themselves on items such as “On the whole, I am satisfied with myself". The RSES has good internal consistency ranging from .77 (Rosenberg, 1965) to .99 (Damji, Clement, \& Noels, 1996) and good test-retest reliability; over a 7-month interval, reliability was calculated as 0.63 (Shorkey \& Whiteman, 1978). This measure has demonstrated strong construct validity and concurrent validity (Carmines \& Zeller, 1979).

\section{Experiences in Close Relationships-Revised (ECR-R; Brennan, Clark, \& Shaver,}

1998). The ECR-R is a 36-item self-report measure of adult attachment style (Fraley, Waller, \& 
Brennan, 2000). Items are rated from 1 (strongly disagree) to 7 (strongly agree). The ECR-R measures participants on two subscales of attachment: Avoidance and Anxiety. Individuals high on the Avoidance subscale are uncomfortable with intimacy and want to be independent (e.g., "I prefer not to be too close to romantic partners"). Individuals high on the Anxiety subscale are afraid of being rejected and abandoned (e.g., "My desire to be very close sometimes scares people away"). This measure has good convergent and discriminant validity (Sibley, Fischer, \& Liu, 2005; Wei, Heppner, Russell, \& Young, 2006) and high internal consistency (Brennan et al., 1998). Reports of test-retest reliability are between .68 and .71 for the two subscales (Lopez \& Gormley, 2002).

Self-Compassion Scale (SCS; Neff, 2003). The SCS is a 26-item self-report measure of self-compassion. Items are rated from 1 (almost never) to 5 (almost always). This scale includes items measuring self-kindness, self-judgement, common humanity, isolation, mindfulness, and over-identification (Neff, 2016). An example of an item representing self-kindness is "I try to be loving toward myself when I'm feeling emotional pain”. Half of the items of this scale are positive indicators of self-compassion, while the others are negative indicators which reflect selfcriticism. This scale has shown good internal reliability (Neff \& Pommier, 2013) and good convergent validity (Neff et al., 2007). However, there is evidence that the positive items are a better representation of self-compassion (Armstrong et al., in press) and are more strongly negatively associated with psychopathology (Muris \& Petrocchi, 2016). For this reason, only the positive items were used in the current work.

\section{Outcome.}

Centre for Epidemiological Studies Depression Scale (CES-D; Radloff, 1977). The CES-D is a 20-item, self-report measure which asks participants about the frequency of 
depressive symptoms during the past week (e.g., "I thought my life had been a failure" or "I talked less than usual"). Participants rate each item from rarely or none of the time (0) to most or all of the time (3). The CES-D has demonstrated high internal consistency with a coefficient alpha of .91 (Schulte et al., 2008). The CES-D is also effective at discriminating individual differences in symptom severity (Radloff, 1977), performing as well as or better than other frequently used measures such as the Beck Depression Inventory (Santor, Zuroff, Ramsay, Cervantes, \& Palacios, 1995). Scores above 16 indicate significant depressive symptoms (Zich, et al., 1990).

Satisfaction With Life Scale (SWLS; Diener, Emmons, Larsen, \& Griffin, 1985). This self-report measure asks participants to rate five statements measuring global satisfaction with life (e.g., "In most ways my life is close to ideal). This measure uses a seven-point Likert-type scale that goes from strongly disagree (1) to strongly agree (7). The SWLS has shown strong internal consistency and good temporal stability with a test-retest correlation coefficient of .82 over two months (Diener, et al., 1985). It also correlates highly with other measures of wellbeing (Lucas, Diener, \& Suh, 1996; Pavot \& Diener, 1993). A total score above 26 indicates very high satisfaction with life, while a score below 9 indicates extreme dissatisfaction.

\section{Compassion - Positive/Negative Affect Scale (C-PNAS; See Appendix C). The C-PNAS} was created for Project HOPE and was based on the Positive and Negative Affect Schedule (PANAS; Watson, Clark, \& Tellegen, 1988). The C-PNAS is a self-report measure that asks participants to indicate the extent to which they currently feel positive, negative, and compassionate affect, from a list of 20 adjectives. The items are rated using a 5-point Likert scale from very slightly or not at all to extremely. The emotion words were chosen based on face validity and expert agreement. The emotion words reflect either positive affect (e.g., "content", 
“joyful”), compassionate affect (e.g., "nurtured", "loving"), or negative affect (e.g., "frustrated", "unhappy"). In this dataset, coefficient alpha was .91 for the Positive Affect Scale, .86 for the Compassionate Affect Scale, and .88 for the Negative Affect Scale.

\section{Procedure}

The current studies used data from Project HOPE - "Harnessing One's Personal Excellence". There were 4374 initial participants recruited within Canada between October 2007 and January 2008. Participants were required to be 18 or older and have daily access to the Internet. Recruitment was conducted through Facebook with ads that were targeted at Canadians. Other recruitment venues included advertisements in the national newspaper and flyers posted at York University; however, the majority of participants were recruited through Facebook. A copy of the advertisement used can be seen in Appendix A. Remuneration was offered as $\$ 30$ for the first group of participants $(n=1168)$ once they completed the first post-test assessment. For budget considerations, subsequent participants were instead entered into a draw for $\$ 1000$ after completing the post-test assessment and entered into additional $\$ 1000$ draws at each follow-up assessment. All aspects of the study were administered online.

After registering online and reading the consent form (See Appendix B), participants were directed to the set of baseline measures described above plus a demographics questionnaire. Copies of these measures can be found in Appendix C. Participants were then randomly assigned to one of 10 exercise conditions. These exercises are briefly outlined below (full text of the exercise instructions can be found in Appendix D). Participants were provided with a rationale and instructions for their assigned exercise. The next day, participants were emailed and asked to return to the website to begin participation in the interventions. Replicating the first positive psychology landmark study by Seligman et al., (2005), participants were instructed to perform 
their given exercise and report back on the website every day for a week which was expected to take approximately 15 minutes per day. Participants were sent an email every day to remind them to visit the website. At the end of the intervention period, participants completed a post-test assessment, which consisted of the CES-D, the SWLS, and the C-PNAS. A copy of their exercise instructions was sent by email to the participants in case they wished to continue practicing the exercise following the treatment period.

The longitudinal component of the study included follow-up at one, three, and six months following the intervention period. Participants were emailed to return for a follow-up assessment with the same outcome measures. Reinforcement emails were sent at two, four, and six months following the intervention period to encourage participants to continue their exercise if they found it helpful.

\section{Active conditions.}

3 Good Things. Participants were asked to write down three good things that they had experienced that day. Then they were asked to reflect on and report about why these good things had happened.

Positive Reinterpretation. Participants were asked to describe a "bothersome" event from their day. They were asked questions intended to provide a positive outlook on the event, such as “How can I grow from this experience?" or "How can I see this event in a more positive light?".

Signature Strengths. Participants initially took the VIA Signature Strength Questionnaire (Authentic Happiness: www.authentichappiness.com), a questionnaire designed to identify their top five personal strengths. Every day, they were instructed to use one of these strengths in a new way, such as in a new setting or with a new person. 
Self-Compassion. Participants were instructed to think about a distressing event or situation from that day and then write a letter to themselves about this event from a caring perspective. The participants were asked to show compassion to themselves and think about what they would say to a friend.

Compassionate Action. In this condition, participants had to act compassionately towards another person for 5 to 15 minutes per day. After, they were asked to describe the action, who the act was with, where it occurred, how long it lasted, and how it made them feel.

Gratitude. Participants were asked to list five things or gifts that they were thankful for that day. These things could be new or stable fixtures from their lives. They were asked to think of new things for each list.

Listening to Music. Participants were to choose and listen to three to four songs that they found uplifting. On the website, the participants listed the songs, how long they listened to the music, and how they felt.

Letter From Your Future Self. Participants were to imagine themselves in a positive future, at a time of their choice. Then, they were instructed to describe this future in as much detail as possible, across domains including their family life and professional development. They were asked to give themselves concrete and compassionate advice on how to achieve these possible futures.

\section{Control Conditions.}

Early Memories. Participants were instructed to describe an early memory in as much detail as they could recall. Prompting questions included "What were you doing?", "What were you feeling?" and "Who else was with you?". 
Early Positive Memories. This exercise was similar to the one above. In this exercise, participants were instructed to recall only positive memories from their early life.

For more information on the rationale and effectiveness of the foregoing interventions, please refer to the following publications: Mongrain \& Anselmo-Matthews, 2012; Mongrain et al., 2011; Seligman et al., 2005; Sergeant \& Mongrain, 2011; Sergeant \& Mongrain, 2015; Shapira \& Mongrain, 2010.

\section{Study 1}

The aim of the first study was to determine the best fitting model of personality in a large adult sample using a wide-range of measures tapping various aspects of personality. These measures were completed at study baseline. Included in these analyses were the Rosenberg SelfEsteem Scale (RSES; Rosenberg, 1965), the Gratitude Questionnaire-6 (GQ-6; McCullough et al., 2002), the five subscales from the Big Five Inventory (BFI; extraversion, neuroticism, agreeableness, conscientiousness, and openness to experience; John et al., 1991), and the two subscales from the Experiences in Close Relationships-Revised (ECR-R; avoidance and anxiety; Brennan et al., 1998). From the Depressive Experiences Questionnaire (DEQ; Blatt et al., 1976), the scales of Self-Criticism and Efficacy were included, as well as the measure of immature dependency (Neediness) proposed by Rude and Burnham (1995). From the Self-Compassion Scale (SCS; Neff, 2003), only the positive items were used as a measure of self-compassion (Armstrong et al., in press; Muris \& Petrocchi, 2016). Exploratory factor analysis was conducted with half of the participants from Project HOPE. These results were validated using confirmatory factor analysis with the second half of the sample. 


\section{Method}

There were 4922 participants in the original dataset from Project HOPE. Participants who did not complete any of the baseline questionnaires were excluded, leaving 4374 participants (baseline completers). The participants were randomly divided into two subsamples, leaving one for exploratory factor analysis $(n=2188)$ and one for confirmatory factor analysis $(n=2186)$. The analyses were conducted using $\mathrm{R}$ version 3.2.2. (R Core Team, 2015), and the following packages: 'car' version 2.1-0 (Fox \& Weisberg, 2011), 'lavaan' version 0.5-20 (Rosseel, 2012), and 'psych' version 1.5.8 (Revelle, 2015).

For the exploratory factor analysis, maximum likelihood estimation was used. Missing data was handled with pairwise deletion. Previous studies on models of personality have shown many inter-factor correlations so the factors were not predicted to be orthogonal. Accordingly, oblimin rotation was used, which allows the factors to correlate. There were no specific hypotheses made concerning the factor structure of the personality variables or the number of factors. Decisions concerning the number of factors to retain were made using multiple criteria: a scree plot of eigenvalues, parallel analysis, factor interpretability, and fit statistics (root mean square error of approximation [RMSEA]; and the Tucker-Lewis Index [TLI]). For RMSEA, values lower than 0.05 indicate a close fit, values between 0.05 and 0.08 indicate reasonable fit, values between 0.08 and 0.10 indicate mediocre fit, and values bigger than 0.10 are considered poor fit (Cudeck \& Browne, 1992). For TLI, values above 0.90 are considered to be adequate fit. For exploratory factor analysis, guidelines suggest choosing the number of factors for which the lower bound of a 90\% confidence interval of RMSEA drops below .05 (Preacher, Zhang, Kim, \& Mels, 2013). A personality scale was considered to have a salient loading on a factor if the factor loading was equal to or greater than 0.30 . 
Confirmatory factor analysis was used with the second subsample to validate the factor structure found with the exploratory factor analysis. To account for the missing data and the multivariate non-normality, full-information maximum likelihood was used and the YuanBentler scaled fit statistics were obtained for more robust fit statistics. Based on the exploratory factor analysis, models were specified a priori and compared to allow for different cross-loadings of the personality scales. Model fit was evaluated based on goodness-of-fit indices, including RMSEA and TLI, the Comparative Fit Index (CFI), and the standardized root mean square residual (SRMR). For TLI, a value above 0.90 is considered to be an adequate fit if accompanied by a low RMSEA value (Hu \& Bentler, 1999). For CFI, values above 0.90 are considered acceptable if RMSEA or SRMR are low (Hu \& Bentler, 1999). For SRMR, values below 0.08 are considered indicative of a good fit (Hu \& Bentler, 1998).

\section{Results}

Correlations and descriptive statics for the baseline personality variables are in Table 1.

\section{Exploratory factor analysis.}

A scree plot showed that three eigenvalues occurred before the remaining eigenvalues plateaued. Parallel analysis, which compares the eigenvalues from the correlation matrix with those from uncorrelated variables, suggested a seven-factor solution. Theoretically, based on previous models of psychology, between two and five factors could be expected. Given that the five-factor model estimated here resulted in low factor loadings for all variables, models with more than five factors were not estimated. Accordingly, two-, three-, four-, and five-factor models were estimated. 
In the two-factor solution, all scales had moderate to strong factor loadings $(\geq 0.30)$ on at least one factor. However, the fit statistics indicated inadequate fit, with RMSEA $=0.10(90 \% \mathrm{CI}$ $0.095-0.105)$ and TLI $=0.82$. Additionally, there were large residual correlations between anxious attachment and neediness (0.20), and between agreeableness and neediness (0.14). The three-factor model had better fit $(\mathrm{RMSEA}=0.072,90 \%$ CI $0.066-0.077$; TLI $=0.91)$. All scales had moderate to strong factor loadings $(\geq 0.30)$ on at least one factor and there were no large residual correlations.

The four-factor solution resulted in an improper solution in that one variable (neediness) had a communality estimate greater than 1.0. The five-factor model showed universally low factor loadings across all variable, with one variable (self-esteem) not loading well onto any factor (all factor loadings $\leq 0.28$ ). The rotated factors were less interpretable than those found with the three-factor model and the fit statistics were not substantially better than the three-factor solution $(\mathrm{RMSEA}=0.062,90 \%$ Confidence Interval $0.055-0.070 ; \mathrm{TLI}=0.93)$.

For these reasons, the three-factor model was chosen as optimal for the current data. The three-factor model showed good model-data fit and had the most interpretable solution. The rotated factor loadings and communalities for this model can be found in Table 2 and the interfactor correlations are in Table 3. The first factor included nine variables with salient loadings above 0.30: extraversion, agreeableness, conscientiousness, self-esteem, gratitude, selfcompassion, and negative loadings from self-criticism, neuroticism, and avoidant attachment. Seven of these variables had moderate to strong factor loadings between $|0.50|$ and $|0.83|$. Higher levels of this factor reflect more positive psychological states and more positive communal relationships with others. The variables with salient loadings on the second factor included neediness, anxious attachment, and neuroticism (which also had a salient loading on the first 
factor). Neediness and anxious attachment had moderate to strong loadings on this factor $(|0.48|$ $|0.99|)$, while the loading from neuroticism was relatively small (0.33). Higher levels on this factor reflect higher levels of immature dependency, anxiety in relationships, and emotional instability. For the third factor, variables with salient loadings included efficacy (0.77), openness to experience (0.44), and two variables which also loaded onto the first factor: gratitude (0.30) and self-criticism (0.31). This factor largely appears to reflect agency, intellect, and curiosity.

\section{Confirmatory factor analysis.}

With the second half of the sample $(n=2186)$, confirmatory factor analysis was used to cross-validate the three-factor model found with exploratory factor analysis. Two models were specified to determine if the cross-loadings seen in the previous analysis would replicate. Model 1 (see Figure 1) had three factors and no cross-loadings, with each observed variable loading onto only one factor. This model fit the data poorly. Both CFI $=0.80$ and TLI $=0.74$ were low, and RMSEA $=0.10$ indicated poor model-data fit $(90 \%$ CI $0.10-0.11)$. Only SRMR $=0.066$ was acceptable.

Model 2 (see Figure 2) had three factors and included all cross-loadings greater than or equal to 0.30 found in the exploratory factor analysis. The goodness-of-fit indices for Model 2 were acceptable, with RMSEA $=0.072(90 \%$ CI $0.68-0.77), \mathrm{CFI}=0.91, \mathrm{SRMR}=0.046$, and $\mathrm{TLI}=0.88$. The residual correlation matrix showed no strong residual relations between variables. Overall, this model was considered acceptable. A chi-square difference test also showed that Model 2 fit the data significantly better than Model $1\left(\chi_{\text {diff }}^{2}(3)=642.97, p<.0001\right)$. Therefore, Model 2 was considered optimal for this data.

All factor loadings in Model 2 were significant, and the completely standardized loadings are in Table 4. Of the nine variables in Factor 1, the majority had moderate to strong factor 
loadings $(|0.44|-|1.10|)$. Only one variable had a weak factor loading (-0.33 for neuroticism). These results confirm Factor 1 as representing self-compassion, a lack of self-criticism, gratitude, self-esteem, agreeableness, secure attachment relationships, conscientiousness, extraversion, and emotional stability. Overall, Factor 1 can be interpreted as internal and interpersonal stability. For Factor 2, all variables had moderate to strong positive factor loadings $(0.48-0.84)$. Factor 2 is defined by interpersonal neediness, anxious attachment relationships, and neuroticism. This factor can be interpreted as insecurity, fear of disconnection, and emotional volatility.

The factor loadings on Factor 3 were positive and ranged from strong ( 0.72 for efficacy) to weak ( 0.18 for gratitude). Factor 3 is defined by efficacy, self-criticism, openness to experience, and, weakly, by gratitude. This factor represents agency and curiosity. The interfactor correlations for the confirmatory factor analysis showed a strong negative correlation between Factor 1 and Factor 2 (-0.73) and a moderate correlation between Factors 1 and $3(0.46)$.

\section{Discussion}

Study 1 investigated the structure of personality in a large Canadian sample. A threefactor model was determined to be the best fit for this data. Higher levels on the first factor reflect an interpersonal orientation, positive mental states, and positive communal relationships with others and with oneself. In other words, those with high scores on this factor have secure, loving relationships, and an absence of inner turmoil. Thus, this factor was labelled 'Equanimity' to reflect both interpersonal and intrapersonal harmony. Those with higher levels on the second factor can largely be described as having immature dependency on others, nervousness, and emotional instability. This factor denotes feelings of threat in relationships. It was labelled 'Insecurity' due to its interpersonally anxious nature and fear of loss. The third factor reflects 
achievement orientation, curiosity, and goal-striving. This factor represents self-efficacy and drive. This factor is referred to as 'Agency' due to its similarity to previous theoretical models (Bakan, 1966; Wiggins, 1991).

Some caveats are worth noting. Three variables had salient loadings on multiple factors. These cross-loadings may reflect that facets of these scales (self-criticism, neuroticism, and gratitude) are related to different personality factors. That is, each variable may have various constituent elements that relate to these three factors in different ways. For example, selfcriticism had the strongest negative loading on Factor 1 (Equanimity) and a moderate positive loading on Factor 3 (Agency). On Factor 1, low self-criticism is consistent with low neuroticism, and high self-compassion and self-esteem. In comparison, the low to moderate factor loading of self-criticism on Factor 3 may reflect striving towards high standards and lofty goals, which is consistent with the ambitious and achievement-oriented focus associated with this personality variable (Mongrain \& Zuroff, 1995). It is also supported by several items in the self-criticism scale such as "There is a considerable difference between who I am now and how I would like to be" and "I often find that I don't live up to my own standards or ideals". When paired with a high sense of self-efficacy (the efficacy variable loaded most highly onto Factor 3), an agentic goal-driven orientation appeared to be an appropriate interpretation of this factor.

Neuroticism had a moderate loading on Factor 2 (Insecurity) and a weak negative loading on Factor 1 (Equanimity). On Factor 2, neuroticism underlines the maladaptive interpersonal styles reflected by neediness and anxious attachment. On Factor 1, the absence of neuroticism indicates emotional stability. Finally, gratitude had a strong loading on Factor 1 (Equanimity) and a weak loading on Factor 3 (Agency). On Factor 1, gratitude can be interpreted as a character strength and an indicator of mental health (Peterson \& Seligman, 2004). The cross- 
loading was weaker for Factor 3 but is consistent with the feeling of appreciation associated with being efficacious in the pursuit of goals.

The pattern of correlations among the personality factors must also be interpreted in the conceptualization of the findings and overall model. The inter-factor correlation between Equanimity and Insecurity was moderate in the exploratory factor analysis and strong in the confirmatory factor analysis. This result is consistent with the interpretation of Factors 1 and 2, and represents the negative relationship between problematic interpersonal anxiety, and selfcompassion accompanied by a positive orientation towards others. The implication of this negative relation between Factors 1 and 2 suggests that it is difficult to have insecure anxiety as well as intrapersonal and interpersonal harmony. At the same time, the presence of two distinct factors within this overarching model of personality suggests the presence of separate origins and functions of these factors. Other well-known models of personality have also shown similarly strong inter-factor correlations (van der Linden, te Nijenhuis, \& Bakker, 2010).

The three factors obtained in this personality model are consistent with previous theoretical models and empirical findings. For example, Equanimity has much in common with Digman's (1997) Alpha, DeYoung's (2006) Stability, and Wiggins' (1991) Communion. Similar to Alpha and Stability, Factor 1 in this study subsumes agreeableness, conscientiousness, and emotional stability, with the addition of self-compassion, self-esteem, and gratitude. It reflects socially desirable traits, and more broadly, stable mental health and wellness, including agreeableness, self-acceptance, and adaptive functioning. This factor also represents the inverse of Eysenck's psychoticism factor, which includes hostility, cruelty, lack of empathy, and lack of conformity to society's rules. 
Agency also has a strong resemblance to previous models. It is consistent with the concept of the same name described by Wiggins (1991). It is also consistent with the factors labelled Beta by Digman (1997) and Plasticity described by DeYoung (2006). Like Beta and Plasticity, Agency includes openness to experience and represents personal growth. Agency additionally denotes efficacy, striving, and a tendency towards exploration, curiosity, and goalachievement. Novelty Seeking from Cloninger's model $(1987,1991)$ and the Behavioural Approach System from Gray (1982) also share some conceptual overlap with Factor 3, reflecting active pursuit of reward and goals. The Behavioural Approach System is often linked with extraversion in Eysenck's model. Although Agency is not a perfect representation of Eysenck's extraversion, these factors share the outgoing and sensation-seeking components.

Factor 2, labelled here as "Insecurity", shares some similarity with Harm Avoidance from Cloninger's model (1987, 1991). Someone high in Harm Avoidance would be fearful and cautious, similar to someone high on Insecurity. However, Insecurity includes the aspect of specifically interpersonal anxiety and dependence, which is not seen in Harm Avoidance. Similarly, Gray's (1982) Behavioural Inhibition System is sensitive to punishment and negative stimuli. An individual high on Insecurity would be hypervigilant for signs of rejection or disapproval from others. Eysenck's neuroticism factor, which denotes excessive or exaggerated fears and worries, is also similar to Insecurity. The current results suggest that a third factor is necessary in the full description of personality in that the Big Two conceptualizations fail to capture the "threat" factor which represents a sense of insecurity in relationships. This finding may have occurred because the range of personality variables included in this study was broader than those included in previous works. The Big Five has been the foundation of previous empirical studies producing two-factor solutions (Digman, 1997; DeYoung, 2006), which may not be comprehensive enough to capture the Insecurity element of personality functioning. The 
personality measures included in the current study may have overrepresented the vulnerability markers of psychopathology and problematic personality functioning; alternatively, this study may have better captured those aspects of personality that were neglected in prior studies.

Insecurity is also similar to the factor of Anxiety from the four-factor Neurobehavioral Dimensional Model (NDM) of personality by Depue and Lenzenweger (2005). This Anxiety factor is similar to neuroticism and serves a "threat-detection" function, reacting to potential danger. The Affiliation factor of the NDM is similar to Equanimity in that it represents valuing close interpersonal bonds, but it lacks the internal harmony and self-compassion that is contained in Equanimity. Similarly, the Agentic Extraversion factor of the NDM is similar to this model's Agency factor, with the addition of interpersonal strivings and dominance. The NDM includes a fourth factor of Constraint, which is viewed as a non-affective factor, representing the reverse of impulsivity. Constraint is thought to modulate the expression of the other three affective factors.

A similar model of personality is found in the Multidimensional Personality Questionnaire by Tellegen and Waller (2008). This model includes Positive Emotionality, Negative Emotionality, and Constraint. Positive Emotionality can be further broken down into Agentic and Communal Components (Hopwood et al., 2011), which are similar to the Agency and Equanimity factors found in this study, respectively. Negative Emotionality maps onto the Insecurity factor. Again, Constraint is lacking in the three-factor model found in Study 1. This construct is best captured by conscientiousness of the five-factor model, and therefore subsumed under the Equanimity factor.

The three-factor model of personality obtained in this study could be conceptualized from a developmental perspective. Under this umbrella, Insecurity represents that secure attachment and safety in relationships is a pre-requisite for further development. Agency represents the 
development of self-efficacy and emancipation, or the development of the self. Finally, Equanimity encapsulates the pinnacle of successful development, where harmony within the self and with others is accomplished. This model is reminiscent of Blatt's model of personality development (Blatt et al., 1976). Insecurity could represent failure to meet the developmental need to develop satisfying relationships, while Agency is a drive to acquire a positive sense of identity. An individual high on Equanimity could be conceptualized as someone who has met both of these needs, having both secure relationships and a stable sense of self. These hypotheses could be useful for future research.

Gilbert's systems of emotion regulation provide another lens for interpreting the three factors found in this study (Gilbert et al., 2008; Gilbert, 2015). Gilbert proposed three types of emotion regulation systems: a threat protection system, a drive-seeking system, and a contentment, soothing, affiliative system. The Equanimity factor maps well onto this affiliative system, with predominant feelings of contentment and safety in relationships. This factor naturally correlates negatively with the Insecurity factor as described by Gilbert's self-protection system. An individual high on the Agency factor might share an active drive-seeking and acquisition-focused system, as described by Gilbert and colleagues (2008). An important specification in Gilbert's model is that these systems of emotion regulation are not completely independent; each individual falls somewhere on the continuum of each system and might be high (or low) in any combination. This is similar to the three factors of Equanimity, Insecurity, and Agency, which each exist on a continuum. In summary, the three factors can be conceptualized as dimensions that vary depending on one's developmental trajectory, both between individuals and within individuals. 
These findings have some limitations worth noting. The sample tested was mildly depressed at baseline and therefore may not be representative of the general population. Distressed individuals may have been self-selected into this study in order to benefit from the positive psychology interventions (although the first wave of participants who were paid may have been motivated by the financial reward). Additionally, this sample was largely female and White. Therefore, the factor structure found may not be completely generalizable to a broader population. The usefulness of these factors as predictors of outcome in positive psychology interventions is examined in the next study.

\section{Study 2}

The aim of Study 2 was to determine how the personality factors discovered in Study 1 would predict outcomes following online positive psychology interventions. Included in these analyses were outcome measures of depression (as measured by the CES-D), satisfaction with life (as measured by the SWLS), absence of negative affect, and presence of positive affect and compassionate affect (as measured by the C-PNAS). Participants were categorized depending on whether they performed an active positive psychology exercise or a control exercise.

The specific research questions were:

1) Do these three factors relate to levels of depression and subjective well-being in conceptually meaningful ways?

2) Do these three factors predict changes in depression and subjective well-being in theoretically-expected ways between baseline and post-test for participants engaged in positive psychology exercises, compared to those in the control conditions?

3) Do these three factors meaningfully predict maintenance of changes between post-test and the six-month follow-up for participants engaged in positive psychology exercises? 
Factor 1 (Equanimity) was hypothesized to correlate with lower depression and higher subjective well-being at baseline due to the psychological wellness inherent in the variables loading on this factor. Due to a ceiling effect, participants high on this factor were predicted to profit less from the positive psychology interventions. Factor 2 (Insecurity) was hypothesized to correlate with higher depression and lower subjective well-being at baseline. Participants high on this factor were predicted to benefit the most from the active positive psychology interventions, given the inherent instability and feelings of interpersonal threat associated with this factor. In addition, past research has shown that positive psychology interventions result in the greatest improvements in subjective well-being for distressed users (Sergeant \& Mongrain, 2015). Factor 3 (Agency) was predicted to be related to lower depression and higher subjective well-being at baseline given the contribution of variables loading on this factor, particularly self-efficacy. Furthermore, participants high on this factor were expected to profit from the active positive psychology exercises due to their goal-driven nature and strivings towards improvement.

\section{Method}

All baseline completers from the Project HOPE dataset were included in the analysis $(N=$ 4374). These analyses were conducted using $R$ version 3.2.2. (R Core Team, 2015), and the following packages: ‘car' version 2.1-0 (Fox \& Sanford, 2011), 'lavaan' version 0.5-20 (Rosseel, 2012), and 'psych' version 1.5.8 (Revelle, 2015).

The research questions above were tested using latent growth curve modeling. To account for missing data and the multivariate non-normality, full-information maximum likelihood was used and robust fit statistics were obtained. Separate models were estimated for each dependent variable (depression, satisfaction with life, positive affect, compassionate affect, and negative affect). The general model estimated can be seen in Figure 3. Each model was a 
piecewise linear growth model, including an intercept factor and two linear slope factors. Slope 1 represented the change in outcome scores from baseline to post-test, while slope 2 represented the change in outcome scores from post-test to the six-month follow-up. This model was specified to account for the expected non-constant change in outcomes following the intervention period (e.g., a decrease in depression from baseline to post-test, and then maintenance of changes or a potential return to baseline over the six-month follow-up period). Because slope 1 was based on only two time points, the residual variance of slope 1 , the covariance of slope 1 with slope 2 , and the covariance of slope 1 with the intercept factor were all restricted to 0 .

The condition variable was coded dichotomously as 'active' or 'control' condition. Factor scores were computed using the latent variables found in the confirmatory factor analysis in Study 1 and centered. Interaction scores between each factor and the condition variable were also computed and included as predictors to test whether the active positive psychology exercises influenced the outcome trajectories differently according to the personality factors.

Some demographic variables were correlated with the outcome variables. For example, age, gender, and income were significantly correlated with depression. Age and income were also significantly correlated with satisfaction with life, positive affect, negative affect, and compassionate affect. The significant correlations between demographic and outcome variables ranged between $|0.05|$ to $|0.16|$; all correlations can be seen in Table 5. Given these associations, age, gender, and income were included as covariates in the subsequent growth curve analyses. Gender was coded as male versus female. The age and income variables were centered. The full list of predictors included Equanimity, Insecurity, Agency, condition (active vs. control), a condition by Equanimity interaction, a condition by Insecurity interaction, a condition by Agency interaction, age, gender, and income. Non-significant interactions were removed from 
the models for each outcome variable to aid final model interpretation. Model fit was evaluated based on goodness-of-fit indices, including TLI, CFI, RMSEA, and SRMR.

\section{Results}

\section{Correlations.}

The correlations among demographic variables, factor scores, and outcome measures at baseline are in Table 5. As predicted by the hypotheses, the three personality factors were correlated with depression and subjective well-being at baseline. Higher scores on Equanimity were associated with lower depression, higher satisfaction with life, fewer negative emotions, and more positive and compassionate emotions. As expected, higher Agency was also associated with lower depression, higher satisfaction with life, fewer negative emotions, and more positive and compassionate emotions, although these correlations were of a lower magnitude compared to Equanimity. The Insecurity factor was associated with higher depression, lower satisfaction with life, more negative emotions, and fewer positive and compassionate emotions.

\section{Participants and Attrition.}

Of the 4374 baseline completers, 3528 continued on and were randomly assigned to an exercise condition, categorized as either an active condition $(n=2819)$ or a control condition $(n$ $=709)$. Out of this sample, $67.8 \%$ completed the post-test measures $(n=2391), 54.6 \%$ completed the one-month follow-up $(n=1926), 38.7 \%$ completed the three-month follow-up $(n$ $=1365)$, and only $27 \%$ completed the six-month follow-up $(n=951)$. The sample sizes for active conditions versus control conditions at each point of data collection can be seen in Table 6 . This rate of attrition is similar to that seen in other online studies (Dandurand, Shultz, \& Onishi, 2008; Parks, 2014). 
Although the method of estimation minimized the loss of data due to attrition, participants who completed outcome measures at each time point were more heavily weighted in the analyses. It is therefore important to consider the characteristics of completers $(n=951)$ versus non-completers $(n=3423)$. Comparisons of mean scores for completers versus noncompleters can be seen in Table 7. Completers scored lower on the CES-D at baseline $(t(3898)=$ $4.91, p<.001)$, higher on the SWLS $(t(3651)=-4.65, p<.001)$, higher on positive affect $(t(3668)=-2.47, p<.05)$, lower on negative affect $(t(3668)=4.67, p<.001)$, higher on compassionate affect $(t(3668)=-3.70, p<.001)$ and were older $(t(4280)=9.19, p<.001)$. Additionally, completers were more likely to be female $\left(\chi^{2}(1, \mathrm{~N}=4258)=11.56, p<.01\right)$. Altogether, those who dropped out were more depressed at baseline, less satisfied with their lives, reported higher negative affect, lower positive affect, and low compassionate affect. Male participants were also more likely to drop out. These results need to be considered in the generalizability of the model.

\section{Latent growth curve models.}

\section{Depression.}

The model seen in Figure 4 fit the data well, with CFI $=0.97, \mathrm{TLI}=0.94$, RMSEA $=$ $0.048(90 \%$ CI $0.042-0.053)$ and SRMR $=0.043$. Overall, the predicted mean depression score at baseline was 19.87 from a model with no predictors included. This represents mild to moderate depression (scores above 16 are considered to be clinically significant; Zich, et al., 1990). The regression estimates for this model can be seen in Table 8. Participants scoring higher on Equanimity reported lower levels of depression at baseline $(\gamma=-6.80, z=-19.40, p<.01)$. Participants scoring high on Insecurity reported higher levels of depression at baseline $(\gamma=3.20$, $z=8.93, p<.01)$ as did participants scoring higher on Agency $(\gamma=1.00, z=4.16, p<.01)$. 
Between baseline and post-test, condition significantly predicted depression $(\gamma=-1.34, z$ $=-3.06, p<.01)$ indicating that being in an active condition was related to greater decreases in depression. Similarly, being in an active condition was related to greater decreases in depression over the six-month follow-up period $(\gamma=-0.31, z=-2.33, p=.02)$. Insecurity also predicted changes in depression, such that higher scores on Insecurity related to greater decreases in depression from baseline to post-test $(\gamma=-1.52, z=-3.85, p<.01)$. Those scoring higher on Insecurity also reported reductions in depression over the six-month follow-up period $(\gamma=-0.50$, $z=-3.94, p<.01)$

\section{Satisfaction with life.}

The model fit the data well, with CFI $=0.97, \mathrm{TLI}=0.95, \mathrm{RMSEA}=0.052(90 \%$ CI 0.046 $-0.057)$ and SRMR $=0.026$. Overall, the predicted mean satisfaction with life score at baseline was 3.99 from a model with no predictors included. This is a below average score on this measure, indicating slight dissatisfaction with life (Pavot \& Diener, 2008). The regression estimates for this model can be seen in Table 9. Participants scoring higher on Equanimity reported higher levels of satisfaction with life at baseline $(\gamma=1.18, z=-31.03, p<.01)$, as expected. Higher scores on Insecurity were also related to higher satisfaction with life as baseline $(\gamma=0.11, z=2.67, p<.01)$ when controlling for the other variables.

Insecurity was significantly related to satisfaction with life over the six-month follow-up period $(\gamma=0.027, z=2.16, p=.03)$ for participants in both the active and control conditions. Higher scores on Insecurity predicted greater increases in satisfaction with life over the followup period. None of the other variables were significantly related to satisfaction with life at baseline or over the six-month follow-up. 


\section{Positive Affect.}

The model fit the data well, with CFI $=0.97, \mathrm{TLI}=0.95, \mathrm{RMSEA}=0.037(90 \%$ CI 0.032 -0.042 ) and $S R M R=0.027$. The predicted mean positive affect score at baseline from a model with no predictors was 2.91 , out of a maximum score of 5. This appears to represent only slightly below average levels of positive emotions compared to the general population (Watson et al., 1988). The regression estimates for this model can be seen in Table 10. Equanimity was significantly related to positive affect at baseline $(\gamma=0.68, z=25.99, p<.01)$ such that higher scores on Equanimity were related to higher levels of positive affect. Insecurity and Agency did not significantly predict positive affect at baseline over and above the other variables.

Being in an active positive psychology intervention predicted a greater increase in positive affect from baseline to post-test $(\gamma=0.092, z=2.51, p=.01)$. Similarly, those in an active positive psychology condition reported a greater increase in positive affect from post-test over the six-month follow-up $(\gamma=0.021, z=2.04, p=.04)$. Equanimity was also related to positive affect over the six-month follow-up period $(\gamma=-0.026, z=-2.60, p<.01)$. Interestingly, those who scored higher on Equanimity reported greater decreases in positive affect over the sixmonth follow-up, although these gamma estimates are small.

Over the six-month follow-up, there was a significant interaction between condition and Agency $(\gamma=0.028, z=2.40, p=.02)$. Tests of simple slopes indicated that there was not a significant relation between Agency and positive affect for participants in the control conditions $(\gamma=-0.018, z=-1.69, p=.09)$ or for participants in the active conditions $(\gamma=0.010, z=1.33, p$

$=.2$ ). Although these simple slopes are not significantly different than zero, the interaction suggests that among participants in the active conditions, higher Agency is associated with 
greater positive affect, but for participants in the control conditions, higher Agency was associated with lower positive affect.

\section{Negative Affect.}

The model fit the data well, with CFI $=0.96, \mathrm{TLI}=0.92, \mathrm{RMSEA}=0.046(90 \%$ CI 0.041 -0.052 ), and $S R M R=0.038$. The predicted mean negative affect score at baseline in a model with no predictors was 2.24 , which is above the mean levels of negative affect reported by the general population (1.74; Watson et al., 1988). The regression estimates for this model are in Table 11. The three personality factors significantly predicted negative affect at baseline. As predicted, participants scoring higher on Equanimity reported lower levels of negative affect at baseline $(\gamma=-0.47, z=-19.75, p<.01)$. Higher scores on Insecurity $(\gamma=0.18, z=7.53, p<.01)$ and higher scores on Agency $(\gamma=0.053, z=3.28, p<.01)$ were related to higher levels of negative affect at baseline.

Between baseline and post-test, there was a significant interaction between condition and Insecurity $(\gamma=-0.11, z=-2.93, p<.01)$. Tests of simple slopes indicated that the relation between Insecurity and negative affect for participants in the control condition was not significant $(\gamma=0.032, z=0.76, p=.45)$. However, there was a significant relation between Insecurity and negative affect for participants in the active conditions $(\gamma=-0.075, z=-2.39, p=$ $.02)$, such that that higher scores on Insecurity were related to greater decreases in negative affect between baseline and post-test for participants completing active positive psychology exercises.

Equanimity predicted increases in negative affect from baseline to post-test $(\gamma=0.090, z$ $=3.10, p<.01)$. Similarly, Equanimity was related to increases in negative affect over the sixmonth follow-up period $(\gamma=0.024, z=2.80, p<.01)$. In comparison, Insecurity was related to decreases in negative affect over the six-month follow-up $(\gamma=-0.017, z=-2.04, p=.04)$. In 
addition, condition predicted the change in negative affect over the six-month follow-up period such that being in an active condition was related to decreases in negative affect over time $(\gamma=$ $0.018, z=-2.00, p=.045)$.

\section{Compassionate affect.}

The model fit the data well, with CFI $=0.98, \mathrm{TLI}=0.96, \mathrm{RMSEA}=0.035(90 \% \mathrm{CI} 0.030$ $-0.040)$ and $\mathrm{SRMR}=0.022$. The predicted mean compassionate affect score at baseline was 3.15 from a model with no predictors included. Although this is a new variable created for Project HOPE, this score appears to reflect moderate levels of compassionate affect compared to the mean scores for positive and negative affect. The regression estimates for this model can be seen in Table 12. The three personality factors significantly predicted compassionate affect at baseline. Higher scores on Equanimity $(\gamma=0.66, z=29.98, p<.01)$, Insecurity $(\gamma=0.13, z=$ 5.49, $p<.01)$, and Agency $(\gamma=0.040, z=2.73, p<.01)$ were related to higher levels of compassionate affect.

Between baseline and post-test, Equanimity was related to decreased levels of compassionate affect $(\gamma=-0.073, z=-2.43, p=.02)$. Similarly, Equanimity was related to decreases in compassionate affect over the six-month follow-up period $(\gamma=-0.034, z=-3.92, p<$ .01). Being in an active condition predicted increases in compassionate affect over the follow-up period $(\gamma=0.034, z=3.58, p<.01)$.

Over the six-month follow-up, there was a significantly interaction between condition and Agency $(\gamma=0.029, z=2.78 p<.01)$. Tests of simple slopes indicated that there was a significant relation between Agency and compassionate affect for participants in the control conditions $(\gamma=-0.018, z=-1.98, p=.048)$, such that higher scores on Agency were related to decreases in compassionate affect over time. The relation between Agency and condition for 
participants in the active conditions was not significantly different from zero, but the effect is in the opposite direction $(\gamma=0.010, z=1.56, p=0.12)$.

\section{Summary.}

The general results of Study 2 provide support for the effectiveness of positive psychology interventions in a large, Canadian sample. Compared to the control groups, the active conditions predicted decreases in depression and increases in positive affect between baseline and post-test. These decreases in depression and increases in positive affect continued between post-test and the six-month follow-up. Additionally, participants in the active exercise saw increases in compassionate affect between post-test and the six-month follow-up, as well as decreases in negative affect. These results provide strong support for the long-term gains obtained from participation in online positive psychology interventions.

As expected, the three personality factors moderated the changes in subjective well-being and depression over the course of the study. Equanimity was related to psychological health at baseline; it was related to initial reports of low depression, low negative affect, high satisfaction with life, high positive affect, and high compassionate affect. Surprisingly, Equanimity also predicted an increase in negative affect, and a decrease in compassionate and positive affect over time, although these gamma estimates are small.

At baseline, higher Insecurity was correlated with higher depression, lower satisfaction with life, more negative emotions, and fewer positive or compassionate emotions. In the latent growth curve models, higher Insecurity predicted higher depression, higher levels of negative affect, but also higher levels of compassionate affect and satisfaction with life at baseline. These gamma estimates were small compared to those for Equanimity, and must be considered within the context of the other personality factors included in the models. These surprising results may 
be due to the variance accounted for by other personality factors, or due to interactions between factors. Over time, Insecurity significantly interacted with condition (active versus control) to predict decrease negative affect at post-test. In addition, higher Insecurity was related to decreases in depression over the intervention period, and decreases in depression, decreases in negative affect, and increases in satisfaction with life over the six-month follow-up period.

At baseline, Agency was related to lower depression, higher satisfaction with life, fewer negative emotions, and more positive and compassionate emotions. Over the six-month followup, those higher on Agency reported the greatest benefits from the positive psychology exercises, with increases in positive and compassionate affect compared to those in the control conditions.

\section{Discussion}

Study 2 investigated how the three-factor model of personality found in Study 1 had a moderating role in determining well-being following positive psychology interventions. All three factors were correlated in theoretically expected ways with depression and subjective well-being at baseline. The personality factors also predicted changes in depression and subjective wellbeing over time, and moderated the efficacy of the positive psychology interventions. Insecurity predicted better immediate responses to the active interventions, supporting the usefulness of positive psychology interventions in those who are distressed (Parks et al., 2012; Sergeant \& Mongrain, 2015; Sin \& Lyubomirsky, 2009). Agency predicted long-term benefits in positive emotional functioning following positive psychology exercises.

Overall, this study supports the effectiveness of online positive psychology interventions. For the average participant, being in an active condition compared to a control condition predicted decreases in depression and increases in positive affect immediately following the intervention period. These benefits were long-lasting, continuing for six months after the 
intervention was complete. This finding is in keeping with previous research showing the efficacy of positive psychology exercises (Seligman et al., 2005; Senf \& Liau, 2013; Sin \& Lyubomirsky, 2009). In addition, being in an active condition predicted decreases in negative affect between post-test and the six-month follow-up. One finding of particular interest is that being in an active condition predicted an increase in compassionate affect between post-test and the six-month follow-up. There are few studies looking at how positive psychology interventions impact feelings of compassion. Being compassionate is related to decreases in depression and enhanced well-being (Musick \& Wilson, 2003; Thoits \& Hewitt, 2001). This finding suggests a potentially lasting and beneficial imprint of positive psychology interventions.

The correlational results, and the latent growth curve models, showed that Equanimity was the personality factor most strongly related to optimal psychological functioning at baseline. This result was expected given that this factor is comprised of variables relating to wellness and stability. For example, low neuroticism, extraversion, agreeableness, and conscientiousness have been shown to predict both higher positive affect and lower negative affect (Costa \& McCrae, 1980; DeNeve \& Cooper, 1998; Gross et al., 1998; Halama, 2005; Işık, \& Üzbe, 2015; McCrae \& Costa, 1991). Similarly, gratitude has been shown to predict higher positive affect and life satisfaction (Emmons \& McCullough, 2003), self-compassion has been related to higher positive affect and lower negative affect (Neff et al., 2007), and self-esteem is related to higher satisfaction with life, positive affect, and lower negative affect (Schimmack \& Diener, 2003). Secure attachment, also loading on the Equanimity factor, is associated with more positive emotions and fewer negative emotions in intimate relationships (Simpson, 1990). Low selfcriticism on this factor relates to fewer depressive symptoms and higher subjective well-being (Blatt et al., 1976; Zuroff, Mongrain, \& Santor, 2004). Altogether, individuals high on 
Equanimity experience self-compassion, a positive sense of self, and harmonious relationships. As such, they may represent the "actualized" individual.

So why did participants high on Equanimity not profit from the positive psychology interventions? In fact, those scoring higher on Equanimity reported increases in negative emotion and decreases in compassionate affect at post-test and at the six-month follow-up, as well as decreases in compassionate affect at the six-month follow-up. It should be noted that these effect sizes were small (regression coefficients ranging from $|0.024|$ to $|0.09|$ ). Furthermore, these results should be in interpreted in the context of the positive relation between Equanimity and high psychological functioning at baseline, implying that these findings may represent regression to the mean. Alternatively, those high on Equanimity may have been disappointed to find they had little to gain from the exercises offered. In any regard, it appears reasonable to conclude that positive psychology exercises may have little to offer for those who are high on this factor.

The Insecurity factor was correlated with higher depression, lower satisfaction with life, more negative affect, and lower compassionate and positive affect at baseline. In support of the hypotheses, Insecurity predicted improvement in depressive symptoms during the intervention period. This factor also predicted improvements in depression, satisfaction with life, and negative affect over the six-month follow-up period. Insecurity was also shown to moderate the effectiveness of positive psychology interventions. For participants in the active conditions, Insecurity was related to decreased negative affect at post-test compared to the control group. The variables loading on this factor are neediness, anxious attachment, and neuroticism, which have all been empirically associated with distress (Cheng \& Furnham, 2003; Jinyao, et al., 2012; McBride, Zuroff, Bacchiochi, \& Bagby, 2006). Individuals high on Insecurity are highly dependent on others and constantly vigilant against the threat of an interpersonal loss. The 
positive psychology exercises may have helped insecure participants self-soothe through the provision of various tools, such as learning to reinterpret negative events, give themselves positive advice from the future, or learning to be self-compassionate. Overall, the short-term and long-term improvements are well-supported for highly Insecure participants.

Agency, the third factor in the personality model, was correlated with higher levels of depression, negative affect, and compassionate affect at baseline. Agency also moderated the benefits of online positive psychology interventions. This factor also predicted increases in positive and compassionate affect longitudinally over the six-month follow-up for participants in the active conditions compared to the control groups. Agency consists of efficacy, self-criticism, openness to experience, and gratitude. These variables have shown a range of relations with subjective well-being and depression in previous research. Self-criticism is related to increases in depression (Blatt et al., 1976; Zuroff et al., 2004), while gratitude has been linked to increases in positive affect and decreases in negative affect (Emmons \& McCullough, 2003; McCullough et al., 2002). Openness to experience has been related to increases in both positive and negative affect (McCrae \& Costa, 1991). Efficacy, and the overall sense of goal-striving seen in this factor, may be the key to understanding why Agency predicted increases in positive emotional functioning over time. Goal-striving predicts increased subjective well-being, although this effect is moderated by goal-striving reasons and goal content (Ehrlich, 2012; Ehrlich \& Bipp, 2016). Sheldon (2001) found that subjective well-being was associated with pursuing and achieving goals; similarly, Sheldon (2009) suggests that need-satisfaction may be the ultimate arbiter for predicting subjective well-being. This may explain the effects of Agency obtained in Study 2. For a person high on Agency, perhaps a longer intervention period is necessary to satisfy their needs and lead to gains in positive and compassionate affect. 
A limitation of Study 2 is that there was a large attrition rate, compromising the generalizability of the findings. Completers were more likely to be female, older, less depressed, and happier at baseline compared to non-completers. Similarly, the sample was on average mildly depressed at baseline and the results may not generalize to non-depressed populations.

\section{General Discussion}

The purpose of this research was to identify the best general factor structure for personality and to investigate the relation between this personality model and positive psychology interventions. In the first study, a three-factor model of personality was identified from a comprehensive set of personality measures. This model was consistent with previous theories of personality; each of the three factors has analogs in prior models of personality. In the second study, this model was used as a framework for understanding individual differences in the response to positive psychology interventions. The three factors were each related to measures of depression and subjective well-being, and interacted with positive psychology exercises to predict outcomes.

This three-factor model, consisting of Equanimity, Agency, and Insecurity, captures the essential features of individual differences in personality functioning. This model and each factor has precedent in the empirical literature. Furthermore, the three factors were significantly related to depression and subjective well-being in theoretically-expected ways. Equanimity represents internal and interpersonal harmony, which is a sense of self-compassion and secure attachments with others. Equanimity is similar to factors found in prior models, such as Digman's (1997) Alpha, Wiggins' (1991) Communion, and the reverse of Eysenck's psychoticism factor. Unsurprisingly, Equanimity is related to low levels of depression and high levels of subjective well-being. Individuals high on Equanimity have little to gain from positive psychology 
interventions because they are already functioning at near optimal levels. In fact, positive psychology interventions may have been slightly detrimental for individuals high on Equanimity, who may already be engaging in their own, preferred positive activities.

Agency represents self-efficacy and goal-striving, with a curious and open nature. Agency is similar to Digman's (1997) Beta, Cloninger's (1987) Novelty Seeking, and Gray’s (1982) Behavioral Approach system. Agency is also similar to Wiggins' (1991) construct of the same name. Agency is correlated with high subjective well-being and low depression. Individuals high on Agency benefitted from positive psychology interventions over time, reporting increases in positive and compassionate affect. These benefits were likely due to the relation between goal-striving and well-being.

The Insecurity factor represents interpersonal anxiety and threat-detection. Insecurity recalls Eysenck's neuroticism and Cloninger's (1987) Harm Avoidance. Insecurity correlated with high levels of distress, as reflected in reported high levels of depressive symptoms and low levels of subjective well-being. Individuals high on Insecurity had the most to gain, and significant decreases in depression and negative affect were reported after only one week of practicing positive psychology exercises. These decreases continued over the six-month followup period, joined by increases in satisfaction with life.

Overall, this model can be seen as a comprehensive framework of personality functioning, combining stable, trait-based individual differences and components that fluctuate over time. The factors of the Big Five are commonly seen as stable across the life span (Costa \& McCrae, 1986; Goldberg, 1990). In comparison, character strengths such as gratitude and selfcompassion have been theorized to increase with intentional practice (Peterson \& Seligman, 2004). Similarly, dependency and self-criticism have been shown to change in the face of 
environmental stressors such as interpersonal conflict (Franche \& Dobson, 1992; Zuroff, Moskowitz, Wielgus, Powers, \& Franko, 1983). Attachment styles were originally conceptualized as being stable across the lifespan (Bowlby, 1988), but more recent data has suggested that some attachment styles are subject to fluctuation (Cozzarelli, Karafa, Collins, \& Tagler, 2003; Davila, Burge, \& Hammen, 1997).

The three-factor model found in this study can be conceptualized from a developmental perspective, similar to Blatt's theory of personality development (Blatt et al., 1976). Arising from the early developmental period, Insecurity may represent a failure to meet the need for secure relationships, while Agency represents the need for a secure self-identity. Equanimity may represent a state of need-satisfaction or successful development. Based on developmental experiences, an individual may have a tendency towards a predominance of one factor over another, but can oscillate in levels of all three factors based on how their needs are met. For example, positive psychology interventions may have met a goal-achievement need for participants high on Agency, resulting in improved well-being. Similarly, individuals high on Insecurity may have had their need for self-soothing met by the exercises. It would be interesting to determine whether one's reported level of the three factors fluctuated following these interventions. In future research, measuring Equanimity, Insecurity, and Agency before and following positive interventions would identify whether these proposed shifts take place.

The findings of these studies also have practical consequences for the study of positive psychology interventions. First, these results support the general efficacy of online positive psychology interventions. Being in an active condition predicted decreases in depression and increases in positive affect both immediately following the exercises and over time. In addition, being in an active condition predicted increases in compassionate affect and decreases in negative affect over time. This finding for compassionate affect is new, and supports the ability 
of positive psychology interventions to influence character strengths in addition to well-being. Depression has a lifetime prevalence in Canada of over 12\% (Patten et al., 2006). Short-term online interventions that can lead to reduced depression offer convenient and efficient self-help for those in distress, particularly those who live in rural areas, far from other mental healthcare options. Furthermore, this three-factor model of personality provides a guide for understanding the role of individual differences in positive psychology interventions.

There are several limitations to these studies. The results may not be wholly generalizable outside of the sample used. This sample is entirely Canadian, moderately depressed at baseline, and self-selected. Additionally, there was a high rate of attrition over time and participants who completed questionnaires at every time point were more likely to be female, older, less depressed, and happier at baseline. Future research should replicate these results in nondepressed samples to confirm generalizability of results. It is also important to replicate this factor structure across other cultures. Studies have shown that culture is an important determinant of well-being (Sheldon \& Hoon, 2007).

The measures included for the factor analysis also had an impact on the resulting model of personality. While these measures were chosen carefully and with consideration of the research on personality and positive psychology, some facets of personality (e.g., hedonism, honesty, impulsivity, constraint) were not explicitly included in these analyses. Furthermore, these conclusions are limited by the specific operationalization of well-being. This study looked solely at subjective well-being. Future studies should include measures of psychological wellbeing to fully capture the impact of these personality factors on well-being. In future studies, more specific interactions between these three factors and types of positive psychology interventions will further understanding of how personality interacts with exercises. Individuals high on Insecurity may do better with specifically self-soothing exercises while individuals high 
on Agency may benefit more from goal-attainment exercises. Also of interest is how interactions between personality factors influences the results. These interactions may have affected how personality factors predicted baseline values of outcome variables in the models, or moderated how participants benefitted over time. For example, a participant who is high on Insecurity and low in Agency may have very different outcomes when compared to a participant who is high on both Insecurity and Agency.

\section{Summary and Concluding Statements}

In conclusion, the three-factor model of personality obtained in this research has significant support, both analytically and theoretically, and is coherent with previous models of personality. It is grounded in the "grand theories", while offering a fresh understanding of the structure of personality. The three-factor model also proved relevant in the study of online positive psychology exercises. Overall, the results from both studies support the overall efficacy of online positive psychology interventions and the utility of these three factors in predicting outcomes following positive psychology interventions. 


\section{References}

Aluja, A., García, Ó., \& García, L. F. (2002). A comparative study of Zuckerman's three structural models for personality through the NEO-PI-R, ZKPQ-III-R, EPQ-RS and Goldberg's 50-bipolar adjectives. Personality and Individual Differences, 33, 713-726.

Aluja, A., Rolland, J., García, L. F., \& Rossier, J. (2007). Dimensionality of the Rosenberg selfesteem scale and its relationships with the three- and the five-factor personality models. Journal of Personality Assessment, 88, 246-249.

Armstrong, B.F., Zuroff, D. C., Mongrain, M., Kelly, A.C., Hermanto, N., Hope, N., \& Koestner, R. (in press). Self-compassion revisited: Examining the dimensionality of the SelfCompassion Scale in community and college samples. Submitted to PLOS ONE.

Ashton, M. C., \& Lee, K. (2007). Empirical, theoretical, and practical advantages of the HEXACO model of personality structure. Personality and Social Psychology Review, 11, $150-166$.

Aziz, S., \& Jackson, C. J. (2001). A comparison between three and five factor models of Pakistani personality data. Personality and Individual Differences, 31, 1311-1319.

Bakan, D. (1966). The duality of human existence: Isolation and communion in Western man. Boston: Beacon.

Blackburn, R., Renwick, S. J. D., Donnelly, J. P., \& Logan, C. (2004). Big Five or Big Two? Superordinate factors in the NEO five factor inventory and the antisocial personality questionnaire. Personality and Individual Differences, 37, 957-970. 
Blaney, P., \& Kutcher, G. (1991). Measures of depressive dimensions: Are they interchangeable? Journal of Personality Assessment, 56, 502-512.

Blatt, S. J., D’Afflitti, J. P., \& Quinlan, D. M. (1976). Experiences of depression in normal young adults. Journal of Abnormal Psychology, 85, 383-389.

Blatt, S. J., Schaffer, C. E., Bers, S. A., \& Quinlan, D. M. (1992). Psychometric properties of the Depressive Experiences Questionnaire for adolescents. Journal of Personality Assessment, 59, 82-98.

Blatt, S. J., Zohar, A. H., Quinlan, D. M., Zuroff, D. C., \& Mongrain, M. (1995). Subscales within the dependency factor of the Depressive Experiences Questionnaire. Journal of Personality Assessment, 64, 319-339.

Blatt, S. J., \& Zuroff, D. C. (1992). Interpersonal relatedness and self-definition: Two prototypes for depression. Clinical Psychology Review, 12, 527-562.

Block, J. (1995). Going beyond the five factors given: Rejoinder to Costa and McCrae (1995) and Goldberg and Saucier (1995). Psychological Bulletin, 117, 226-229.

Block, J. (2010). The five-factor framing of personality and beyond: Some ruminations. Psychological Inquiry, 21, 2-25.

Borkenau, P., \& Ostendorf, F. (1990). Comparing exploratory and confirmatory factor analysis: A study on the 5-factor model of personality. Personality and Individual Differences, 11, 515-524.

Bowlby, J. (1988). A secure base: Parent-child attachment and healthy human development. Basic Books, New York, NY. 
Brennan, K. A., Clark, C. L., \& Shaver, P. R. (1998). Self-report measurement of adult attachment: An integrative overview. Attachment theory and close relationships. (pp. 4676) Guilford Press, New York, NY.

Buchanan, K. E. \& Bardi, A. (2010). Acts of kindness and acts of novelty affect life satisfaction. The Journal of Social Psychology, 150, 235-237.

Carlo, G., Knight, G. P., Roesch, S. C., Opal, D., \& Davis, A. (2014). Personality across cultures: A critical analysis of Big Five research and current directions. American Psychological Association, Washington, DC.

Carmines, E.G., \& Zeller, R.A. (1979). Reliability and validity assessment. Beverly Hills, CA: Sage Publications.

Carver, C. S., \& White, T. L. (1994). Behavioral inhibition, behavioral activation, and affective responses to impending reward and punishment: The BIS/BAS Scales. Journal of Personality and Social Psychology, 67, 319-333.

Cheng, H., \& Furnham, A. (2003). Personality, self-esteem, and demographic predictions of happiness and depression. Personality and Individual Differences, 34, 921-942.

Cloninger, C. R. (1987). A systematic method for clinical description and classification of personality variants: A proposal. Archives of General Psychiatry, 44, 573-588.

Cloninger, C. R., Przybeck, T. R., \& Švrakić, D. M. (1991). The tridimensional personality questionnaire: U.S. normative data. Psychological Reports, 69, 1047-1057.

Cloninger, C. R., Švrakić, D. M., \& Przybeck, T. R. (1993). A psychobiological model of temperament and character. Archives of General Psychiatry, 50, 975-990. 
Costa, P. T., \& McCrae, R. R. (1980). Influence of extraversion and neuroticism on subjective well-being: Happy and unhappy people. Journal of Personality and Social Psychology, 38, 668-678.

Costa, P. T., \& McCrae, R. R. (1992). Four ways five factors are basic. Personality and Individual Differences, 13, 653-665.

Cozzarelli, C., Karafa, J. A., Collins, N. L., \& Tagler, M. J. (2003). Stability and change in adult attachment styles: Associations with personal vulnerabilities, life events, and global construals of self and others. Journal of Social and Clinical Psychology, 22, 315-346.

Cudeck, R., \& Browne, M. W. (1992). Constructing a covariance matrix that yields a specified minimizer and a specified minimum discrepancy function value. Psychometrika, 57, 357369.

Dandurand, F., Shultz, T. R., \& Onishi, K. H. (2008). Comparing online and lab methods in a problem-solving experiment. Behavior Research Methods, 40, 428-434.

Damji, T., Clément, R., \& Noels, K. A. (1996). Acculturation mode, identity variation, and psychosocial adjustment. The Journal of Social Psychology, 136, 493-500.

Davila, J., Burge, D., \& Hammen, C. (1997). Why does attachment style change? Journal of Personality and Social Psychology, 73, 826-838.

De Raad, B. (1998). Five big, big five issues: Rationale, content, structure, status, and cross cultural assessment. European Psychologist, 3, 113-124.

Deci, E.L., \& Ryan, R.M. (2000). The "what" and "why" of goal pursuits: Human needs and the self-determination of behavior. Psychological Inquiry, 11, 227-268. 
Deci, E. L., \& Ryan, R. M. (2008). Hedonia, eudaimonia, and well-being: An introduction. Journal of Happiness Studies, 9, 1-11.

Depue, R. A., \& Lenzenweger, M. F. (2005). A neurobehavioral dimensional model of personality disturbance. In M. F. Lenzenweger, \& J. F. Clarkin (Eds.), 2nd ed.; major theories of personality disorder (2nd ed.) (2nd ed. ed., pp. 391-453, Chapter xiii, 464 Pages). Guilford Press, New York, NY.

DeNeve, K. M., \& Cooper, H. (1998). The happy personality: A meta-analysis of 137 personality traits and subjective well-being. Psychological Bulletin, 124, 197-229.

Denissen, J. J. A., Geenen, R., van Aken, Marcel A. G., Gosling, S. D., \& Potter, J. (2008). Development and validation of a Dutch translation of the Big Five Inventory (BFI). Journal of Personality Assessment, 90, 152-157.

DeYoung, C. G. (2006). Higher-order factors of the big five in a multi-informant sample. Journal of Personality and Social Psychology, 91, 1138-1151.

DeYoung, C. G., Quilty, L. C., \& Peterson, J. B. (2007). Between facets and domains: 10 aspects of the Big Five. Journal of Personality and Social Psychology, 93, 880-896.

DeYoung, C. G., Peterson, J. B., \& Higgins, D. M. (2002). Higher-order factors of the Big Five predict conformity: Are there neuroses of health? Personality and Individual Differences, 33, 533-552.

Dickerhoof, R. M. (2007). Expressing optimism and gratitude: A longitudinal investigation of cognitive strategies to increase well-being. Dissertation Abstracts International: Section B: The Sciences and Engineering, 68, 4174-4174. 
Diener, E., Emmons, R. A., Larsen, R. J., \& Griffin, S. (1985). The Satisfaction with Life Scale. Journal of Personality Assessment, 49, 71-75.

Diener, E., \& Lucas, R. E. (1999). Personality and subjective well-being. Well-being: The foundations of hedonic psychology. (pp. 213-229) Russell Sage Foundation, New York, NY.

Digman, J. M. (1997). Higher-order factors of the big five. Journal of Personality and Social Psychology, 73, 1246-1256.

Draycott, S. G., \& Kline, P. (1995). The Big Three or the Big Five- the EPQ-R vs the NEO-PI: a research note, replication and elaboration. Personality and Individual Differences, 18, 801-804.

Eaves, L. J., Eysenck, H. J., \& Martin, N. G. (1989). Genes, culture and personality: An empirical approach. Academic Press, San Diego, CA.

Ehrlich, C. (2012). Be careful what you wish for but also why you wish for it - Goal-striving reasons and subjective well-being. The Journal of Positive Psychology,7, 493-503.

Ehrlich, C., \& Bipp, T. (2016). Goals and subjective well-being: Further evidence for goalstriving reasons as an additional level of goal analysis. Personality and Individual Differences, 89, 92-99.

Emmons, R. A. (2004). The psychology of gratitude: An introduction. Oxford University Press, New York, NY. 
Emmons, R. A., \& McCullough, M. E. (2003). Counting blessings versus burdens: An experimental investigation of gratitude and subjective well-being in daily life. Journal of Personality and Social Psychology, 84, 377-389.

Eysenck, H. J. (1967). The biological basis of personality. Springfield, IL: Charles C. Thomas.

Eysenck, H. J. (1990). Biological dimensions of personality. In L. A. Pervin (Ed.), Handbook of personality: Theory and research (pp. 244-276). New York: Guilford.

Eysenck, H.J. \& Eysenck, S.B.G. (1991). Eysenck Personality Scales (EPS Adult). Hodder \& Stoughton, London.

Eysenck, S. B., Eysenck, H. J., \& Barrett, P. (1985). A revised version of the psychoticism scale. Personality and Individual Differences, 6, 21-29.

Fang, J., \& Yao, S. (2008). Reliability and validity of Chinese version of the depressive experiences questionnaire: A comparison of two scoring systems. Chinese Mental Health Journal, 22, 184-188.

Ferguson, E., \& Patterson, F. (1998). The five factor model of personality: Openness a distinct but related construct. Personality and Individual Differences, 24, 789-796.

Fox, J., \& Weisberg, S. (2011). An $\{R\}$ Companion to Applied Regression, Second Edition. Thousand Oaks CA: Sage. URL: http://socserv.socsci.mcmaster.ca/jfox/Books/Companion

Fraley, R. C., Waller, N. G., \& Brennan, K. A. (2000). An item response theory analysis of selfreport measures of adult attachment. Journal of Personality and Social Psychology, 78, $350-365$. 
Franche, R., \& Dobson, K. S. (1992). Self-criticism and interpersonal dependency as vulnerability factors to depression. Cognitive Therapy and Research, 16, 419-435.

Furnham, A., \& Christoforou, I. (2007). Personality traits, emotional intelligence and multiple happiness. North American Journal of Psychology, 9, 439-462.

Gilbert, P. (2009). The nature and basis for compassion focused therapy. Hellenic Journal of Psychology, 6, 273-291.

Gilbert, P. (2015). An evolutionary approach to emotion in mental health with a focus on affiliative emotions. Emotion Review, 7, 230-237.

Gilbert, P., McEwan, K., Mitra, R., Franks, L., Richter, A., \& Rockliff, H. (2008). Feeling safe and content: A specific affect regulation system? Relationship to depression, anxiety, stress, and self-criticism. The Journal of Positive Psychology, 3, 182-191.

Gill, C. M., \& Hodgkinson, G. P. (2007). Development and validation of the Five-Factor Model Questionnaire (FFMQ): An adjectival-based personality inventory for use in occupational settings. Personnel Psychology, 60, 731-766.

Goldberg, L. R. (1990). An alternative "description of personality": The big-five factor structure. Journal of Personality and Social Psychology, 59, 1216-1229.

Gray, J. A. (1982). The neuropsychology of anxiety: An enquiry into the functions of the septohippocampal system. Clarendon Press/Oxford University Press, New York, NY.

Gross, J. J., Sutton, S. K., \& Ketelaar, T. (1998). Relations between affect and personality: Support for the affect-level and affective reactivity views. Personality and Social Psychology Bulletin, 24, 279-288. 
Halama, P. (2005). Relationship between meaning in life and the Big Five personality traits in young adults and the elderly. Studia Psychologica, 47, 167-178.

Heath, A. C., Cloninger, C. R., \& Martin, N. G. (1994). Testing a model for the genetic structure of personality: A comparison of the personality systems of Cloninger and Eysenck. Journal of Personality and Social Psychology, 66, 762-775.

Hewitt, J. P. (2009). The social construction of self-esteem. Oxford handbook of positive psychology (2nd ed.). (pp. 217-224) Oxford University Press, New York, NY.

Hirsh, J. B., \& Peterson, J. B. (2008). Predicting creativity and academic success with a "fakeproof" measure of the Big Five. Journal of Research in Personality, 42, 1323-1333.

Hopwood, C. J., Donnellan, M. B., Blonigen, D. M., Krueger, R. F., McGue, M., Iacono, W. G., \& Burt, S. A. (2011). Genetic and environmental influences on personality trait stability and growth during the transition to adulthood: A three-wave longitudinal study. Journal of Personality and Social Psychology, 100, 545-556.

Houston, T.K., Cooper, L.A., Vu, H.T., Kahn, J., Toser, J., \& Ford, D.E. (2001). Screening the public for depression through the internet. Psychiatric Services, 52(3), 362-367.

Hu, L., \& Bentler, P. M. (1998). Fit indices in covariance structure modeling: Sensitivity to underparameterized model misspecification. Psychological Methods, 3, 424-453.

Hu, L., \& Bentler, P. M. (1999). Cutoff criteria for fit indexes in covariance structure analysis: Conventional criteria versus new alternatives. Structural Equation Modeling, 6, 1-55.

Işık, Ş., \& Üzbe, N. (2015). Personality traits and positive/negative affects: An analysis of meaning in life among adults. Kuram Ve Uygulamada Eğitim Bilimleri, 15, 587-595. 
Ispas, D., Iliescu, D., Ilie, A., \& Johnson, R. E. (2014). Exploring the cross-cultural generalizability of the five-factor model of personality: The Romanian NEO PI-R. Journal of Cross-Cultural Psychology, 45, 1074-1088.

Jinyao, Y., Xiongzhao, Z., Auerbach, R. P., Gardiner, C. K., Lin, C., Yuping, W., \& Shuqiao, Y. (2012). Insecure attachment as a predictor of depressive and anxious symptomology. Depression and Anxiety, 29, 789-796.

John, O. P. (1990). The "big five" factor taxonomy: Dimensions of personality in the natural language and in questionnaires. Handbook of personality: Theory and research. (pp. 66100) Guilford Press, New York, NY.

John, O. P., Angleitner, A., \& Ostendorf, F. (1988). The lexical approach to personality: A historical review of trait taxonomic research. European Journal of Personality, 2, 171203.

John, O. P., Donahue, E. M., \& Kentle, R. L. (1991). The Big Five Inventory--Versions 4a and 54. Berkeley, CA: University of California, Berkeley, Institute of Personality and Social Research.

John, O. P., \& Naumann, L. P. (2010). Surviving two critiques by Block? The resilient Big Five have emerged as the paradigm for personality trait psychology. Psychological Inquiry, 21, 44-49.

John, O. P., \& Srivastava, S. (1999). The big five trait taxonomy: History, measurement, and theoretical perspectives. Handbook of personality: Theory and research ( $2 \mathrm{nd} \mathrm{ed}$.$) . (pp.$ 102-138) Guilford Press, New York, NY. 
Joseph, S., \& Wood, A. (2010). Assessment of positive functioning in clinical psychology: Theoretical and practical issues. Clinical Psychology Review, 30, 830-838.

Joshanloo, M. (2015). Revisiting the empirical distinction between hedonic and eudaimonic aspects of well-being using exploratory structural equation modeling. Journal of Happiness Studies, doi:http://dx.doi.org/10.1007/s10902-015-9683-z

Keyes, C. L. M. (2005). Mental illness and/or mental health? Investigating axioms of the complete state model of health. Journal of Consulting and Clinical Psychology, 73, 539548.

Keyes, C. L. M. (Ed.). (2013). Mental well-being: International contributions to the study of positive mental health. Dordrecht: Springer.

Kim, S. J., Lee, S. J., Yune, S. K., Sung, Y. H., Bae, S. C., Chung, A., . . Lyoo, I. K. (2006). The relationship between the biogenetic temperament and character and psychopathology in adolescents. Psychopathology, 39, 80-86.

Kokkinos, C. M., Panayiotou, G., Charalambous, K., Antoniadou, N., \& Davazoglou, A. (2010). Greek EPQ-J: Further support for a three-factor model of personality in children and adolescents. Journal of Psychoeducational Assessment, 28, 259-269.

Korp, P. (2006). Health on the internet: Implications for health promotion. Health Education Research, 21, 78-86.

Krieger, T., Hermann, H., Zimmermann, J., \& grosse Holtforth, M. (2015). Associations of selfcompassion and global self-esteem with positive and negative affect and stress reactivity in daily life: Findings from a smart phone study. Personality and Individual Differences, 87, 288-292. 
Lamb, M. E., Chuang, S. S., Wessels, H., Broberg, A. G., \& Hwang, C. P. (2002). Emergence and construct validation of the big five factors in early childhood: A longitudinal analysis of their ontogeny in Sweden. Child Development, 73, 1517-1524.

Lopez, F. G., \& Gormley, B. (2002). Stability and change in adult attachment style over the firstyear college transition: Relations to self-confidence, coping, and distress patterns. Journal of Counseling Psychology, 49, 355-364.

Lucas, R. E., Diener, E., \& Suh, E. (1996). Discriminant validity of well-being measures. Journal of Personality and Social Psychology, 71, 616-628.

Lyubomirsky, S., Dickerhoof, R., Boehm, J. K., \& Sheldon, K. M. (2011). Becoming happier takes both a will and a proper way: An experimental longitudinal intervention to boost well-being. Emotion, 11, 391-402.

Lyubomirsky, S., \& Layous, K. (2013). How do simple positive activities increase wellbeing? Current Directions in Psychological Science, 22, 57-62.

Lyubomirsky, S., Sheldon, K. M., \& Schkade, D. (2005). Pursuing happiness: The architecture of sustainable change. Review of General Psychology, 9, 111-131.

Mardaga, S., \& Hansenne, M. (2007). Relationships between Cloninger's biosocial model of personality and the behavioral inhibition/approach systems (BIS/BAS). Personality and Individual Differences, 42, 715-722.

McAdams, D. P., \& Pals, J. L. (2006). A new big five: Fundamental principles for an integrative science of personality. American Psychologist, 61, 204-217. 
McAdams, D. P., \& Walden, K. (2010). Jack Block, the Big Five, and personality from the standpoints of actor, agent, and author. Psychological Inquiry, 21, 50-56.

McBride, C., Zuroff, D. C., Bacchiochi, J., \& Bagby, R. M. (2006). Depressive Experiences Questionnaire: Does it measure maladaptive and adaptive forms of dependency? Social Behavior and Personality, 34, 1-16.

McCrae, R. R., \& Costa, P. T. (1986). Clinical assessment can benefit from recent advances in personality psychology. American Psychologist, 41, 1001-1003.

McCrae, R. R., \& Costa, P. T. (1987). Validation of the five-factor model of personality across instruments and observers. Journal of Personality and Social Psychology, 52, 81-90.

McCrae, R. R., \& Costa, P. T. (1991). Adding liebe und arbeit: The full five-factor model and well-being. Personality and Social Psychology Bulletin, 17, 227-232.

McCrae, R. R., \& John, O. P. (1992). An introduction to the five-factor model and its applications. Journal of Personality, 60, 175-215.

McCullough, M. E., Emmons, R. A., \& Tsang, J. (2002). The grateful disposition: A conceptual and empirical topography. Journal of Personality and Social Psychology, 82, 112-127.

McKenzie, J. (1998). Fundamental flaws in the five factor model: A re-analysis of the seminal correlation matrix from which the "openness-to-experience" factor was extracted. Personality and Individual Differences, 24, 475-480.

Mikulincer, M., \& Shaver, P. R. (2007). Boosting attachment security to promote mental health, prosocial values, and inter-group tolerance. Psychological Inquiry, 18, 139-156. 
Mitchell, J., Stanimirovic, R., Klein, B., \& Vella-Brodrick, D. (2009). A randomised controlled trial of a self-guided internet intervention promoting well-being. Computers in Human Behavior, 25, 749-760.

Mitchell, J., Vella-Brodrick, D., \& Klein, B. (2010). Positive psychology and the internet: A mental health opportunity. Electronic Journal of Applied Psychology, 6, 30-41.

Mongrain, M. (2007). Project Hope Canada: Harnessing One’s Potential for Excellence. Retrieved from http://www.projecthopecanada.com

Mongrain, M., \& Anselmo-Matthews, T. (2012). Do positive psychology exercises work? A replication of Seligman et al. (2005). Journal of Clinical Psychology, 68, 382-38.

Mongrain, M., Barnes, C., Barnhart, R. \& Zalan, L. (in press). Lessons from the Grinch: Practicing kindness alleviates depression in disagreeable individuals. Journal of Personality and Social Psychology.

Mongrain, M., Chin, J. M., \& Shapira, L. B. (2011). Practicing compassion increases happiness and self-esteem. Journal of Happiness Studies, 12, 963-981.

Mongrain, M., \& Zuroff, D. C. (1995). Motivational and affective correlates of dependency and self-criticism. Personality and Individual Differences, 18, 347-354.

Morizot, J. (2014). Construct validity of adolescents' self-reported big five personality traits: Importance of conceptual breadth and initial validation of a short measure. Assessment, 21, 580-606. 
Muris, P., \& Petrocchi, N. (2016). Protection or vulnerability? A meta-analysis of the relations between the positive and negative components of self-compassion and psychopathology. Clinical Psychology \& Psychotherapy, doi:http://dx.doi.org/10.1002/cpp.2005

Musick, M. A. \& Wilson, J. (2003). Volunteering and depression: The role of psychological and social resources in different age groups. Social Science \& Medicine, 56, 259-269.

Neff, K. D. (2003). The development and validation of a scale to measure self-compassion. Self and Identity, 2, 223-250.

Neff, K. D. (2016). The Self-Compassion Scale is a valid and theoretically coherent measure of self-compassion. Mindfulness, 7, 264-274.

Neff, K. D., \& Pommier, E. (2013). The relationship between self-compassion and other-focused concern among college undergraduates, community adults, and practicing meditators. Self and Identity, 12, 160-176.

Neff, K. D., Rude, S. S., \& Kirkpatrick, K. L. (2007). An examination of self-compassion in relation to positive psychological functioning and personality traits. Journal of Research in Personality, 41, 908-916.

$\mathrm{Ng}, \mathrm{W}$. (2012). Neuroticism and well-being? Let's work on the positive rather than negative aspects. The Journal of Positive Psychology, 7, 416-426.

$\mathrm{Ng}$, W. (2015). Boosting well-being with positive psychology interventions: Moderating role of personality and other factors. Journal of Contemporary Psychotherapy, 45, 79-87. 
Olivier, M., \& Herve, M. (2015). The big five questionnaire for children (BFQ-C): A French validation on 8- to 14-year-old children. Personality and Individual Differences, 87, 5558.

Parks, A. C. (2014). A case for the advancement of the design and study of online positive psychological interventions. The Journal of Positive Psychology, 9, 502-508.

Parks, A. C., Della Porta, M. D., Pierce, R. S., Zilca, R., \& Lyubomirsky, S. (2012). Pursuing happiness in everyday life: The characteristics and behaviors of online happiness seekers. Emotion, 12, 1222-1234.

Patten, S. B., Wang, J. L., Williams, J. V. A., Currie, S., Beck, C. A., Maxwell, C. J., \& elGuebaly, N. (2006). Descriptive epidemiology of major depression in Canada. The Canadian Journal of Psychiatry, 51, 84-90

Pavot, W., \& Diener, E. (1993). Review of the Satisfaction with Life Scale. Psychological Assessment, 5, 164-172.

Pavot, W., \& Diener, E. (2008). The Satisfaction with Life Scale and the emerging construct of life satisfaction. Journal of Positive Psychology, 3, 137-152

Peterson, C., \& Seligman, M. E. P. (2004). Character strengths and virtues: A handbook and classification. American Psychological Association Oxford University Press, Washington New York, DC NY.

Preacher, K. J., Zhang, G., Kim, C., \& Mels, G. (2013). Choosing the optimal number of factors in exploratory factor analysis: A model selection perspective. Multivariate Behavioral Research, 48, 28-56. 
R Core Team (2015). R: A language and environment for statistical computing. R Foundation for Statistical Computing, Vienna, Austria. URL https://www.R-project.org/.

Radloff, L. (1977). The CES-D Scale: A self-report depression scale for research in the general population. Applied Psychological Measurement, 1, 385-401.

Revelle, W. (2015) psych: Procedures for Personality and Psychological Research, Northwestern University, Evanston, Illinois, USA, http://CRAN.Rproject.org/package $=$ psych Version $=1.5 .8$.

Ritterband, L. M., Gonder-Frederick, L. A., Cox, D. J., Clifton, A. D., West, R. W., \& Borowitz, S. M. (2003). Internet interventions: In review, in use, and into the future. Professional Psychology: Research and Practice, 34, 527-534.

Roberts, B. W., Kuncel, N. R., Shiner, R., Caspi, A., \& Goldberg, L. R. (2007). The power of personality: The comparative validity of personality traits, socioeconomic status, and cognitive ability for predicting important life outcomes. Perspectives on Psychological Science, 2, 313-345.

Rosenberg, M. (1965). Society and the adolescent self-image. Princeton, NJ: Princeton University Press.

Rosseel, Y. (2012). lavaan: An R Package for Structural Equation Modeling. Journal of Statistical Software, 48, 1-36. URL http://www.jstatsoft.org/v48/i02/.

Rude, S.S. \& Burnham, B.L. (1995). Connectedness and neediness: Factors of the DEQ and SAS dependency scales. Cognitive Therapy and Research, 19, 323-340. 
Ryan, R.M., \& Deci, E.L. (2001). On happiness and human potentials: A review of research on hedonic and eudaimonic well-being. Annual Review of Psychology, 52, 141-166.

Sandin, B., Valiente, R. M., Olmedo, M., Chorot, P., \& Santed, M. A. (2002). Versión española del cuestionario EPQR-abreviado (EPQR-A) (II): Replicación factorial, fiabilidad y validez. Revista De Psicopatología y Psicología Clínica, 7, 207-216.

Santor, D. A., Zuroff, D. C., \& Fielding, A. (1997). Analysis and revision of the depressive experiences questionnaire: Examining scale performance as a function of scale length. Journal of Personality Assessment, 69, 145-163.

Santor, D. A., Zuroff, D. C., Ramsay, J. O., Cervantes, P., \& Palacios, J. (1995). Examining scale discriminability in the BDI and CES-D as a function of depressive severity. Psychological Assessment, 7, 131-139.

Scarr, S., Webber, P. L., Weinberg, R. A., \& Wittig, M. A. (1981). Personality resemblance among adolescents and their parents in biologically related and adoptive families. Journal of Personality and Social Psychology, 40, 885-898.

Schimmack, U., \& Diener, E. (2003). Predictive validity of explicit and implicit self-esteem for subjective well being. Journal of Research in Personality, 37, 100-106.

Schmitt, D. P., Allik, J., McCrae, R. R., \& Benet-Martínez, V. (2007). The geographic distribution of big five personality traits: Patterns and profiles of human self-description across 56 nations. Journal of Cross-Cultural Psychology, 38, 173-212.

Scholte, R. H. J., \& De Bruyn, E. E. J. (2004). Comparison of the giant three and the big five in early adolescents. Personality and Individual Differences, 36, 1353-1371. 
Schulte, F. S., Mongrain, M., \& Flora, D. B. (2008). Healthy and unhealthy dependence: Implication for major depression. British Journal of Clinical Psychology, 47, 341-353.

Seligman, M.E.P., \& Csikszentmihalyi, M. (Eds.) (2000). Positive psychology. American Psychologist, 55, 5-14.

Seligman, M. E., Steen, T. A., Park, N., \& Peterson, C. (2005). Positive psychology progress: Empirical validation of interventions. American Psychologist, 60, 410-421.

Senf, K., \& Liau, A. K. (2013). The effects of positive interventions on happiness and depressive symptoms, with an examination of personality as a moderator. Journal of Happiness Studies, 14, 591-612.

Sergeant, S., \& Mongrain, M. (2011). Are positive psychology exercises helpful for people with depressive personality styles? The Journal of Positive Psychology, 6, 260-272.

Sergeant, S., \& Mongrain, M. (2014). An online optimism intervention reduces depression in pessimistic individuals. Journal of Consulting and Clinical Psychology, 82, 263-274.

Sergeant, S., \& Mongrain, M. (2015). Distressed users report a better response to online positive psychology interventions than nondistressed users. Canadian Psychology, 56, 322-331.

Shapira, L. B., \& Mongrain, M. (2010). The benefits of self-compassion and optimism exercises for individuals vulnerable to depression. The Journal of Positive Psychology, 5, 377-389.

Sheldon, K. M. (2001). The self-concordance model of healthy goal striving: When personal goals correctly represent the person. Life goals and well-being: Towards a positive psychology of human striving. (pp. 18-36) Hogrefe \& Huber Publishers, Ashland, OH. 
Sheldon, K. M. (2009). Providing the scientific backbone for positive psychology: A multi-level conception of human thriving. Psihologijske Teme, 18, 267-284.

Sheldon, K. M., \& Hoon, T. H. (2007). The multiple determination of well-being: Independent effects of positive traits, needs, goals, selves, social supports, and cultural contexts. Journal of Happiness Studies, 8, 565-592.

Shiota, M. N., Keltner, D., \& John, O. P. (2006). Positive emotion dispositions differentially associated with Big Five personality and attachment style. The Journal of Positive Psychology, 1, 61-71.

Shorkey, C. T., \& Whiteman, V. L. (1978). Correlations between standard English and dialectical Spanish versions of five personality scales. Psychological Reports, 43, 910.

Sibley, C. G., Fischer, R., \& Liu, J. H. (2005). Reliability and validity of the revised experiences in close relationships (ECR-R) self-report measure of adult romantic attachment. Personality and Social Psychology Bulletin, 31, 1524-1536.

Simpson, J. A. (1990). Influence of attachment styles on romantic relationships. Journal of Personality and Social Psychology, 59, 971-980.

Sin, N. L., \& Lyubomirsky, S. (2009). Enhancing well-being and alleviating depressive symptoms with positive psychology interventions: A practice-friendly meta-analysis. Journal of Clinical Psychology: In Session, 65, 467-487.

Tellegen, A., \& Waller, N. G. (2008). Exploring personality through test construction: Development of the multidimensional personality questionnaire. In G. J. Boyle, G. Matthews \& D. H. Saklofske (Eds.), The SAGE handbook of personality theory and assessment, vol 2: Personality measurement and testing; the SAGE handbook of 
personality theory and assessment, vol 2: Personality measurement and testing (pp. 261292, Chapter xxiv, 717 Pages). Sage Publications, Inc, Thousand Oaks, CA.

Thoits, P. A., \& Hewitt, L. N. (2001). Volunteer work and well-being. Journal of Health and Social Behaviour, 42, 115-131.

Trofimova, I. (2014). Observer bias: An interaction of temperament traits with biases in the semantic perception of lexical material. PLOS ONE, 9, 1-28.

van der Linden, D., te Nijenhuis, J., \& Bakker, A. B. (2010). The general factor of personality: A meta-analysis of big five intercorrelations and a criterion-related validity study. Journal of Research in Personality, 44, 315-327.

Watson, D.; Clark, L. A.; Tellegen, A. (1988). "Development and validation of brief measures of positive and negative affect: The PANAS scales". Journal of Personality and Social Psychology, 54, 1063-1070.

Wei, M., Heppner, P. P., Russell, D. W., \& Young, S. K. (2006). Maladaptive perfectionism and ineffective coping as mediators between attachment and future depression: A prospective analysis. Journal of Counseling Psychology, 53, 67-79.

Wiggins, J. S. (1991). Agency and communion as conceptual coordinates for the understanding and measurement of interpersonal behavior. Thinking clearly about psychology: Essays in honor of Paul E. Meehl, vol. 1: Matters of public interest; vol. 2: Personality and psychopathology. (pp. 89-113) University of Minnesota Press, Minneapolis, MN.

Wolff, H., \& Kim, S. (2012). The relationship between networking behaviors and the Big Five personality dimensions. The Career Development International, 17, 43-66. 
Yamagata, S., Suzuki, A., Ando, J., Ono, Y., Kijima, N., Yoshimura, K., . . Jang, K. L. (2006). Is the genetic structure of human personality universal? A cross-cultural twin study from North America, Europe, and Asia. Journal of Personality and Social Psychology, 90, 987-998.

You, T. Y., Kim, M. U., \& Lee, D. H. (1997). The Big-Five personality test: Development and criterion-related validation. Korean Journal of Industrial \& Organizational Psychology, 10, 85-102.

Zeidner, M., \& Shani-Zinovich, I. (2011). Do academically gifted and nongifted students differ on the big-five and adaptive status? Some recent data and conclusions. Personality and Individual Differences, 51, 566-570.

Zheng, L., Goldberg, L. R., Zheng, Y., Zhao, Y., Tang, Y., \& Liu, L. (2008). Reliability and concurrent validation of the IPIP big-five factor markers in China: Consistencies in factor structure between internet-obtained heterosexual and homosexual samples. Personality and Individual Differences, 45, 649-654.

Zich, J.M., Attkisson, C.C., \& Greenfield, (1990). Screening for depression in primary care clinics: The CES-D and the BDI. International Journal of Psychiatry in Medicine, 20(3), 259-277.

Zuckerman, M., Kuhlman, D. M., \& Camac, C. (1988). What lies beyond E and N? Factor analyses of scales believed to measure basic dimensions of personality. Journal of Personality and Social Psychology, 54, 96-107. 
Zuroff, D.C., Igreja, I., \& Mongrain, M. (1990). Dysfunctional attitudes, dependency, and selfcriticism as predictors of depressive mood states: A 12-month longitudinal study. Cognitive Therapy and Research, 14, 315-326.

Zuroff, D. C., Mongrain, M., \& Santor, D. A. (2004). Conceptualizing and measuring personality vulnerability to depression: Comment on Coyne and Whiffen (1995). Psychological Bulletin, 130(3), 489-511.

Zuroff, D. C., Moskowitz, D. S., Wielgus, M. S., Powers, T. A., \& Franko, D. L. (1983). Construct validation of the dependency and self-criticism scales of the depressive experiences questionnaire. Journal of Research in Personality, 17, 226-241. 
Table 1. Correlation matrix and descriptive statistics for Study 1 personality variables at baseline.

\begin{tabular}{|c|c|c|c|c|c|c|c|c|c|c|c|c|c|}
\hline & 1. & 2. & 3. & 4. & 5. & 6. & 7. & 8. & 9. & 10. & 11. & 12. & 13. \\
\hline 1. Neediness ${ }^{\mathrm{a}}$ & 1.00 & & & & & & & & & & & & \\
\hline 2. Self-Criticism ${ }^{a}$ & 0.50 & 1.00 & & & & & & & & & & & \\
\hline 3. Efficacy ${ }^{\mathrm{a}}$ & -0.23 & 0.14 & 1.00 & & & & & & & & & & \\
\hline 4. Neuroticism ${ }^{\mathrm{b}}$ & 0.60 & 0.61 & -0.10 & 1.00 & & & & & & & & & \\
\hline 5. Extraversion ${ }^{\mathrm{b}}$ & -0.33 & -0.26 & 0.24 & -0.32 & 1.00 & & & & & & & & \\
\hline 6. Agreeableness ${ }^{b}$ & -0.20 & -0.42 & 0.17 & -0.33 & 0.15 & 1.00 & & & & & & & \\
\hline 7. Conscientiousness ${ }^{b}$ & -0.35 & -0.35 & 0.25 & -0.33 & 0.19 & 0.31 & 1.00 & & & & & & \\
\hline 8. Openness ${ }^{\mathrm{b}}$ & -0.18 & 0.02 & 0.33 & -0.12 & 0.26 & 0.13 & 0.07 & 1.00 & & & & & \\
\hline 9. Avoidant ${ }^{\mathrm{c}}$ & 0.18 & 0.42 & -0.09 & 0.25 & -0.27 & -0.27 & -0.21 & -0.10 & 1.00 & & & & \\
\hline 10. Anxious ${ }^{c}$ & 0.61 & 0.49 & -0.01 & 0.49 & -0.17 & -0.24 & -0.27 & -0.07 & 0.23 & 1.00 & & & \\
\hline 11. Self-Esteem ${ }^{\mathrm{d}}$ & -0.42 & -0.49 & 0.16 & -0.44 & 0.26 & 0.23 & 0.30 & 0.13 & -0.27 & -0.35 & 1.00 & & \\
\hline 12. Gratitude ${ }^{\mathrm{e}}$ & -0.35 & -0.46 & 0.30 & -0.42 & 0.32 & 0.40 & 0.29 & 0.23 & -0.36 & -0.35 & 0.44 & 1.00 & \\
\hline 13. Self-Compassion ${ }^{\mathrm{f}}$ & -0.47 & -0.51 & 0.20 & -0.55 & 0.25 & 0.33 & 0.29 & 0.23 & -0.27 & -0.37 & 0.45 & 0.48 & 1.00 \\
\hline Mean & 0.17 & 0.32 & -0.33 & 3.32 & 3.17 & 3.72 & 3.45 & 3.80 & 3.20 & 3.98 & 2.75 & 5.44 & 2.89 \\
\hline Standard Deviation & 0.82 & 1.04 & 1.06 & 0.84 & 0.82 & 0.64 & 0.70 & 0.65 & 1.20 & 1.27 & 0.71 & 1.18 & 0.82 \\
\hline
\end{tabular}

${ }^{\mathrm{a}}$ As measured by the Depressive Experiences Questionnaire (Blatt et al., 1995; Rude \& Burnham, 1995). ${ }^{\mathrm{b}}$ As measured by the Big Five Inventory (John, Donahue, \& Kentle, 1991). ' As measured by the Experiences in Close Relationships-Revised (Brennan, Clark, \& Shaver, 1998). ${ }^{\mathrm{d}}$ Rosenberg Self-Esteem Scale (Rosenberg, 1965). ${ }^{\mathrm{e}}$ Gratitude Questionnaire-6 (McCullough, Emmons, \& Tsang, 2002). ${ }^{\mathrm{f}}$ Positive items from the Self-Compassion Scale (Armstrong et al., in press; Muris \& Petrocchi, 2016; Neff, 2003). $N=4375$. 
Table 2. Standardized factor loadings and communalities for the three-factor model.

\begin{tabular}{lcccc}
\hline & Factor 1 & Factor 2 & Factor 3 & Communalities \\
\hline Neediness & 0.01 & $\mathbf{0 . 9 9}$ & -0.05 & 0.98 \\
Self-Criticism & $\mathbf{- 0 . 8 3}$ & 0.11 & $\mathbf{0 . 3 1}$ & 0.86 \\
Efficacy & -0.01 & -0.09 & $\mathbf{0 . 7 7}$ & 0.62 \\
Neuroticism & $\mathbf{- 0 . 5 0}$ & $\mathbf{0 . 3 3}$ & -0.01 & 0.54 \\
Extraversion & $\mathbf{0 . 3 0}$ & -0.09 & 0.28 & 0.22 \\
Agreeableness & $\mathbf{0 . 5 9}$ & 0.16 & 0.15 & 0.30 \\
Conscientiousness & $\mathbf{0 . 3 7}$ & -0.11 & 0.18 & 0.24 \\
Openness & 0.08 & -0.07 & $\mathbf{0 . 4 4}$ & 0.22 \\
Avoidant & $\mathbf{- 0 . 5 3}$ & -0.11 & -0.06 & 0.24 \\
Anxious & -0.26 & $\mathbf{0 . 4 8}$ & 0.08 & 0.43 \\
Self-Esteem & $\mathbf{0 . 5 6}$ & -0.13 & 0.12 & 0.44 \\
Gratitude & $\mathbf{0 . 6 5}$ & 0.04 & $\mathbf{0 . 3 0}$ & 0.49 \\
Self-Compassion & $\mathbf{0 . 5 5}$ & -0.14 & 0.18 & 0.45
\end{tabular}

Note. Bold indicates a factor loading greater than $0.30{ }^{\dagger}$ cross-loading. 
Table 3. Inter-factor correlations for the three-factor model.

\begin{tabular}{lccc}
\hline & Factor 1 & Factor 2 & Factor 3 \\
\hline Factor 1 & 1.00 & & \\
Factor 2 & -0.54 & 1.00 & \\
Factor 3 & 0.05 & -0.14 & 1.00 \\
\hline
\end{tabular}


Table 4. Completely standardized factor loadings, standard errors, and p-values for Model 2.

\begin{tabular}{|c|c|c|c|}
\hline & & Std. Factor Loadings & Standard error \\
\hline \multirow[t]{9}{*}{ Factor 1} & Self-Criticism & -1.10 & 0.035 \\
\hline & Neuroticism & -0.33 & 0.035 \\
\hline & Extraversion & 0.44 & 0.018 \\
\hline & Agreeableness & 0.52 & 0.015 \\
\hline & Conscientiousness & 0.47 & 0.016 \\
\hline & Avoidant & -0.49 & 0.030 \\
\hline & Self-Esteem & 0.56 & 0.020 \\
\hline & Gratitude & 0.61 & 0.026 \\
\hline & Self-Compassion & 0.68 & 0.018 \\
\hline \multirow[t]{3}{*}{ Factor 2} & Neediness & 0.84 & 0.018 \\
\hline & Neuroticism & 0.48 & 0.036 \\
\hline & Anxious & 0.72 & 0.026 \\
\hline \multirow[t]{4}{*}{ Factor 3} & Efficacy & 0.72 & 0.030 \\
\hline & Self-Criticism & 0.65 & 0.042 \\
\hline & Openness & 0.46 & 0.016 \\
\hline & Gratitude & 0.18 & 0.031 \\
\hline
\end{tabular}

Note: All factor loadings were significant with $\mathrm{p}<.01$. 
Table 5. Correlation matrix and descriptive statistics for Study 2 variables at baseline.

\begin{tabular}{|c|c|c|c|c|c|c|c|c|c|c|c|}
\hline & 1. & 2. & 3. & 4. & 5. & 6. & 7. & 8. & 9. & 10. & 11. \\
\hline 1. CES-D ${ }^{\mathrm{a}}$ & 1.00 & & & & & & & & & & \\
\hline 2. $\mathrm{SWLS}^{\mathrm{b}}$ & $-0.57 *$ & 1.00 & & & & & & & & & \\
\hline 3. Positive ${ }^{c}$ & $-0.59 *$ & $0.60 *$ & 1.00 & & & & & & & & \\
\hline 4. Negative ${ }^{c}$ & $0.73^{*}$ & $-.53^{*}$ & $-0.56^{*}$ & 1.00 & & & & & & & \\
\hline 5. Compassionate ${ }^{c}$ & $-0.52 *$ & $0.54 *$ & $0.82 *$ & $-0.53 *$ & 1.00 & & & & & & \\
\hline 6. Age & $-0.05^{*}$ & $-0.05^{*}$ & $0.07 *$ & $-0.04 *$ & $0.08^{*}$ & 1.00 & & & & & \\
\hline 7. Gender ${ }^{\mathrm{d}}$ & $-0.05^{*}$ & -0.03 & 0.16 & 0.01 & -0.03 & $-0.08 *$ & 1.00 & & & & \\
\hline 8. Income $\mathrm{e}^{\mathrm{e}}$ & $-0.16^{*}$ & 0.16 & $0.10^{*}$ & $-0.12 *$ & $0.09 *$ & $0.38 *$ & -0.01 & 1.00 & & & \\
\hline 9. Equanimity ${ }^{f}$ & $-0.64^{*}$ & $0.67 *$ & $0.64 *$ & $-0.64 *$ & $0.64^{*}$ & $0.15^{*}$ & -0.02 & $0.19 *$ & 1.00 & & \\
\hline 10. Insecurity & $0.60 *$ & $-0.52 *$ & $-0.53 *$ & $0.58 *$ & $-0.48 *$ & $-0.19 *$ & $-0.06^{*}$ & $-0.19 *$ & $-0.83^{*}$ & 1.00 & \\
\hline 11. Agency & $-0.18^{*}$ & $0.27 *$ & $0.27 *$ & $-0.20 *$ & $0.29 *$ & $0.06^{*}$ & -0.02 & $0.14 *$ & $0.40 *$ & $-0.29 *$ & 1.00 \\
\hline Mean & 20.65 & 3.90 & 2.87 & 2.29 & 3.15 & 33.50 & 1.18 & 3.83 & 0.02 & -0.01 & -0.01 \\
\hline Standard Deviation & 14.48 & 1.58 & 1.05 & 0.94 & 0.89 & 11.37 & 0.39 & 2.64 & 0.96 & 0.86 & 0.86 \\
\hline
\end{tabular}

${ }^{a}$ Centre for Epidemiological Studies Depression Scale (Radloff, 1977). ${ }^{\mathrm{b}}$ Satisfaction with Life Scale (Diener, Emmons, Larsen, \& Griffin, 1985). ${ }^{\mathrm{c}}$ Positive affect, negative affect, and compassionate affect, as measured by the Compassionate - Positive/Negative Affect Scale. ${ }^{\mathrm{d}} \mathrm{Female}$ $=1$, Male $=2 .{ }^{\text {e }}$ Yearly household income reported as $1=$ "Less than $\$ 10,000 ", 2=" \$ 10,000-\$ 20,000 ", 3=" \$ 20,000-\$ 30,000 ", 4=" \$ 30,000-$ $\$ 40,000 ", 5=" \$ 40,000-\$ 50,000 ", 6=" 50,000-\$ 60,000 ", 7=" \$ 60,000-\$ 70,000 ", 8=" \$ 70,000-\$ 80,000 ", 9=" 80,000-90,000 ", 10=\$ 90,000-$

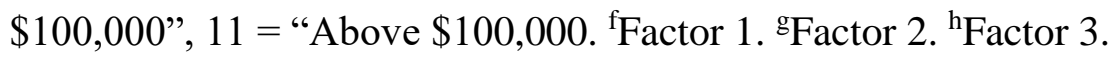

$* p<.05$. 
Table 6. Sample size over time (active conditions vs. control conditions).

\begin{tabular}{lccccc}
\hline & Baseline & Post-test & One month & Three months & Six months \\
\hline Control & 709 & 503 & 403 & 282 & 204 \\
Exercise & 2819 & 1888 & 1523 & 1083 & 747 \\
\hline Total $N$ & 3528 & 2391 & 1926 & 1365 & 951 \\
\hline
\end{tabular}


Table 7. Mean scores on baseline variables for completers versus non-completers.

\begin{tabular}{lcc}
\hline & Completers & Non-Completers \\
\hline CES-D $^{\mathrm{a}}$ & 18.50 & 21.25 \\
SWLS $^{\mathrm{b}}$ & 4.12 & 3.83 \\
Positive $^{\mathrm{c}}$ & 2.95 & 2.84 \\
Negative $^{\mathrm{c}}$ & 2.16 & 2.33 \\
Compassionate $^{\mathrm{c}}$ & 3.24 & 3.12 \\
Percentage Female & $85.87 \%$ & $80.79 \%$ \\
\hline
\end{tabular}

${ }^{\mathrm{a}}$ Centre for Epidemiological Studies Depression Scale (Radloff, 1977). ${ }^{\mathrm{b}}$ Satisfaction with Life Scale (Diener, Emmons, Larsen, \& Griffin, 1985). ${ }^{\mathrm{c}}$ Positive affect, negative affect, and compassionate affect, as measured by the Compassionate - Positive/Negative Affect Scale. 
Table 8. Regression estimates for the latent growth curve model of depression.

\begin{tabular}{|c|c|c|c|}
\hline & Variables & Estimate & SE \\
\hline \multirow{6}{*}{ Intercept } & Equanimity & $-6.80 *$ & 0.35 \\
\hline & Insecurity & $3.20 *$ & 0.36 \\
\hline & Agency & $1.00 *$ & 0.24 \\
\hline & Age & $0.091 *$ & 0.016 \\
\hline & Gender & $1.81 *$ & 0.45 \\
\hline & Income & $-0.33^{*}$ & 0.074 \\
\hline \multirow[t]{7}{*}{ Slope 1} & Equanimity & 0.20 & 0.38 \\
\hline & Insecurity & $-1.52 *$ & 0.39 \\
\hline & Agency & -0.13 & 0.25 \\
\hline & Condition & $-1.34 *$ & 0.44 \\
\hline & Age & 0.004 & 0.017 \\
\hline & Gender & -0.047 & 0.48 \\
\hline & Income & 0.033 & 0.075 \\
\hline \multirow[t]{7}{*}{ Slope 2} & Equanimity & 0.092 & 0.13 \\
\hline & Insecurity & $-0.50 *$ & 0.13 \\
\hline & Agency & -0.070 & 0.082 \\
\hline & Condition & -0.31 & 0.13 \\
\hline & Age & -0.002 & 0.005 \\
\hline & Gender & 0.093 & 0.16 \\
\hline & Income & -0.022 & 0.024 \\
\hline
\end{tabular}

$* p<.05$ 
Table 9. Regression estimates for the latent growth curve model of satisfaction with life.

\begin{tabular}{l|l|c|c}
\hline & Variables & Estimate & SE \\
\hline Intercept & Equanimity & $1.18^{*}$ & 0.038 \\
& Insecurity & $0.11^{*}$ & 0.040 \\
& Agency & -0.004 & 0.026 \\
& Age & $-0.025^{*}$ & 0.002 \\
& Gender & $0.12^{*}$ & 0.052 \\
& Income & $0.064^{*}$ & 0.008 \\
\hline Slope 1 & Equanimity & -0.023 & 0.035 \\
& Insecurity & 0.051 & 0.037 \\
& Agency & 0.015 & 0.026 \\
& Condition & 0.046 & 0.042 \\
& Age & $-0.004^{*}$ & 0.002 \\
& Gender & -0.012 & 0.048 \\
& Income & 0.005 & 0.007 \\
\hline Slope 2 & Equanimity & -0.013 & 0.012 \\
& Insecurity & $0.027^{*}$ & 0.012 \\
& Agency & 0.010 & 0.009 \\
& Condition & 0.024 & 0.013 \\
& Age & -0.00 & 0.001 \\
& Gender & -0.021 & 0.018 \\
& Income & 0.004 & 0.002 \\
\hline
\end{tabular}

$* p<.05$ 
Table 10. Regression estimates for the latent growth curve model of positive affect.

\begin{tabular}{|c|c|c|c|}
\hline & Variables & Estimate & SE \\
\hline \multirow{6}{*}{ Intercept } & Equanimity & $0.68 *$ & 0.026 \\
\hline & Insecurity & 0.011 & 0.027 \\
\hline & Agency & 0.033 & 0.017 \\
\hline & Age & -0.001 & 0.001 \\
\hline & Gender & $-0.096^{*}$ & 0.035 \\
\hline & Income & -0.004 & 0.006 \\
\hline \multirow[t]{7}{*}{ Slope 1} & Equanimity & -0.047 & 0.033 \\
\hline & Insecurity & 0.045 & 0.035 \\
\hline & Agency & -0.028 & 0.022 \\
\hline & Condition & $0.092 *$ & 0.037 \\
\hline & Age & $-0.004^{*}$ & 0.001 \\
\hline & Gender & -0.033 & 0.042 \\
\hline & Income & $0.014 *$ & 0.007 \\
\hline \multirow[t]{8}{*}{ Slope 2} & Equanimity & $-0.026^{*}$ & 0.010 \\
\hline & Insecurity & 0.011 & 0.010 \\
\hline & Agency & -0.018 & 0.010 \\
\hline & Condition & $0.021 *$ & 0.010 \\
\hline & Cond*Agency & $0.028 *$ & 0.012 \\
\hline & Age & $-0.001 *$ & 0.00 \\
\hline & Gender & -0.005 & 0.014 \\
\hline & Income & $0.006 *$ & 0.002 \\
\hline
\end{tabular}

$* p<.05$ 
Table 11. Regression estimates for the latent growth curve model of negative affect.

\begin{tabular}{|c|c|c|c|}
\hline & Variables & Estimate & SE \\
\hline Intercept & $\begin{array}{l}\text { Equanimity } \\
\text { Insecurity } \\
\text { Agency } \\
\text { Age } \\
\text { Gender } \\
\text { Income }\end{array}$ & $\begin{array}{c}-0.47 * \\
0.18^{*} \\
0.053^{*} \\
0.006^{*} \\
-0.053 \\
-0.009\end{array}$ & $\begin{array}{l}0.024 \\
0.024 \\
0.016 \\
0.001 \\
0.030 \\
0.005\end{array}$ \\
\hline Slope 1 & $\begin{array}{l}\text { Equanimity } \\
\text { Insecurity } \\
\text { Agency } \\
\text { Condition } \\
\text { Cond*Insecurity } \\
\text { Age } \\
\text { Gender } \\
\text { Income }\end{array}$ & $\begin{array}{c}0.090 * \\
0.032 \\
-0.002 \\
-0.046 \\
-0.11 * \\
-0.001 \\
0.008 \\
-0.003\end{array}$ & $\begin{array}{l}0.029 \\
0.042 \\
0.019 \\
0.033 \\
0.037 \\
0.001 \\
0.038 \\
0.006\end{array}$ \\
\hline Slope 2 & $\begin{array}{l}\text { Equanimity } \\
\text { Insecurity } \\
\text { Agency } \\
\text { Condition } \\
\text { Age } \\
\text { Gender } \\
\text { Income }\end{array}$ & $\begin{array}{c}0.024 * \\
-0.017 * \\
0.002 \\
-0.018^{*} \\
-0.00 \\
0.021 * \\
-0.002\end{array}$ & $\begin{array}{l}0.008 \\
0.008 \\
0.006 \\
0.009 \\
0.00 \\
0.010 \\
0.002\end{array}$ \\
\hline
\end{tabular}

$* p<.05$ 
Table 12. Regression estimates for the latent growth curve model of compassionate affect.

\begin{tabular}{|c|c|c|c|}
\hline & Variables & Estimate & SE \\
\hline \multirow{6}{*}{ Intercept } & Equanimity & $0.66 *$ & 0.022 \\
\hline & Insecurity & $0.13 *$ & 0.023 \\
\hline & Agency & $0.040 *$ & 0.015 \\
\hline & Age & 0.00 & 0.001 \\
\hline & Gender & -0.003 & 0.029 \\
\hline & Income & -0.008 & 0.005 \\
\hline \multirow[t]{7}{*}{ Slope 1} & Equanimity & $-0.073 *$ & 0.030 \\
\hline & Insecurity & 0.019 & 0.032 \\
\hline & Agency & 0.021 & 0.020 \\
\hline & Condition & 0.059 & 0.033 \\
\hline & Age & $-0.004^{*}$ & 0.001 \\
\hline & Gender & 0.012 & 0.037 \\
\hline & Income & $0.015 *$ & 0.006 \\
\hline \multirow[t]{8}{*}{ Slope 2} & Equanimity & $-0.034^{*}$ & 0.009 \\
\hline & Insecurity & -0.006 & 0.009 \\
\hline & Agency & $-0.018 *$ & 0.009 \\
\hline & Condition & $0.034 *$ & 0.009 \\
\hline & Cond*Agency & $0.029 *$ & 0.010 \\
\hline & Age & $-0.001 *$ & 0.00 \\
\hline & Gender & -0.016 & 0.012 \\
\hline & Income & $0.006 *$ & 0.002 \\
\hline
\end{tabular}

$* p<.05$

$* * p<.01$ 


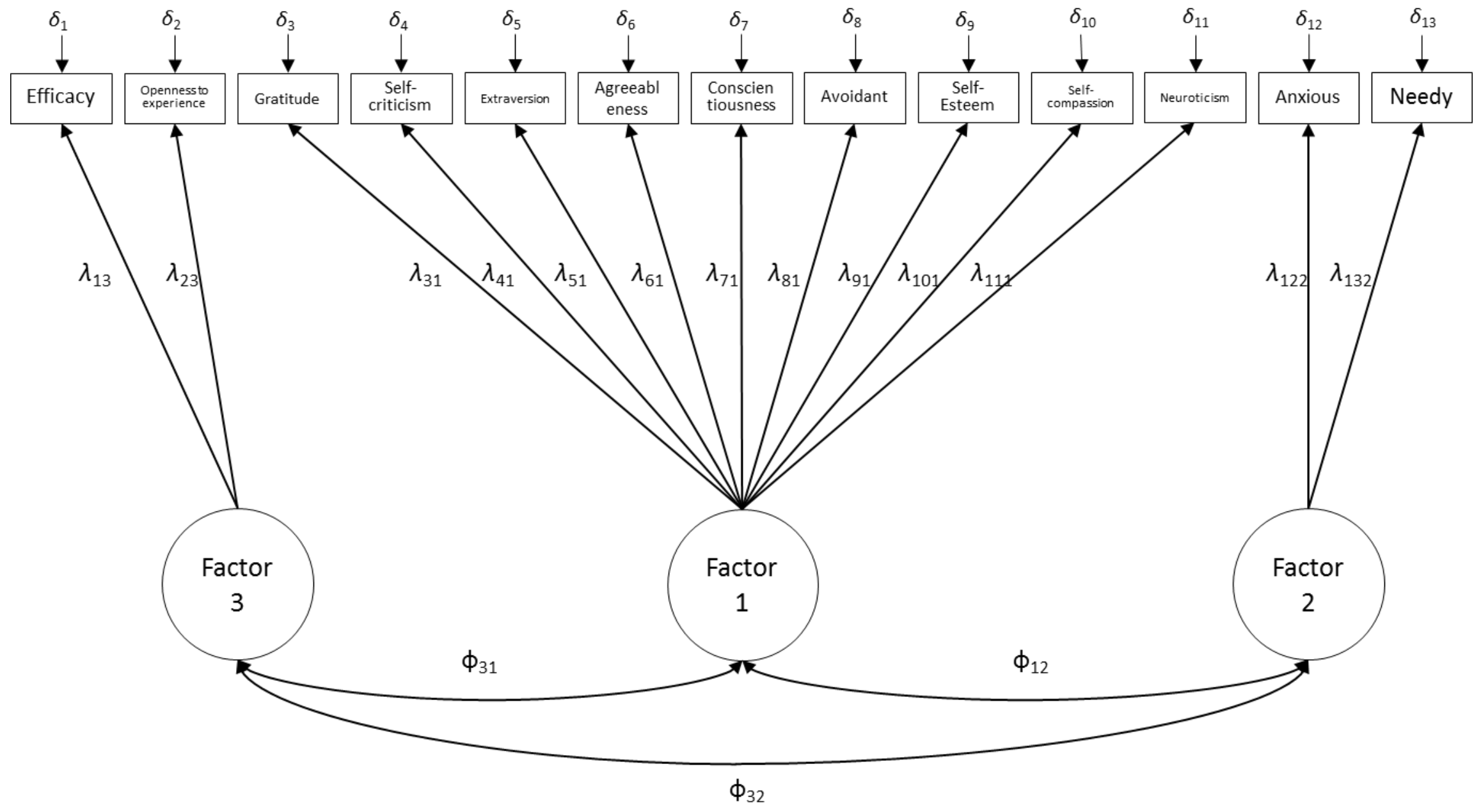

Figure 1. Confirmatory Factor Analysis, Model 1 


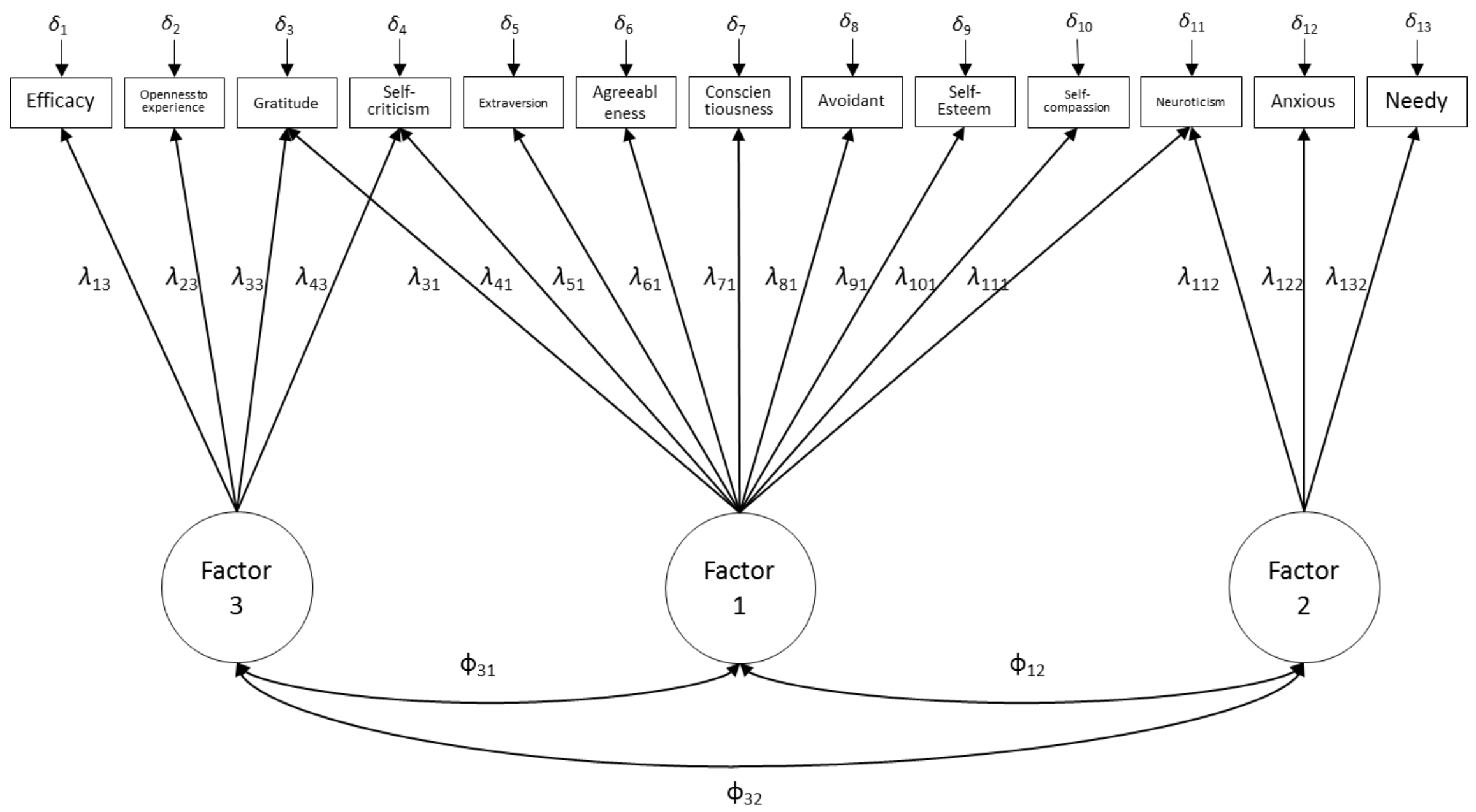

Figure 2. Confirmatory Factor Analysis, Model 2. 


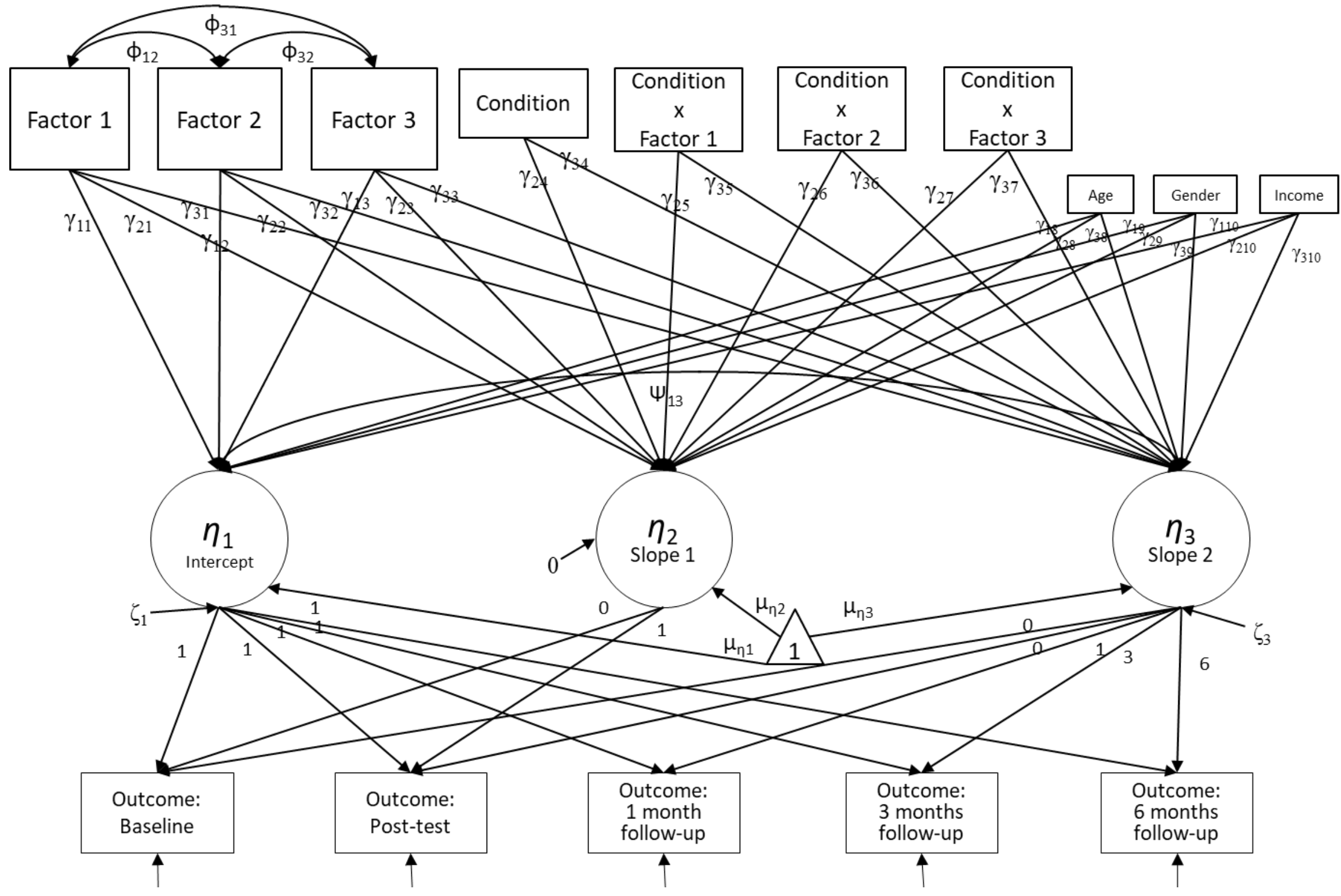

Figure 3. Latent growth curve model. 


\section{Appendix A: Project HOPE Advertisement}

\section{Feel Better- Participate in Project HOPE}

Online study by York University researchers looking at the effects of mental exercises on wellbeing and mood. Participants paid $\$ 30$ and entered in $\$ 1,000$ draws.

Go to www.ProjectHopeCanada.com 


\section{Appendix B: Consent Form}

\section{Consent Form}

This study will examine effects of various online self-help exercises on mood and well-being. You must be 18 years old to participate.

Participation in this study will involve logging on to this website for 8 consecutive days and will consist of the following steps:

A) On the first day you will complete a set of personality and mood questionnaires on this website. This phase of the study will require between 45 minutes to 1.5 hours depending on the condition to which you are assigned. You are randomly assigned to one of the daily exercises being studied.

B) On days 2 through 8 you will complete your daily exercises, which will take $5-15$ minutes each day. You may be assigned to an online daily writing exercise or you may alternately be given a task to complete each day following which you will answer some questions online. On the 8th day you will also be asked to complete a series of questionnaires (20 minutes).

C) In order to assess long-term effects of these activities you will be encouraged to continue to use these exercises after the completion of the initial study period. We will ask you to return to the website after 1 month, 3 months, and 6 months to complete questionnaires. These follow-up sessions will take approximately 15 minutes to complete. You can terminate your involvement in this study at any time and do not have to complete all aspects of the project.

Participants will be entered in a draw for $\$ 1,000$ after completing the first week. There will also be a $\$ 1,000$ draw upon completion of the 1 month, 3 month, and 6 month follow-up measures. Odds of winning depend on the final number of participants completing each follow-up. Failure to participate in one follow-up session does not exclude the possibility of participating in the subsequent follow-ups.

There are no evident risks inherent in this project. In previous research of this type, participants have reported benefiting from some of the exercises assigned. You may refrain from answering any questions you are not comfortable with. You may also contact Dr. Mongrain, the project director at (416) 736-5115, Ext. 66193 or York University's Human Participants Review SubCommittee at (416) 736-5055 (research@yorku.ca) with any concerns you may have.

This research has been reviewed and approved by the Human Participants Review SubCommittee within the context of York's Senate policy on Research ethics. All information, including your online responses to the daily exercises and questionnaires will be kept confidential to the limits allowed by law. Participants will be assigned ID numbers, which will be used in place of names in files which are kept in the custody of the research team and which are unavailable to others. The master list matching names (and contact information) to ID numbers will only be available to the researcher in charge of contacting you (e.g. for remuneration purposes or debriefing). All information derived by the study will be used for research purposes only, and the data obtained will be destroyed within a year of the final publication. 


\section{Participant Consent}

By clicking the Agree button below you are stating that you understand the above information and agree to participate in this study. This does not commit you to all phases of the project and you may withdraw from it at any time. A copy of this page will be sent to the email address you have provided for us. 


\section{Appendix C: Personality and Outcome Measures}

\section{Depressive Experiences Questionnaire}

Listed below are a number of statements concerning personal characteristics and traits. Read each item and decide whether you agree or disagree and to what extent. If you strongly agree, circle7; if you strongly disagree, circle 1; The midpoint, if you are neutral or undecided, is 4 .

1. I set my personal goals and standards as high as possible.

\section{Strongly \\ Disagree}

Strongly

Agree

2. Without support from others who are close to me, I would be helpless.

$\begin{array}{lllllll}1 & 2 & 3 & 4 & 5 & 6 & 7\end{array}$

I tend to be satisfied with my current plans and goals, rather than striving for higher goals.

4. Sometimes I feel very big, and other times I feel very small.

$\begin{array}{lllllll}1 & 2 & 3 & 4 & 5 & 6 & 7\end{array}$

5. When I am closely involved with someone, I never feel jealous.

$\begin{array}{lllllll}1 & 2 & 3 & 4 & 5 & 6 & 7\end{array}$

6. I urgently need things that only other people can provide.

$\begin{array}{lllllll}1 & 2 & 3 & 4 & 5 & 6 & 7\end{array}$

7. I often find that I don't live up to my own standards or ideals.

8. I feel I am always making full use of my potential abilities.

9. The lack of permanence in human relationships doesn't bother me.

10. If I fail to live up to expectations, I feel unworthy.

11. Many times I feel helpless.

$\begin{array}{lllllll}1 & 2 & 3 & 4 & 5 & 6 & 7\end{array}$

12. I seldom worry about being criticized for things I have said or done.

13. There is a considerable difference between how I am now and how I would like to be.

14. I enjoy sharp competition with others.

15. I feel I have many responsibilities that I must meet.

16. There are times when I feel "empty" inside.

17. I tend not to be satisfied with what I have.

18. I don't care whether or not I live up to what other people expect of me. 
Strongly

Disagree
Strongly

Agree

19. I become frightened when I feel alone.

20. I would feel like I'd be losing an important part of myself if I lost a very close friend.

21. People will accept me no matter how many mistakes I have made.

22. I have difficulty breaking off a relationship that is making me unhappy.

23. I often think about the danger of losing someone who is close to me.

24. Other people have high expectations of me.

25. When I am with others, I tend to devalue or "undersell" myself.

26. I am not very concerned with how other people respond to me.

27. No matter how close a relationship between two people is, there is always a large amount of uncertainty and conflict.

28. I am very sensitive to others for signs of rejection.

29. It's important for my family that I succeed.

30. Often, I feel I have disappointed others.

31. If someone makes me angry, I let him (her) know how I feel.

32. I constantly try, and very often go out of my way, to please or help people I am close to.

33. I have many inner resources (abilities, strengths).

34. I find it very difficult to say "No" to the requests of friends.

35. I never really feel secure in a close relationship.

36. The way I feel about myself frequently varies: there are times when I feel extremely good about myself and other times when I see only the bad in me and feel like a total failure

37. Often, I feel threatened by change.

38. Even if the person who is closest to me were to leave, I could still "go it alone."

$\begin{array}{lllllll}1 & 2 & 3 & 4 & 5 & 6 & 7\end{array}$

$\begin{array}{lllllll}1 & 2 & 3 & 4 & 5 & 6 & 7\end{array}$

$\begin{array}{lllllll}1 & 2 & 3 & 4 & 5 & 6 & 7\end{array}$

$\begin{array}{lllllll}1 & 2 & 3 & 4 & 5 & 6 & 7\end{array}$

$\begin{array}{lllllll}1 & 2 & 3 & 4 & 5 & 6 & 7\end{array}$

$\begin{array}{lllllll}1 & 2 & 3 & 4 & 5 & 6 & 7\end{array}$

$\begin{array}{lllllll}1 & 2 & 3 & 4 & 5 & 6 & 7\end{array}$

$\begin{array}{lllllll}1 & 2 & 3 & 4 & 5 & 6 & 7\end{array}$

$\begin{array}{lllllll}1 & 2 & 3 & 4 & 5 & 6 & 7 \\ 1 & 2 & 3 & 4 & 5 & 6 & 7 \\ 1 & 2 & 3 & 4 & 5 & 6 & 7 \\ 1 & 2 & 3 & 4 & 5 & 6 & 7\end{array}$

$\begin{array}{llllllll}1 & 2 & 3 & 4 & 5 & 6 & 7\end{array}$

$\begin{array}{lllllll}1 & 2 & 3 & 4 & 5 & 6 & 7\end{array}$

$\begin{array}{lllllll}1 & 2 & 3 & 4 & 5 & 6 & 7\end{array}$

$\begin{array}{lllllll}1 & 2 & 3 & 4 & 5 & 6 & 7\end{array}$

$\begin{array}{lllllll}1 & 2 & 3 & 4 & 5 & 6 & 7\end{array}$


Strongly

Disagree
Strongly

Agree

39. One must continually work to gain love from another person: that is, love has to be earned.

40. I am very sensitive to the effects my words or actions have on the feelings of other people.

41. I often blame myself for things I have done or said to someone.

42. I am a very independent person.

43. I often feel guilty.

44. I think of myself as a very complex person, one who has "many sides."

45. I worry a lot about offending or hurting someone who is close to me.

46. Anger frightens me.

47. It is not "who you are," but "what you have accomplished" that counts.

48. I feel good about myself whether I succeed or fail.

49. I can easily put my own feelings and problems aside, and devote my complete attention to the feelings and problems of someone else.

50. If someone I cared about became angry with me, I would feel threatened that he (she) might leave me.

51. I feel comfortable when I am given important responsibilities.

52. After a fight with a friend, I must make amends as soon as possible.

53. I have a difficult time accepting weaknesses in myself.

54. It is more important that I enjoy my work than it is for me to have my work approved.

55. After an argument, I feel very lonely.

56. In my relationships with others, I am very concerned about what they can give to me.

57. I rarely think about my family.

$\begin{array}{lllllll}1 & 2 & 3 & 4 & 5 & 6 & 7\end{array}$

$\begin{array}{lllllll}1 & 2 & 3 & 4 & 5 & 6 & 7\end{array}$

$\begin{array}{lllllll}1 & 2 & 3 & 4 & 5 & 6 & 7\end{array}$

$\begin{array}{lllllll}1 & 2 & 3 & 4 & 5 & 6 & 7\end{array}$

$\begin{array}{lllllll}1 & 2 & 3 & 4 & 5 & 6 & 7\end{array}$

$\begin{array}{lllllll}1 & 2 & 3 & 4 & 5 & 6 & 7\end{array}$

$\begin{array}{lllllll}1 & 2 & 3 & 4 & 5 & 6 & 7\end{array}$

$\begin{array}{lllllll}1 & 2 & 3 & 4 & 5 & 6 & 7\end{array}$

$\begin{array}{lllllll}1 & 2 & 3 & 4 & 5 & 6 & 7\end{array}$

$\begin{array}{lllllll}1 & 2 & 3 & 4 & 5 & 6 & 7\end{array}$

$\begin{array}{lllllll}1 & 2 & 3 & 4 & 5 & 6 & 7 \\ 1 & 2 & 3 & 4 & 5 & 6 & 7\end{array}$

$\begin{array}{lllllll}1 & 2 & 3 & 4 & 5 & 6 & 7\end{array}$

$\begin{array}{lllllll}1 & 2 & 3 & 4 & 5 & 6 & 7\end{array}$


Strongly

Strongly

Disagree

Agree

58. Very frequently, my feelings toward someone close to me vary: there are times when I feel completely angry and other times when I feel all-loving towards that person.

$\begin{array}{lllllll}1 & 2 & 3 & 4 & 5 & 6 & 7\end{array}$

59. What I do and say has a very strong impact on those around me.

60. I sometimes feel that I am "special."

61. I grew up in an extremely close family.

62. I am very satisfied with myself and my accomplishments.

63. I want many things from someone I am close to.

64. I tend to be very critical of myself.

65. Being alone doesn't bother me at all.

$\begin{array}{lllllll}1 & 2 & 3 & 4 & 5 & 6 & 7 \\ 1 & 2 & 3 & 4 & 5 & 6 & 7 \\ 1 & 2 & 3 & 4 & 5 & 6 & 7 \\ 1 & 2 & 3 & 4 & 5 & 6 & 7 \\ 1 & 2 & 3 & 4 & 5 & 6 & 7 \\ 1 & 2 & 3 & 4 & 5 & 6 & 7 \\ 1 & 2 & 3 & 4 & 5 & 6 & 7 \\ 1 & 2 & 3 & 4 & 5 & 6 & 7\end{array}$

66. I very frequently compare myself to standards or goals.

(c) Blatt, D’Affilitti, \& Quinlan, 1976. 


\section{Big Five Inventory}

Here are a number of characteristics that may or may not apply to you. For example, do you agree that you are someone who likes to spend time with others? Please write a number next to each statement to indicate the extent to which you agree or disagree with that statement.

1. Disagree strongly, 2. Disagree a little, 3. Neither agree nor disagree, 4. Agree a little, 5. Agree strongly

I see myself as someone who...

1. Is talkative

2. Tends to find fault with others

3. Does a thorough job

4. Is depressed, blue

5. Is original, comes up with new ideas

6. Is reserved

7. Is helpful and unselfish with others

8. Can be somewhat careless

9. Is relaxed, handles stress well

10. Is curious about many different things

__11. Is full of energy

12. Starts quarrels with others

13. Is a reliable worker

14. Can be tense

15. Is ingenious, a deep thinker

16. Generates a lot of enthusiasm

17. Has a forgiving nature

18. Tends to be disorganized

19. Worries a lot

20. Has an active imagination

21. Tends to be quiet

22. Is generally trusting

23. Tends to be lazy

24. Is emotionally stable, not easily upset

25. Is inventive

26. Has an assertive personality
27. Can be cold and aloof

28. Perseveres until the task is finished

29. Can be moody

30. Values artistic, aesthetic experiences

31. Is sometimes shy, inhibited

32. Is considerate and kind to almost everyone

33. Does things efficiently

34. Remains calm in tense situations

35. Prefers work that is routine

36. Is outgoing, sociable

37. Is sometimes rude to others

38. Makes plans and follows through with them

39. Gets nervous easily

40. Likes to reflect, play with ideas

41. Has few artistic interests

42. Likes to cooperate with others

43. Is easily distracted

44. Is sophisticated in art, music, or literature 


\section{Gratitude Questionnaire-6}

The following 6 statements concern your feelings about your life as a whole. For each item, indicate how well it describes you by placing a check mark in the appropriate box.

1. I have so much in life to be thankful for.

$$
\text { Strongly Disagree Disagree Slightly Disagree Neutral Slightly Agree Agree Strongly Agree }
$$

2. If I had to list everything that I felt grateful for, it would be a very long list.

Strongly Disagree Disagree Slightly Disagree Neutral Slightly Agree Agree Strongly Agree

3. When I look at the world, I don't see much to be grateful for.

Strongly Disagree Disagree Slightly Disagree Neutral Slightly Agree Agree Strongly Agree

4. I am grateful to a wide variety of people.

Strongly Disagree Disagree Slightly Disagree Neutral Slightly Agree Agree Strongly Agree

5. As I get older, I find myself more able to appreciate the people, events, and situations that have been part of my life history.

Strongly Disagree Disagree Slightly Disagree Neutral Slightly Agree Agree Strongly Agree

6. Long amounts of time can go by before I feel grateful to something or someone.

Strongly Disagree Disagree Slightly Disagree Neutral Slightly Agree Agree Strongly Agree 


\section{Rosenberg Self-Esteem Scale}

This questionnaire measures how you think and feel about yourself in general. Read each statement and indicate your level of agreement using the scale provided.

\begin{tabular}{|c|c|c|c|}
\hline \multirow{2}{*}{ Strongly Agree } & Agree & Disagree & Strongly Disagree \\
\hline
\end{tabular}

I feel that I am a person of worth, at

1. least on an equal basis with others

2. I feel that I have a number of good qualities

All in all I am inclined to feel that I

am a failure.

I am able to do things as well as most

4. other people

I feel I do not have much to be proud

5. of

I take a positive attitude towards

6. myself

2

3

4

7. On the whole, I am satisfied with myself

1

I wish I could have more respect for

8. myself

9. I certainly feel useless at times

10. At times I think I am no good at all.

2

3

4

1

2

3

4 


\section{Experiences in Close Relationships - Revised}

The following 36 statements concern how you feel in romantic relationships. We are interested in how you generally experience romantic relationships, not just what is happening in a current relationship. Respond to each statement by indicating how much you agree or disagree with it. Using the scale provided, click on the statement that corresponds to how you generally feel.

\begin{tabular}{|c|c|c|c|c|c|c|}
\hline $\begin{array}{c}\text { Strongly } \\
\text { Disagree }\end{array}$ & Disagree & $\begin{array}{c}\text { Somewhat } \\
\text { Disagree }\end{array}$ & Neutral & $\begin{array}{c}\text { Somewhat } \\
\text { Agree }\end{array}$ & Agree & $\begin{array}{c}\text { Strongly } \\
\text { Agree }\end{array}$ \\
\hline
\end{tabular}

1. I prefer not to show a partner how I feel deep down.

2. I worry about being abandoned.

3. I am very comfortable being close to romantic partners.

4. I worry a lot about my relationships.

5. Just when my partner starts to get close to me I find myself pulling away.

6. I worry that my romantic partners won't care about me as much as I care about them.

7. I get uncomfortable when my romantic partner wants to get very close.

8. I worry a fair amount about losing my partner.

9. I don't feel comfortable opening up to romantic partners.

10. I often wish my partner's feelings for me were as strong as my feelings for him.

11. I want to get close to my partner but I find myself pulling back.

12. I often want to merge completely with romantic partners, and this sometimes scares them away.

13. I am nervous when partners get too close to me.

14. I worry about being alone.

15. I feel comfortable sharing my private thoughts and feelings with my partner.

16. My desire to be very close sometimes scares people away.

17. I try to avoid getting too close to my partner.

18. I need a lot of reassurance that I am loved by my partner.

19. I find it relatively easy to get close to my partner.

20. Sometimes I feel that I force my partners to show more feeling, more commitment.

21. I find it difficult to allow myself to depend on romantic partners.

22. I do not often worry about being abandoned.

23. I prefer not to be too close to romantic partners.

24. If I can't get my partner to show interest in me, I get upset or angry.

25. I tell my partner just about everything.

26. I feel that my partner(s) don't want to get as close as I would like.

27. I usually discuss my problems and concerns with my partner.

28. When I'm not involved in a relationship, I feel somewhat anxious and insecure.

29. I feel comfortable depending on romantic partners.

30. I get frustrated when my partner is not around as much as I would like.

31. I don't mind asking romantic partners for comfort, advice, or help.

32. I get frustrated when my romantic partners are not available when I need them.

33. It helps to turn to my romantic partner in times of need.

34. When my romantic partner disapproves of me, I feel really bad about myself.

35. I turn to my partner for many things, including comfort and reassurance.

36. I resent it when my partner spends time away from me. 


\section{Self-Compassion Scale}

Please read each statement carefully before answering. To the left of each item, indicate how often you behave in the stated manner, using the following scale:

\section{Almost}

never

1
2
3

\section{Almost \\ always}

4
5

1. I'm disapproving and judgmental about my own flaws and inadequacies.

2. When I'm feeling down I tend to obsess and fixate on everything that's wrong.

3. When things are going badly for me, I see the difficulties as part of life that everyone goes through.

4. When I think about my inadequacies, it tends to make me feel more separate and cut off from the rest of the world.

5. I try to be loving towards myself when I'm feeling emotional pain.

6. When I fail at something important to me I become consumed by feelings of inadequacy.

7. When I'm down and out, I remind myself that there are lots of other people in the world feeling like I am.

8. When times are really difficult, I tend to be tough on myself.

9. When something upsets me I try to keep my emotions in balance.

10. When I feel inadequate in some way, I try to remind myself that feelings of inadequacy are shared by most people.

11. I'm intolerant and impatient towards those aspects of my personality I don't like.

12. When I'm going through a very hard time, I give myself the caring and tenderness I need.

13. When I'm feeling down, I tend to feel like most other people are probably happier than I am. 
14. When something painful happens I try to take a balanced view of the situation.

15. I try to see my failings as part of the human condition.

16. When I see aspects of myself that I don't like, I get down on myself.

17. When I fail at something important to me I try to keep things in perspective.

18. When I'm really struggling, I tend to feel like other people must be having an easier time of it.

19. I'm kind to myself when I'm experiencing suffering.

20. When something upsets me I get carried away with my feelings.

21. I can be a bit cold-hearted towards myself when I'm experiencing suffering.

22. When I'm feeling down I try to approach my feelings with curiosity and openness.

23. I'm tolerant of my own flaws and inadequacies.

24. When something painful happens I tend to blow the incident out of proportion.

25. When I fail at something that's important to me, I tend to feel alone in my failure.

26. I try to be understanding and patient towards those aspects of my personality I don't like. 


\section{Centre for Epidemiological Studies - Depression Scale}

Using the scale below, indicate the number which best describes how often you felt or behaved this way, DURING THE PAST WEEK.

$1=$ Rarely or none of the time (less than 1 day)

$2=$ Some or a little of the time (1-2 days)

3 = Occasionally or a moderate amount of time (3-4 days)

$4=$ Most or all of the time (5-7 days)

During the past week:

1. I was bothered by things that usually don't bother me.

2. I did not feel like eating; my appetite was poor.

3. I felt that I could not shake off the blues even with the help from my family or friends.

4. I felt that I was just as good as other people.

5. I had trouble keeping my mind on what I was doing.

6. I felt depressed.

7. I felt that everything I did was an effort.

8. I felt hopeful about the future.

9. I thought my life had been a failure.

10. I felt fearful.

11. My sleep was restless.

12. I was happy.

13. I talked less than usual.

14. I felt lonely.

15. People were unfriendly.

16. I enjoyed life.

17. I had crying spells.

18. I felt sad.

19. I felt that people disliked me.

20. I could not get going.

(C) Radloff, 1977 


\section{Satisfaction with Life Scale}

Below are five statements with which you may agree or disagree. Using the scale below, indicate your agreement with each item by placing the appropriate number on the line preceding that item. Please be open and honest in your responding.

$$
\begin{aligned}
& 1=\text { Strongly disagree } \\
& 2=\text { Disagree } \\
& 3=\text { Slightly disagree } \\
& 4=\text { Neither agree nor disagree } \\
& 5=\text { Slightly agree } \\
& 6=\text { Agree } \\
& 7=\text { Strongly Agree }
\end{aligned}
$$

1. In most ways my life is close to ideal.

2. The conditions of my life are excellent.

3. I am satisfied with my life

4. So far I have gotten the important things I want in life.

5. If I could live my life over, I would change almost nothing. 


\section{Compassionate - Positive/Negative Affect Scale}

This scale consists of a number of words and phrases that describe different feelings and emotions. Read each item and then mark the appropriate answer indicating how you feel right now.

\begin{tabular}{|c|c|c|c|c|}
\hline $\begin{array}{c}\text { Very Slightly or } \\
\text { Not at All }\end{array}$ & $\begin{array}{c}\text { A Little } \\
\text { Moderately }\end{array}$ & Moderately & Quite A Bit & Extremely \\
\hline
\end{tabular}

1. Comforted

2. Undeserving

3. Compassionate

4. Judgmental

5. Nurtured

6. Stupid

7. Loving

8. Soothed

9. Content

10. Sympathetic

11. Worried/Anxious

12. Нарpy

13. Frustrated

14. Joyful

15. Unhappy

16. Pleased

17. Depressed/Blue

18. Enjoyment/Fun

19. Angry/Hostile

20. Grateful

$\begin{array}{lllll}1 & 2 & 3 & 4 & 5 \\ 1 & 2 & 3 & 4 & 5 \\ 1 & 2 & 3 & 4 & 5 \\ 1 & 2 & 3 & 4 & 5 \\ 1 & 2 & 3 & 4 & 5 \\ 1 & 2 & 3 & 4 & 5 \\ 1 & 2 & 3 & 4 & 5 \\ 1 & 2 & 3 & 4 & 5 \\ 1 & 2 & 3 & 4 & 5 \\ 1 & 2 & 3 & 4 & 5 \\ 1 & 2 & 3 & 4 & 5 \\ 1 & 2 & 3 & 4 & 5 \\ 1 & 2 & 3 & 4 & 5 \\ 1 & 2 & 3 & 4 & 5 \\ 1 & 2 & 3 & 4 & 5 \\ 1 & 2 & 3 & 4 & 5 \\ 1 & 2 & 3 & 4 & 5 \\ 1 & 2 & 3 & 4 & 5 \\ 1 & 2 & 3 & 4 & 5 \\ 1 & 2 & 3 & 4 & 5\end{array}$




\section{Appendix D: Exercise Instructions}

\section{Three Good Things in Life}

We think too much about what goes wrong and not enough about what goes right in our lives. Of course, sometimes it makes sense for us to analyse bad events so that we can learn from them and avoid them in the future. However, people tend to spend more time thinking about what is bad in life than is helpful. Worse, this tendency to focus on bad events sets us up for anxiety and depression. One way to keep this from happening is to develop our ability to think about the good in life. Most of us are not nearly as good at analyzing good events as we are at analyzing bad events, so this is a skill that needs practice. As you become better at focusing on the good in your life, you will likely become more grateful for what you have and more hopeful about the future. So let's get started.

Your assignment is as follows:

Every night for one week, set aside 10 minutes before you go to bed. Use that time to write down three things that went really well on that day and why they went well. Log on to the website and use the space provided to write about the events. This is vital because it is important that you have a physical record of what you wrote. It is not enough to do this exercise in your head. The three things you list can be relatively small in importance ("My husband picked up my favourite ice cream for dessert on the way home from work today") or relatively large in importance ("My sister just gave birth to a healthy baby boy"). Next to each positive event in your list, answer the question, "Why did this good thing happen?" For example, someone might write that her husband picked up ice cream "because my husband is really thoughtful sometimes" or "because I remembered to call him from work to remind him to stop by the grocery store." When asked why her sister gave birth to a healthy baby boy, someone might write that "God was looking out for her" or "She did everything right during her pregnancy."

Writing about "why" the positive events in your life happened may seem awkward at first, but please stick with it for one week. It will get easier. After seven nights of doing this exercise, you will be asked to fill out some questionnaires so that we can learn how this exercise affected you.

To review, here are the steps of this exercise:

1) Every night before bed for one week, think about three good things that went well that day.

2) Log onto the website to write down the three things that went well.

3) Then write down why each thing went well.

4) After doing this exercise for one week, fill out the follow-up questionnaires.

You are now ready to begin!

One good thing that happened today is:

Why did this good thing happen?

A second good thing that happened today is:

Why did this good thing happen?

A third good thing that happened today is:

Why did this good thing happen?

(C) 2007 Dr. Myriam Mongrain, York University 


\section{Positive Reinterpretation}

Often, everyday hassles cause tremendous stress. Previous research suggests that one way to increase well-being is to reframe these negative events in positive terms. Trying to find the silver lining in problems and viewing them as opportunities for growth and development may have many positive benefits.

For the next seven days, this exercise will require you to set aside 10 minutes before you go to bed every night to log on to this website and briefly describe the most bothersome event in your day. You will also be asked to answer 4 questions that will help you to reinterpret the event in more positive terms. On the final day you will be asked to fill out some follow-up questionnaires.

This exercise will ask you to briefly describe the most bothersome event in your day. You will then be asked to answer 4 questions that will help you to reinterpret the event in more positive terms. Positive thinking is a strength of character that takes practice in order to develop, so we ask you to think of these exercises as helping you to build a new strength that you can use all the time. The benefits of this work may not be immediate, but like exercising to 'get in shape,' the advantages emerge over time with continued practice so try to stick with it for 1 week.

To review:

1) Log on to this website every night for 7 nights. In the areas indicated please describe the most bothersome event in your day.

2) Answer the 4 questions about this experience.

3) On the $7^{\text {th }}$ night, please respond to a series of questionnaires so we can see how the exercise affected you.

Below is an example of how one might complete this exercise.

Briefly describe the most bothersome event that occurred today.

I got into an argument with my roommate after she told me to wash my dishes. She made me feel like a slob who never picks up after herself. It's like I'm living back at home with my mother. I hate being told what to do.

1) How can I grow from this experience?

I guess living with her will help me to learn how to live with others, to get along with people who are different from me. This might help in the future career-wise and otherwise.

2) How can I see this event in a different, more positive light?

She wasn't trying to be mean or demanding. She's just a neat-freak, as she admitted herself. It must have been unpleasant for her as well. She is a really good friend and she's not really asking for much. I guess I'm glad she came to me.

3) Is there something good in what happened?

At least now she got it off her chest and I know how she feels. I can help clean up a bit more. It's not fun. But I guess it's the right thing to do anyway. I should learn to kick my messiness habit, and now is as good a time as any.

4) What can I learn from this experience? 
I can learn to be more conscientious about housework. I'm learning to compromise and get along with people with different needs from my own. I'm learning more about my roommate.

You are now ready to try for yourself!

Briefly describe the most bothersome event that occurred today.

1) How can I grow from this experience?

2) How can I see this event in a different, more positive light?

3) Try to find something good in what happened. Use the space below.

4) What can I learn from this experience? 


\section{Signature Strengths}

Honesty. Loyalty. Perseverance. Creativity. Kindness. Wisdom. Courage. Fairness. These and about 16 other character strengths are valued in almost every culture in the world. We believe that people can get more satisfaction out of life if they learn to identify which of these character strengths they possess in abundance and then use them as much as possible whether working, loving, or playing.

This exercise consists of two parts. You will take a questionnaire that gives you feedback about your strengths. This will take about 45 minutes.

The next day you will be asked to use these strengths in new ways every day for one week and to report back to us each day to describe how you did so. On the last day you will also be asked to fill out some follow-up questionnaires.

Here are the steps to follow:

1) Register for the Authentic Happiness website at www.authentichappiness.com. Registration is free of charge and allows you to access the website's questionnaires.

2) Take the VIA Signature Strength Questionnaire on the Authentic Happiness website. Write down the feedback you receive about your five highest strengths (your signature strengths). List your 5 strengths below.

Here are the instructions for the rest of the week (beginning tomorrow, and after you have completed the VIA Signature Strengths Questionnaire). Skim them quickly now. They will be repeated for you tomorrow:

Every day for the next seven days use one of your top five strengths in a way that you have not before. You might use your strength in a new setting or with a new person. It's your choice. At the end of each day log on to the website to write about how you used your strength that day.

You are now ready to begin!

Go to www.authentichappiness.com to find out about your strengths.

What are your 5 strengths?

Here are the specific steps to follow:

1) Every day for the next seven days use one of your top five strengths in a way that you have not before. You might use your strength in a new setting or with a new person. It's your choice. At the end of each day log on to the website to write about how you used your strength that day. Here are some examples of how people have used their strengths in new ways:

a. One of Tracy's signature strengths is love of learning. She chose to spend some time browsing the internet for information about how to brew beer at home, something she had always wanted to try.

b. One of Russell's signature strengths is fairness. He decided to exercise this strength by devising a system that he and his roommates could use to split up household chores so that everyone contributed equally. 
c. Judy's top strength is an appreciation of beauty and excellence. She decided to take a walk during her lunch hour so that she could enjoy the brilliantly coloured Fall leaves.

d. Kent's signature strength is playfulness/humour. He chose to sneak into the bathroom at work and post some funny comic strips on the stall walls.

2) After seven days of reporting back to us about how you used your strengths in new ways, please take the follow-up questionnaires.

You are now ready to begin!

Which strength did you use today?

How did you use this strength in a new way today? 


\section{Self-Compassion}

This exercise involves learning how to feel greater compassion towards yourself. This ability has been associated with many mental health benefits, with recent research showing that being compassionate to yourself when you are stressed or upset may reduce problems like anxiety and depression. The goal of this exercise is to help you refocus your thoughts and feelings on being accepting, supportive, and caring for yourself.

Having compassion for yourself is a strength of character that takes practice in order to develop, so we ask you to think of this exercise as helping you to build a new strength that you can use all the time, both in your daily life as well as when you feel distressed. The benefits of this work may not be immediate, but like exercising to 'get in shape,' the advantages can emerge over time with continued practice. So try to stick with it over the next week.

We ask that you think about an event or situation that occurred today that was distressing, or left you feeling upset.

Now, we'd like you to write a one paragraph letter to yourself about this distressing event or situation. You should write this letter to yourself from a caring perspective, providing compassion to yourself in regards to your emotional distress. Before you begin your first letter, please read the sample daily letter provided. On days 2-7, you can refresh your memory by reading the example provided, or immediately begin your letter.

Today's Event: Failing my Science Exam

My Dear Friend,

I am sorry to hear that you had an upsetting day today. I know you are unhappy that when you got back your exam today, you found out that you failed. I understand why you feel distressed about this and I would feel the same if I was in your position. I know how hard you studied for that exam and you have every right to be upset.

It's not your fault that you did not do as well as you had hoped, it was a very hard exam. You tried the best you could and that's something to be proud of. Sometimes these things happen, it does not mean you are stupid or inferior, or any less of a person. Failing one exam doesn't mean that you are a failure, or that you will to continue to do poorly in school. What would you say to a friend who was going through the same experience? Probably that no one in the world is perfect and that everyone writes a bad exam at one time or another.

People will not judge you and will still like you if they were to find out you didn't do as well as you had anticipated. People who truly love and support you will not care about how well you do in school, and will instead focus on your wonderful personality qualities. I still think you are an intelligent, caring person with a really good sense of humour! You deserve to forgive yourself there is so much in your life to be happy about!

To start writing your own letter, try to feel that part of you that can be kind and understanding of others. Think about what you would say to a friend in your position, or what a friend would say to you in this situation. Try to have understanding for your distress (e.g. I am sad you feel distressed...) and realize your distress makes sense. Try and be good to yourself. We would like 
you to write whatever comes to you, but make sure this letter provides you with what you think you need to hear in order to feel nurtured and soothed about your stressful situation or event. This letter may take about

5-15 minutes to write, and there is no "right" or "wrong" way of doing it.

Please write your letter in the space provided below. 


\section{Compassionate Action}

This exercise involves helping or supporting others for brief periods of time over the next week. It is believed that when we help and care for others, benefits are provided not only to the person being helped, but to ourselves as well. Some have even argued that the more we can love and appreciate others, the more positive energy comes back to us. That is why caring for and helping others may be the best possible thing we can do for ourselves.

\section{Examples of Compassionate Action include:}

- Providing assistance to an acquaintance

- Helping a roommate/neighbour

- Talking to a homeless person

- Making small talk with someone having a hard day

- Calling a friend who is having a hard time

- Simply being more loving to those around you

The goal of this exercise is to practice being accepting, supportive, and caring towards others for the next seven days. Being compassionate to others is a strength of character that takes practice in order to develop, so we ask you to think of this exercise as helping you to build a new strength that you can use all the time. The benefits of this work may not be immediate, but like exercising to 'get in shape,' the advantages can emerge over time with continued practice. So try to stick with it for this week.

We asked that you act compassionately towards someone today for 5 to 15 minutes. That is, you were requested to actively help someone or interact with them in a supportive and caring manner. How did you try to help or interact with someone in a supportive and considerate way? In your response, please answer the following:

- Describe your compassionate action.

- Who was the person(s) you were interacting with?

- Where did this occur?

- How long did this interaction last and how did it make you feel? 


\section{Gratitude}

This exercise involves harnessing feelings of thankfulness for big or small things in your life. It intends to make you feel more grateful for your life circumstances, which has been associated with many mental health benefits.

Being grateful is a strength of character that takes practice in order to develop, so we ask you to think of this exercise as helping you to build a new strength that you can use all the time, both in your daily life as well as when you feel distressed. The benefits of this work may not be immediate, but like exercising to 'get in shape,' the advantages emerge over time with continued practice. So try to stick with it for this week.

For example, you may be grateful today for:

- My inner-strength

- Reading a good book

- For meeting new and interesting people at school

- For my dad for surprising me and taking me out for dinner

- For my iPod

- For my friend's understanding

- For a nice hot shower after a long day

- Having a good laugh with my mom

- Learning new things from my teachers/professors

Now, in the space provided below, please list 5 things (or gifts) that you are grateful or thankful for today. These can be things that are stable in your life, or something new that occurred to you. If you feel it is appropriate, you can list some of the things you are grateful/thankful for that you listed in previous entries, but we encourage you to try and think of new things daily.

Today, I am grateful/thankful for the following things in my life: 


\section{Musical Bliss}

This exercise involves selecting and listening to music that you find uplifting and that makes you feel good. Listening to music can help you express yourself emotionally and self-reflect. It is being used more and more as a form of therapy and is believed to increase one's positive emotions and level of happiness. In short, research has suggested that listening to music that is positive and pleasurable to you may have many benefits, including greater psychological wellbeing.

During the day tomorrow, we would like you to choose and listen to 3 or 4 songs that you find uplifting. These can be favourite songs that 'make you feel good,' and you can listen to the same song more than once. You can engage in this exercise anywhere; however, we ask that you remain focused on the music. Set aside 10 minutes before bed and log on to this website where we will ask you brief questions about your experience. On the last day, we will also ask you to fill out a brief set of questionnaires to find out more about your experience.

Now, please answer the following questions:

- What is the artists name and the title of the songs you listened to today, if known?

○ Artist:

- Song title :

○ Artist:

○ Song title :

○ Artist:

- Song title :

○ Artist:

- Song title :

- How long did you listen to the music for?

- Less than 5 minutes

○ 5-10 minutes

- 10-15 minutes

○ 15 minutes or more

- What were your feelings while listening to the music?

$\circ$ List briefly 


\section{Letter From Your Future Self}

\section{"To accomplish great things we must not only act but also dream, not only plan} but also believe." Anatole France

We sometimes think too much about what goes wrong and not enough about possibilities for a better future. Of course, sometimes it makes sense for us to analyse bad events in order to prevent them from occurring again, but to project them into the future can also create selffulfilling prophecies. One way to keep this from happening is to develop our ability to have a positive vision for our future. To think about appealing possibilities is the first step in making positive changes in our lives. As you become better at focusing on a positive future, you will likely become more optimistic and motivated to take small steps in that direction. So let's get started.

Every night for one week, you will be asked to set aside 10 minutes to write a letter from your future self to your current self. Writing a letter from a "future self" may seem awkward at first, but please stick with it for one week. There is no 'right' or 'wrong' answer and it will get easier. After seven nights of doing this exercise, you will be asked to fill out some questionnaires.

To review, here are the steps of this exercise:

1) Every night before bed for one week, log on to the web site to read your instructions for your letter.

2) Then write the letter, and focus on the positive images you have created throughout the next day.

3) After doing this exercise for one week, fill out the follow-up questionnaires.

You are now ready to begin!

Imagine yourself in the future ( 6 months/ 1 year / 2 years/ 5 years /10 years from now Pick a time frame that makes sense to you). Imagine you are in a better place where you have resolved some of the issues that are concerning you now.

1) Describe where you are, what you are doing, and what is happening in your life. Enrich with as much detail as possible:

2) Tell yourself the crucial things you realized or the critical steps you took to get there. Give yourself some sage and compassionate advice from a better future.

Remember the positive images you have created, and log on to the website tomorrow night. 


\section{Early Memories}

The unexamined life is not worth living (Socrates).

The importance of self-knowledge and understanding has long been recognized. We believe that a strong sense of self and an understanding of the factors that have come to make you the person you are today are essential components of well-being. Our early life experiences can influence us and play a role in how we think and act later on in our lives. It may be important to reflect upon these early experiences to gain a better understanding of the person we are today. In addition, research has shown that writing about one's life experiences can enhance psychological wellbeing and even lead to physical benefits.

This simple exercise requires you to write about your earliest memories. Out of all the experiences of a lifetime, we only hold on to a few in the form of early memories. The few experiences that are remembered are likely of some importance. Again, a careful consideration of our earliest memories may help us to better understand who we are today and ultimately lead to increased self-acceptance and well-being.

Your assignment is as follows:

Every night for one week, set aside 10 minutes before you go to bed. Use that time to think of an early memory and log into the website and write it down in as much detail as possible in the space provided for you. Try to remember what you were doing, what you were feeling, and the other people who were with you. (If you cannot remember some of the details, that is OK. Just type down what you can remember.)

After seven nights of doing this exercise fill out the follow-up questionnaires so that we can learn how this exercise affected you.

To review, here are the steps of this exercise:

1) Every night for one week, log on to the website to write down an early memory in as much detail as possible.

2) On the $7^{\text {th }}$ night, fill out the follow-up questionnaires so that we can learn about your experience.

You are now ready to begin!

Describe an early memory in as much detail as possible. What you were doing? What were you were feeling? Who else was with you? (If you cannot remember some of the details, that is OK. Just type down what you can remember.) 


\section{Early Positive Memories}

The unexamined life is not worth living (Socrates).

The importance of self-knowledge and understanding has long been recognized. We believe that a strong sense of self and an understanding of the factors that have come to make you the person you are today are essential components of well-being. Our early life experiences can influence us and play a role in how we think and act later on in our lives. It may be important to reflect upon these early experiences to gain a better understanding of the person we are today.

However, we sometimes have the tendency to focus on negative memories more than on positive ones, a tendency that sets us up for anxiety and depression. A careful consideration of our past may help us to better understand who we are today and ultimately lead to increased selfacceptance and well-being, particularly when we focus on the positive aspects. Research has also shown that writing about one's life experiences can enhance psychological well-being and even lead to physical benefits so try to stick with it for 1 week.

Here are some examples of early positive memories:

a. I remember my little sister coming home for the first time from the hospital. I remember being in awe of her. I thought she was a toy for me to play with. She was like a little doll and I was amazed at how alive she was. I remember my mother and me giving her her first bath. I was amazed by this tiny person moving around in the water.

b. I remember my fifth birthday party. It snowed and my parents let everyone come over for a pizza. I remember having a lot of fun. I remember playing hide and seek in the house and pretending that we were Ninja Turtles. It was a good time.

Your assignment is as follows:

To review, here are the steps of this exercise:

3) Every night for one week, log on to the website to write down an early positive memory in as much detail as possible.

4) On the $7^{\text {th }}$ night, fill out the follow-up questionnaires so that we can learn about your experience.

You are now ready to begin!

Describe an early positive memory in as much detail as possible. If you cannot remember some of the details, that's OK. Just type down what you can remember. Try to include what you were doing, what you were feeling, and the other people who were with you. 